Reactor Technology (TID-4500, 16th Ed.) $\mathrm{AEC}$ Research and

Development Report

ARGONNE NATIONAL LABORA TORY

9700 South Cass Avenue

Argonne, Illinois

TERMINAL REPOR T ON THE BOILING SLURRY

REACTOR EXPERIMENT (SLURREX)

by

G. A. Freund, J. D. Lokay, G. C. Milak and J. C. MacAlpine*

Reactor Engineering Division

* On Leave from Iowa State University

December 1960

Operated by The University of Chicago under

Contract W-31-109-eng-38 


\section{DISCLAIMER}

This report was prepared as an account of work sponsored by an agency of the United States Government. Neither the United States Government nor any agency Thereof, nor any of their employees, makes any warranty, express or implied, or assumes any legal liability or responsibility for the accuracy, completeness, or usefulness of any information, apparatus, product, or process disclosed, or represents that its use would not infringe privately owned rights. Reference herein to any specific commercial product, process, or service by trade name, trademark, manufacturer, or otherwise does not necessarily constitute or imply its endorsement, recommendation, or favoring by the United States Government or any agency thereof. The views and opinions of authors expressed herein do not necessarily state or reflect those of the United States Government or any agency thereof. 


\section{DISCLAIMER}

Portions of this document may be illegible in electronic image products. Images are produced from the best available original document. 
TABLE OF CONTENTS

Page

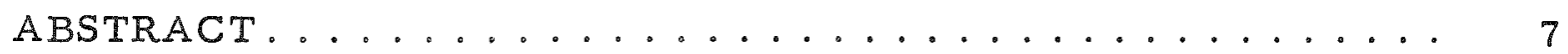

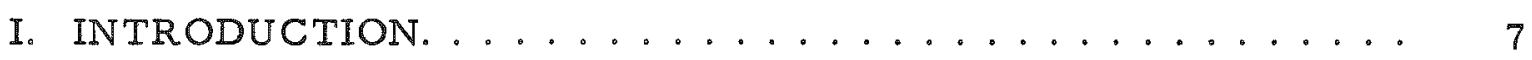

II. $\operatorname{SUMMARY} \ldots \ldots \ldots \ldots \ldots$

III. DESIGN DESCRIPTION ....................... 10

A. Plant Arrangement ..................... 10

B. Reactor System ...................... 10

C. Heat Dissipation. .................. 15

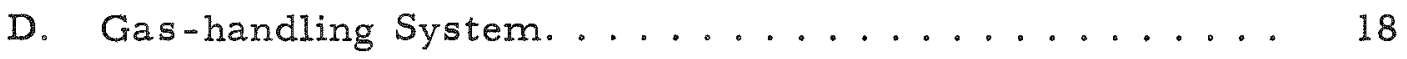

E. Fuel-handling System ................ 21

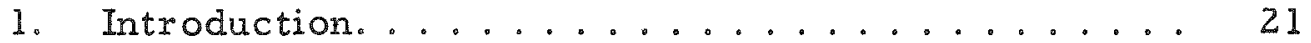

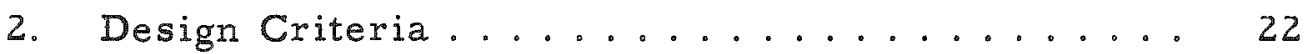

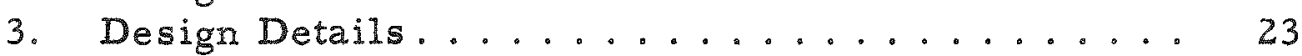

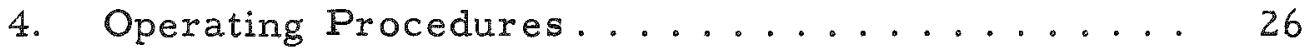

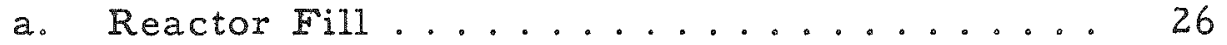

b. Normal Reactor Drain and Rinse....... 27

c. Reactor Concentration Increase ....... 27

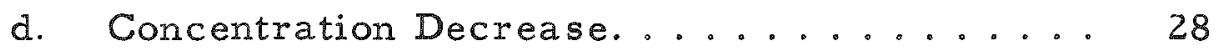

e. Water Distribution ................ 28

F. Miscellaneous Systems ................ 29

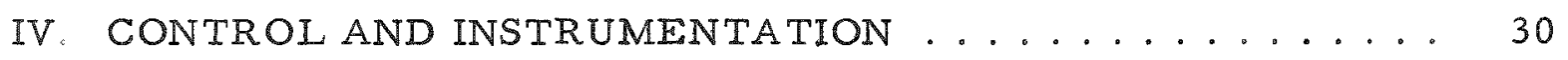

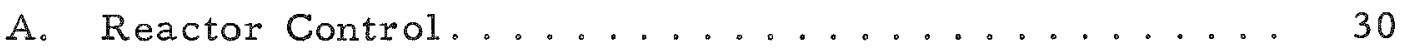

B. Scram and Alarm System.................. 30

C. Process Instrumentation ................. 32

V. HEAT TRANSFER AND FLUID FLOW ............. 33

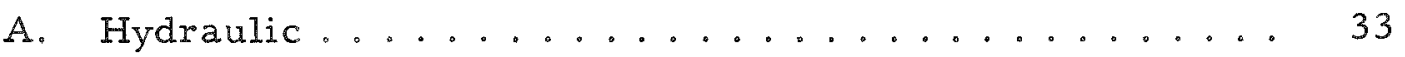

B. Core Void Fraction Distribution ........... 34

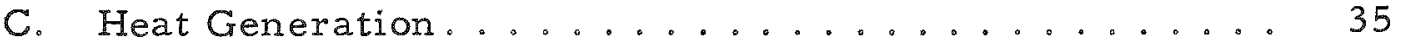

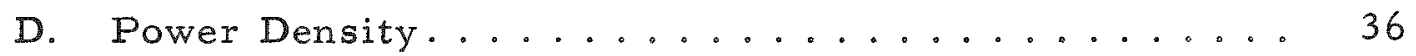

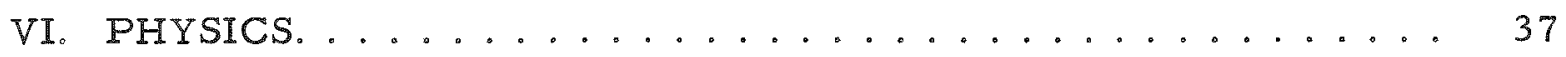

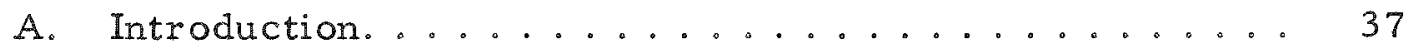

B. Preliminary Criticality Calculations .......... 37

C. Determination of Core Height............ 42 
Page

VII. CHEMISTRY ................... 44

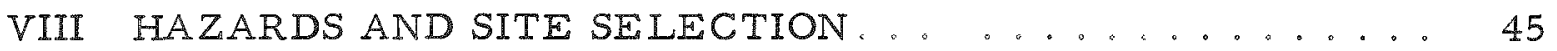

IX PROPOSED SCHEDULE................ 49

X. EXPERIMENTAL PROGRAM ............. 50

A. Reactor Stability and Safety............ 50

B. Hydrodynamics , ................. 51

C. Physics ....................... 51

D. Response and Control Characteristics ........ 51

E Vapor Transport and Separation ........... 51

F Radioactive Gas Evolution ............. 52

G Water Decomposition . ................ 52

H. Slurry Behavior ................... 52

I. Structural Material Behavior ............ 53

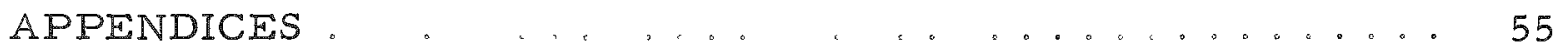

A Half-scale Mockup................ 55

B. Preliminary Consideration in the Design of a Catalytic Recombiner.................... 67

C. Systems for Removing Xenon and Krypton........ 73

D. Compressor Rating for the Gas Handling System.... 80

E. Derivation of the Hydraulic Equation ......... 82

F Dosage Calculations ................. 87

G. Physical Properties of Aqueous Thoria Slurries .... 91

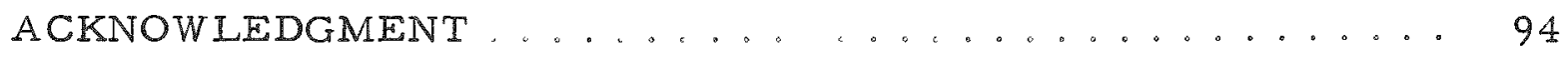

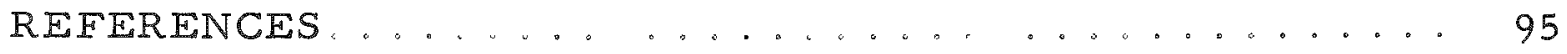


No.

Title

Page

I SLURREX Design Parameters ................ 8

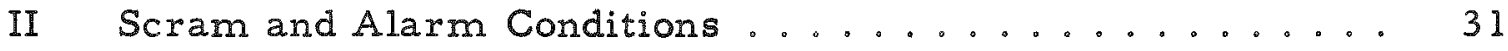

III Calculated Material Bucklings and Reflector Savings for Various $\mathrm{UO}_{3} \cdot \mathrm{H}_{2} \mathrm{O}-\mathrm{ThO}_{2}-\mathrm{H}_{2} \mathrm{O}$ Mixtures............ 38

IV Proposed Schedule for SLURREX ............ 49

V Proposed Hydraulic Experimental Program ......... 65

VI Parameters of Representative Charcoal Bed Designs .... 78

VII Sutton's Meteorological Constants............. 87

VIII Reduction Factor for Dosage to Cyclic Operation...... 88

IX Dosage from 5-Mw Steady-state Operation ......... 89

$\mathrm{X}$ Dosage from $5-\mathrm{Mw}$ Cyclic Operation ............ 89

XI Dosage from $1000 \mathrm{Mw}-\mathrm{sec}$ Transient............8 89

XII Reduction Factor Due to Distance from Cloud Path during Inversion. ...................... 90 


\section{LIST OF FIGURES}

No.

Title

Page

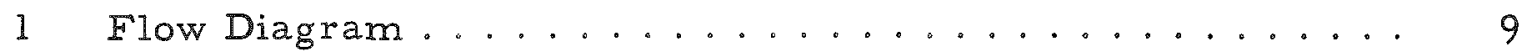

2 Plant Layout - Plan View...................... 11

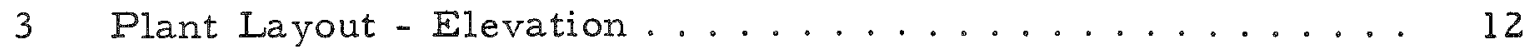

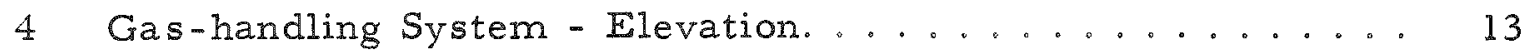

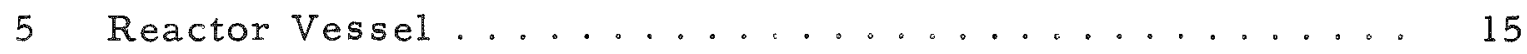

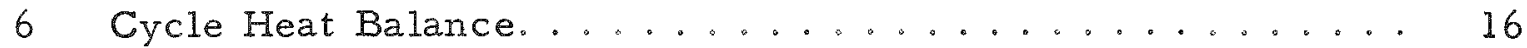

7 Fuel-handling System .................. 24

8 Two-phase Steam Velocity and Circulation Velocity vs Void

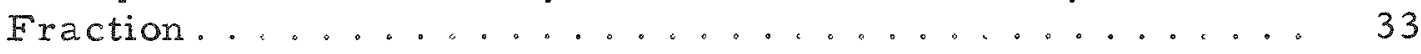

9 Power Output vs Void Fraction at 10.2 Atm.......... 34

10 Void Fractions vs Core Length.............. 35

11 Power Density as a Function of Core Steam Volume Fraction

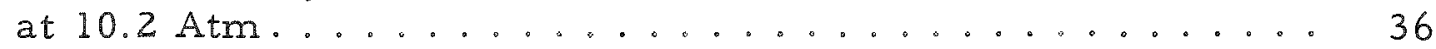

12 Power Density as a Function of Pressure .......... 36

13 Slurry Concentration for a Critical Reactor .........440

14 Uranium and Thoria Concentrations as a Function of Void

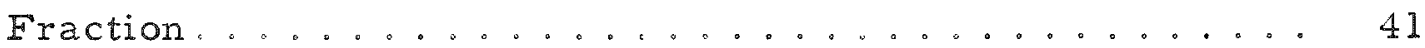

15 Slurry Total Weight for Critical Reactor ........... 41

16 Core Model for Calculating an Equivalent Cylindrical

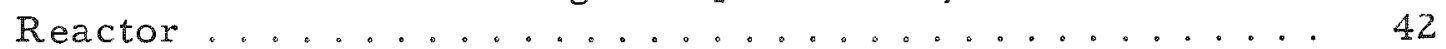

17 Effect of Size of Destructive Transient upon Dosage Due to $10 \%$ Fission Product Release after Infinite 5-Mw

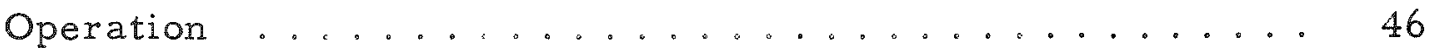

$18 \gamma$-Dosage vs Downstream Distance for Maximum Credible Accident....................... 47

19 Half-scale Mockup Facility ................. 56

20 Half-scale Slurry Mockup Vessel .............. 57

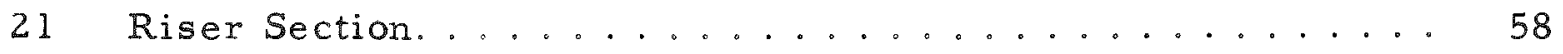

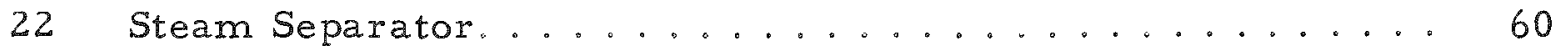

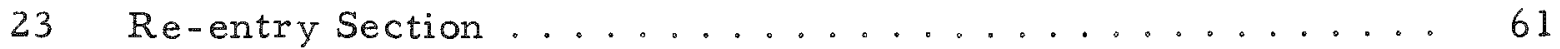

24 Hydrogen Production vs Diameter of Slurry Particle . . . . 67

25 Per Cent Recombinations vs ${ }^{\circ} \mathrm{C}$ Superheat. .......... 70 


\section{LIST OF FIGURES}

No.

Title

Page

26 Per Cent Recombination vs Inlet Gas Concentration ....... 71

27 Recombiner Exit Temperature vs Hydrogen Production

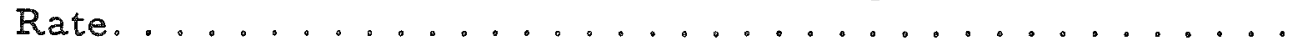

28 Theoretical Charcoal Bed Volume vs Carrier

Flow Rate......................... 75

29 Tube Radius vs Carrier Flow Rate ... . . . . . . . . . 77

30 Circulation Velocity $\left(V_{0}\right)$ vs Voids in Riser during Gas Injection. ..................... 80

31 Gas Flow Rate at Compressor Intake vs Circulation Velocity $\left(\mathrm{V}_{0}\right) \ldots \ldots \ldots \ldots \ldots \ldots \ldots \ldots . \ldots \ldots$

32 Compressor Power vs Circulation Velocity $\left(V_{0}\right) \ldots \ldots . \ldots 8$

33 Sectional Breakdown for Hydraulic Analysis of Reactor Vessel.......................... 82

34 Power Decay from Operation at $120 \mathrm{Mw}-\mathrm{hr} /$ Day ....... 88

35 Slurry Density vs $\mathrm{ThO}_{2}$ Concentration ............. 92

$36 \mathrm{ThO}_{2}$ Volume Per Cent vs Concentration. ............ 92

$37 \mathrm{ThO}_{2}$ Weight Per Cent vs Concentration ............ 93

38 Specific Heat vs Concentration ................ 93

39 Conversion of Volumetric Concentrations to Weight

Ratios ........................... 94 


\title{
TERMINAL REPORT ON THE BOILING SLURRY REACTOR EXPERIMENT (SLURREX)
}

\author{
by \\ G. A. Freund, J. D. Lokay, G. C Milak \\ and J.C. MacAlpine
}

\begin{abstract}
A plant layout of SLURREX has been prepared on the basis of preliminarydesign and sizing of major components. The reactor vessel has been designed in detail, assuming the use of commercially available fittings. A hydraulic analysis of this vessel indicates that the design power of $5 \mathrm{Mw}$ can be extracted with 50\% exit steam voids A half-scale mockup of the reactor vessel has been designed and constructed to verify experimentally the results of the theoretical hydraulic analysis. Physics calculations have allowed the selection of core parameters and have indicated that about $545 \mathrm{~g}$ of thoria (containing $10 \%$ of $93 \%$ enriched urania) per $\mathrm{kg}$ of water are required for design power at 102 -atm saturation pressure. An initial hazards analysis has shown that SLURREX can be operated safely at the proposed site near EBR-II at the National Reactor Testing Station. Preliminarydeterminations of process variables for measurement, alarm, and scram have been made, and some selection of instrument types has been carried out.
\end{abstract}

\section{INTRODUCTION}

This report is a documentation, from inception in 1959 to termination in 1960, of the design and development effort by the Reactor Engineering Division pertinent to construction of an aqueous boiling slurry reactor experiment. More specifically, it describes the present status of the reactor design, the problems involved, and the various approaches pursued.

A preliminary design study of this reactor experiment, identified as SLURREX, was published as ANL-6148 (1)

The design and construction of a half-scale, atmospheric pressure mockup of the reactor vessel for SLURREX are described in Appendix A. 


\section{SUMMARY}

The primary purposes of the SLURREX experiment are to determine whether predicted high power densities can be achieved under stable conditions and to explore the safetycharacteristics of the boiling slurry reactor concept. Incidental to attaining these goals, one can expect to obtain important engineering information in suchareas of question as slurrybehavior under irradiation, water decomposition, fission gas evolution, and steam separation.

A flow diagram of the SLURREX plant is given in Fig. 1. The plant is arranged into four major systems: reactor, heat dissipation, gas handling, and fuel handling. The reactor system consists of the components necessary for natural circulation and production of dry steam. The heatdissipation system condenses the steam and returns it as feedwater to the reactor system. The gas-handling system serves a two fold purpose:

(1) to deal with the undesirable gases, such as fission and radiolytic decomposition products, and (2) to supply gas needed for various reactor operations. The fuel-handling system contains the components necessary for filling and draining the reactor and varying its fuel concentration.

Design parameters for SLURREX are summarized in Table I.

Table I

SLLRREX DESTGN PARAMETERS

(at Design Power)

System Performance

\begin{tabular}{|c|c|c|c|}
\hline $\begin{array}{l}\text { Type of Reactor } \\
\text { Reactor Thermal Output } \\
\text { Reactor Electrical Output } \\
\text { Steam Production } \\
\text { Operating Pressure } \\
\text { Operating Temperature }\end{array}$ & $\begin{array}{l}\text { Natural-circulation } \\
\text { boiling } \\
5 \mathrm{Nw} \\
\text { Vone } \\
7.55 \times 10^{3} \mathrm{~kg} / \mathrm{hr} \\
10.2 \mathrm{~atm} \\
181^{\circ} \mathrm{C}\end{array}$ & $\begin{array}{l}\text { Feedwater Temperature } \\
\text { Cooling Water Temperature } \\
\text { Recirculation Ratio } \\
\text { Iydrogen Production }(G=1.3) \\
\text { Xe and Kr Production } \\
\text { Design Life }\end{array}$ & $\begin{array}{l}109^{\circ} \mathrm{C} \\
35^{\circ} \mathrm{C} \\
88 \\
4.7 \mathrm{~kg} / \mathrm{hr} \\
5 \times 10^{-5} \mathrm{~kg} / \mathrm{hr} \\
1000 \text { equivalent full-power } \\
\text { hours }\end{array}$ \\
\hline \multicolumn{4}{|c|}{ Core and Fuel } \\
\hline $\begin{array}{l}\text { Core Diameter } \\
\text { Core L/D Ratio, equivalent } \\
\text { Average Power Density } \\
\text { Exit Steam Voids } \\
\text { Type of Aqueous Slurry }\end{array}$ & $\begin{array}{l}59.6 \mathrm{~cm} \\
1.25 \\
24 \mathrm{kw} / \mathrm{liter} \\
50 \% \\
\mathrm{ThO}_{2} \cdot \operatorname{LO}_{2.5}\end{array}$ & $\begin{array}{l}\text { 1235 Enrichment } \\
\text { Tranium: Thorium Ratio } \\
\text { Oxide Concentration } \\
\text { Approximate Fuel Requirements }\end{array}$ & $\begin{array}{l}93^{\circ} \\
1: 9 \\
54.5 \mathrm{gm} / \mathrm{kg} \text { water } \\
36 \mathrm{~kg} \mathrm{I}^{235}\end{array}$ \\
\hline Wethod of Control & & lethod of Shutdown & \\
\hline $\begin{array}{l}\text { 1. Vechanical Control Rod } \\
\text { 2. Gas Injection into Downcomer } \\
\text { 3. Change in Fuel Concentration }\end{array}$ & & $\begin{array}{l}\text { 1. Mechanical Pod } \\
\text { 2. Dump into Slurry Storage }\end{array}$ & \\
\hline
\end{tabular}

Most of the reactor components are located in three flooded shield tanks. These tanks and auxiliary equipment are enclosed in an Armco building. The proposed site of the reactor building is at the National Reactor Testing Station, three-fourths mile southeast of the EBR-II complex. Reactor operation is carried out from a control trailer one-half mile away. 


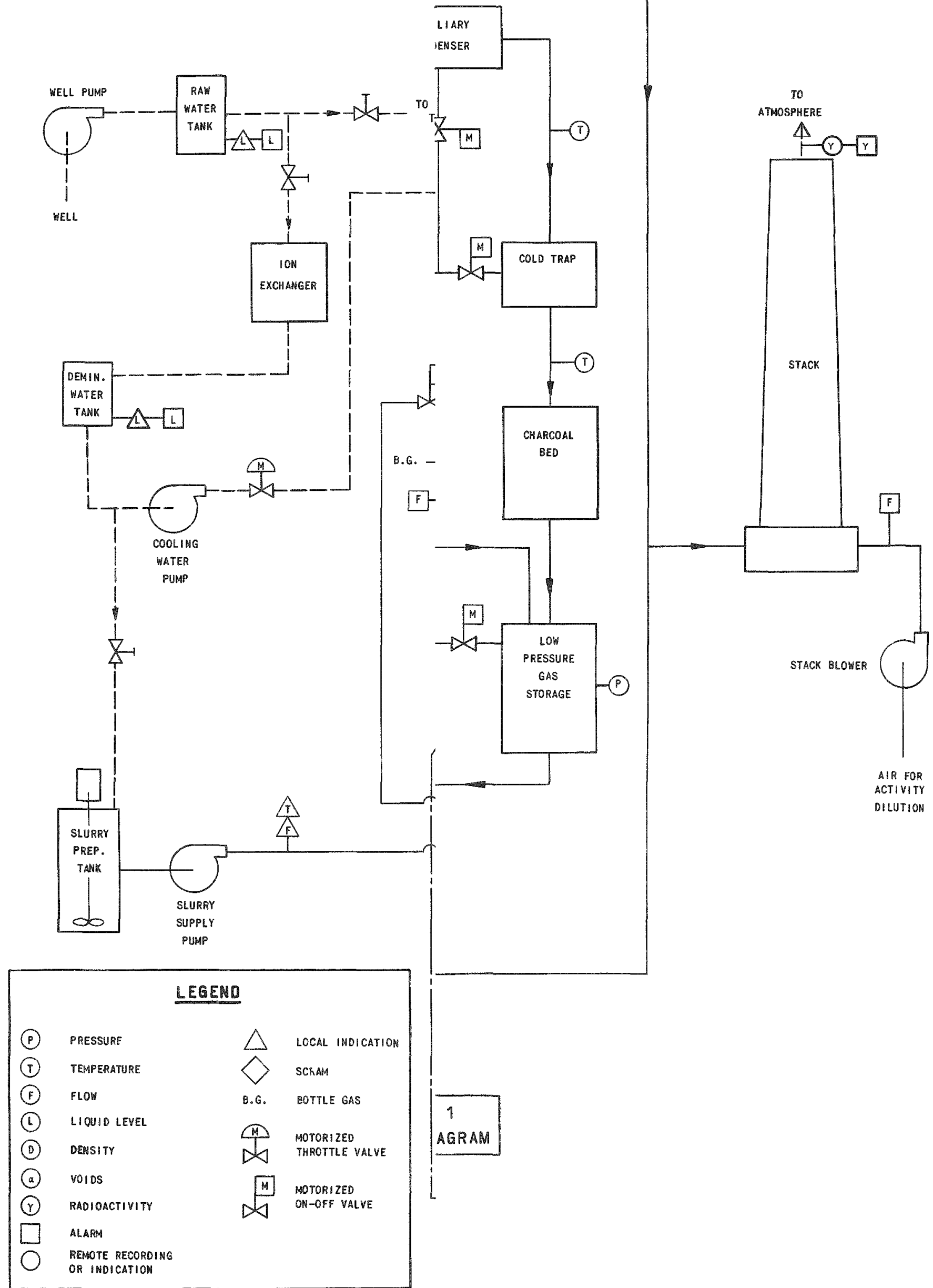




\section{DESIGN DESCRIPTION}

A. Plant Arrangement

A proposed plant layout is shown in Figs. 2, 3, and 4. It consists of three water-filled shield tanks, with the supply components of the gashandling system located externally. These components are the storage tanks and a concrete-lined cavity to house the compressor and associated valving. The three tank layouts attempt to separate the highly radioactive slurry components into two groups: those such as the reactor vessel and the expansion tanks requiring a deep tank (shield tank No. 1); and those likely to be subject to maintenance, such as the slurry storage pump and valves (shield tank No. 2). Tank No. 3 contains the other less radioactive components which normally handle only water or gas, such as condensers, recombiners, feedwater pump, and condensate storage tank.

The flooded-tank concept is believed to be more suitable for maintenance of a reactor experiment than dry-compartment shielding. Access to components is from the tank top, where a system of grid work and safety grating is used. Standard underwater lights should be acceptable if the shield water is treated to clarify it.

The three shield tanks are all $10.5 \mathrm{~m}$ high; tanks Nos. 1 and 2 are $3.7 \mathrm{~m}$ in diameter and tank No. 3 is $5.5 \mathrm{~m}$. The tanks are located in line. In order to provide sufficient shielding, water levels in the three tanks should be maintained at about $9.75,7.0$, and $6.7 \mathrm{~m}$, respectively.

This layout was prepared just prior to termination of the project. In line with emphasis on maintenance, some obvious improvements can be suggested in order to reduce the working distance, such as placing the slurry pump at the top instead of the bottom of the storage coil. Improvements of this kind are a part of a detailed maintenance philosophy which as yet has not been developed. Some preliminary investigations were made, however, on methods of disassembly, including quick-disconnect couplings, swivel connectors, in-line check valves, and freeze plugs.

B. Reactor System

A reactor vessel with separate downcomers is preferred to a cylindrical vessel with internal guide structure, because of greater flexibility and ease in obtaining experimental data. As will be shown in Section V-D, these advantages are gained at the expense of some power density because the additional hydraulic losses reduce circulation velocity.

Three variations of the separate downcomer design have been studied: (1) a 24-in. diameter core, a 12-in. diameter riser, and two separate 8-in. downcomers; (2) a single 10-in. downcomer; and (3) a full 24-in. riser. 


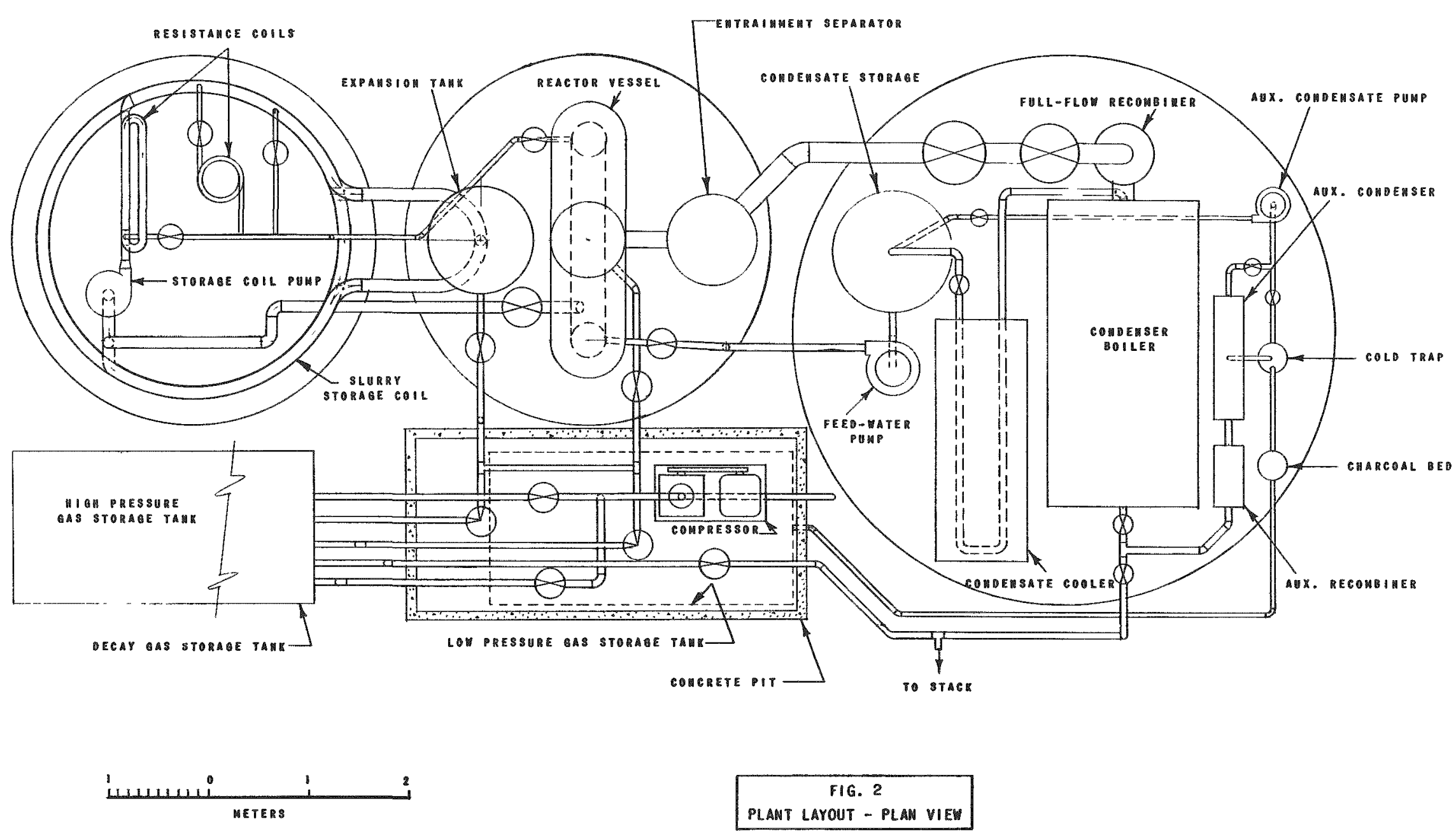


TAMS 2

TAMEK 1

TA

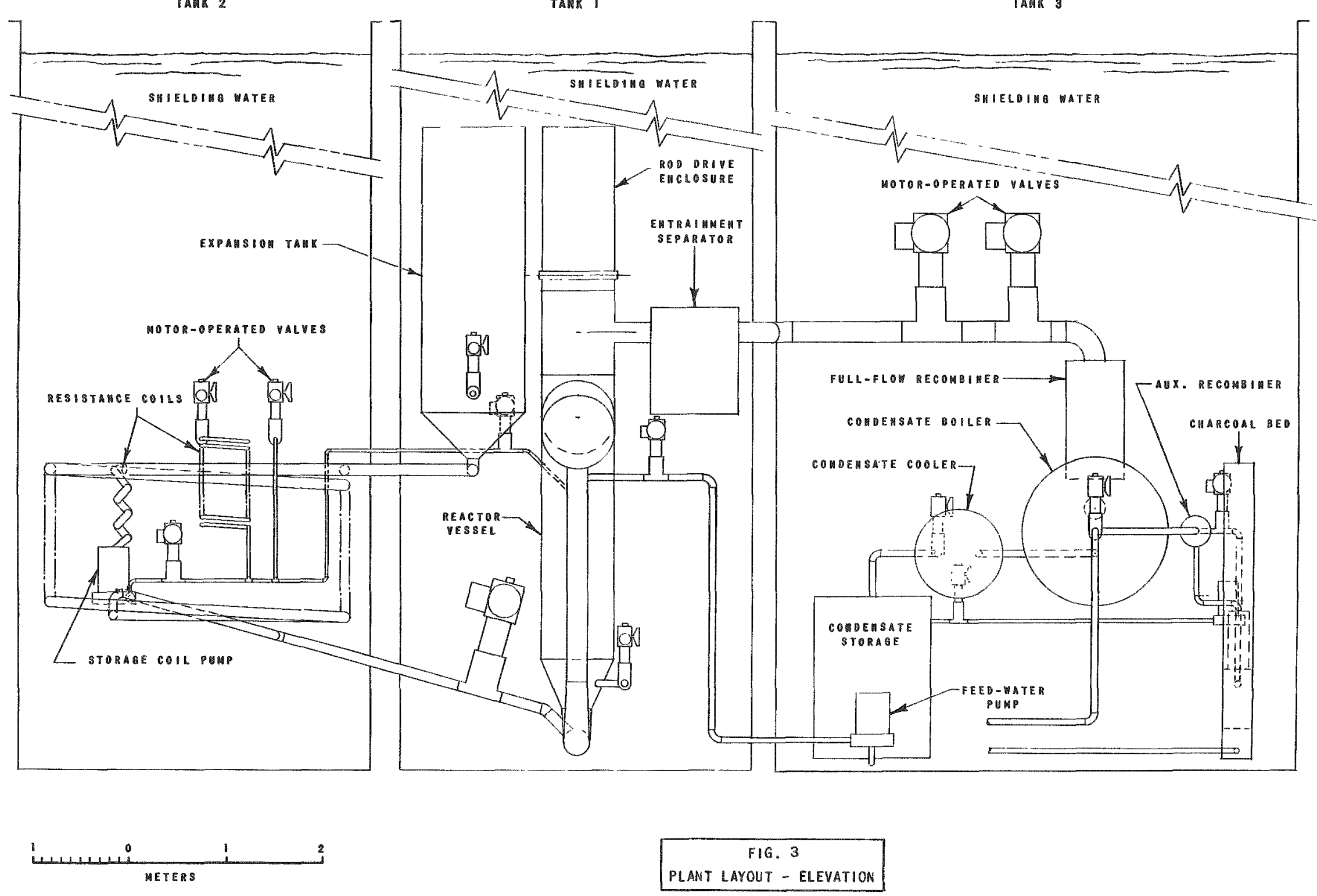


GAS-HIGH PRESSURE TANK
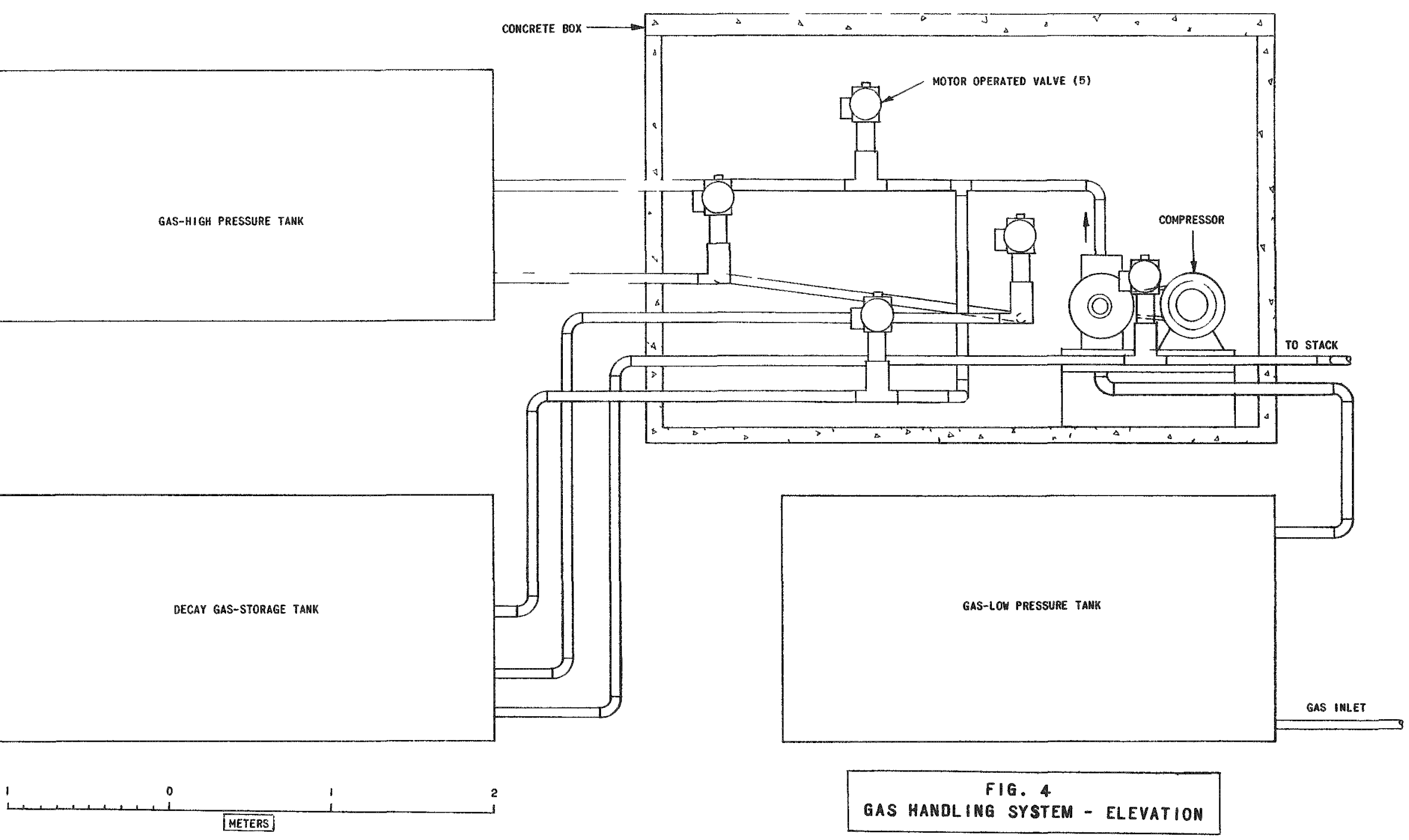

FIG. 4

GAS HANDLING SYSTEM - ELEVATION 
In the single-downcomer system, a higher liquid level in the steam separator is required in order to maintain a sufficiently low, horizontal, liquid velocity to prevent steam carryunder. Therefore, the saving in slurry volume is only about $5 \%$. The two-downcomer system offers the following advantages:

(1) considerably more interface area is provided for steam separation.

(2) eight-inch downcomers are definitely always safe, so no poisoning is required.

The increase in slurry volume resulting from the $24-$ in. $r$ iser is partially offset by a shorter riser height while still offering the following advantages:

(1) no disturbance in the riser to influence void determination:

(2) bettex assurance of reasonable fluid velocities entering the steam separator:

(3) flexibility in effective core height; and

(4) use of a full-diameter control rod.

Both the 12-in. and 24-in. risers require poisoning.

The design incorporating the 24-in. riser has therefore been adopted. A hydraulic study shows that for $5-\mathrm{Mw}$ operation the void fraction increases only slightly with increasing riser height over the range considered. Thus, the height selection results from instrumentation requirements for measur ing the riser void fraction, rather than from the exit void fraction. Based on the use of currently available diaphragm-type differential pressure transmitters, the minimum distance between taps is about $75 \mathrm{~cm}$. An allowance of $75 \mathrm{~cm}$ beyond the estimated core end for reaching stable void values yields a 24-in. pipe section length of $210 \mathrm{~cm}$ and an overall reactor vessel height of $500 \mathrm{~cm}$.

The design of the $r$ eactor vessel (Fig. 5) is similar to the mockup vessel (Appendix A) and, except for larger pipe sizes, stainless steel is used as the construction material. The core, riser, and steam separator are 24-in. Schedule 10 pipe and fittings; the downcomers are 8-in. Schedule 10 pipe; and the concentric expander below the core is 10 in. to 24 in. The sausage shape of the steam separator is based on the desire to avaid flat surfaces where slurry can settle out. The details of fabrication and design of poison plates for the riser and steam separator will be based on experience from construction of the mockup vessel. The control rod is described in Section IV. 


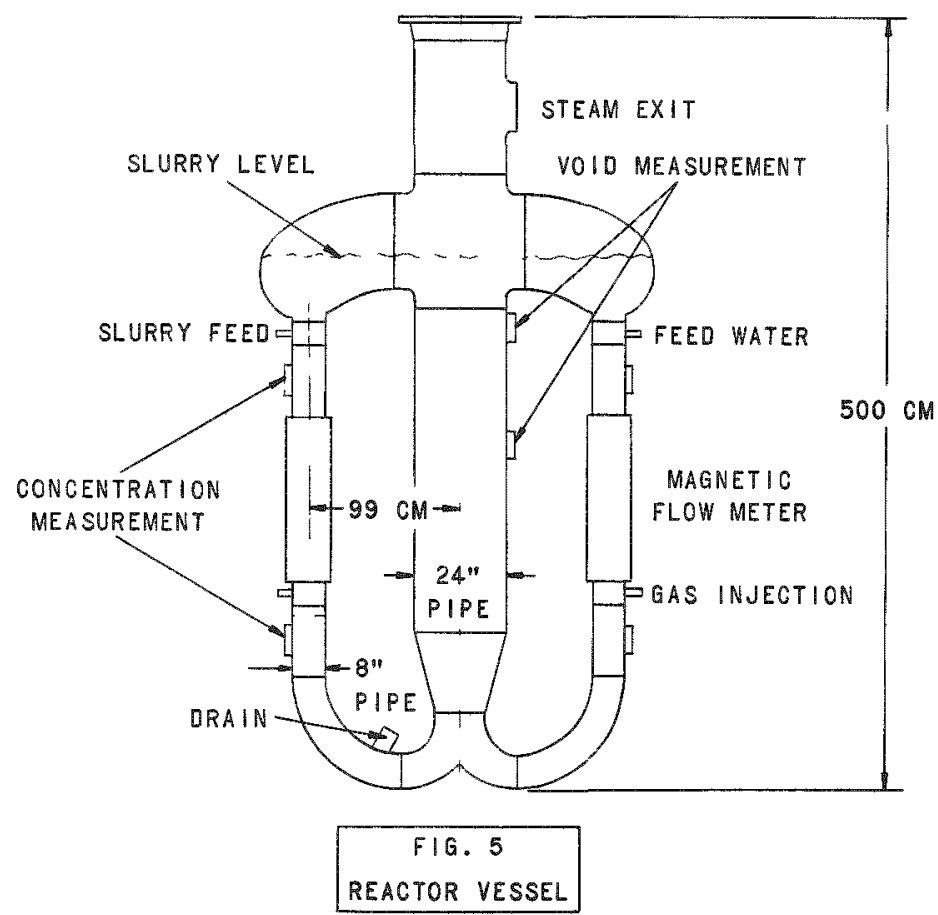

The problems of entrainment and carryover are recognized, but detailed study was deferred pending preliminary results from the operation of the mockup. As a first step, a steam deflector is designed into the steam separator, as illustrated on the mockup vessel (see Fig. 21 in Appendix A). Additional separation equipment can be incorporated into the top of the reactor vessel, if it does not interfere with the control rod and its mechanism; or the steam can pass into equipment immediately external to the reactor.

It is planned to insulate the reactor vessel with material packed into an external sheet metal casing to prevent water in-leakage. Preliminary analysis indicates that a thermal shield is not necessary.

C. Heat Dissipation

The heat-dissipation system consists of three components: the full-flow recombiner, the condenser boiler, and the condensate cooler.

A system heat balance is presented in Fig. 6 for $1-M w$ and $5-M w$ operation. Several assumptions were made to simulate a practical heat cycle:

(1) $99 \frac{1}{2} \%$ steam quality at the high-pressure side of the throttle at $5 \mathrm{Mw}$ and $99 \%$ at $1 \mathrm{Mw}$; 


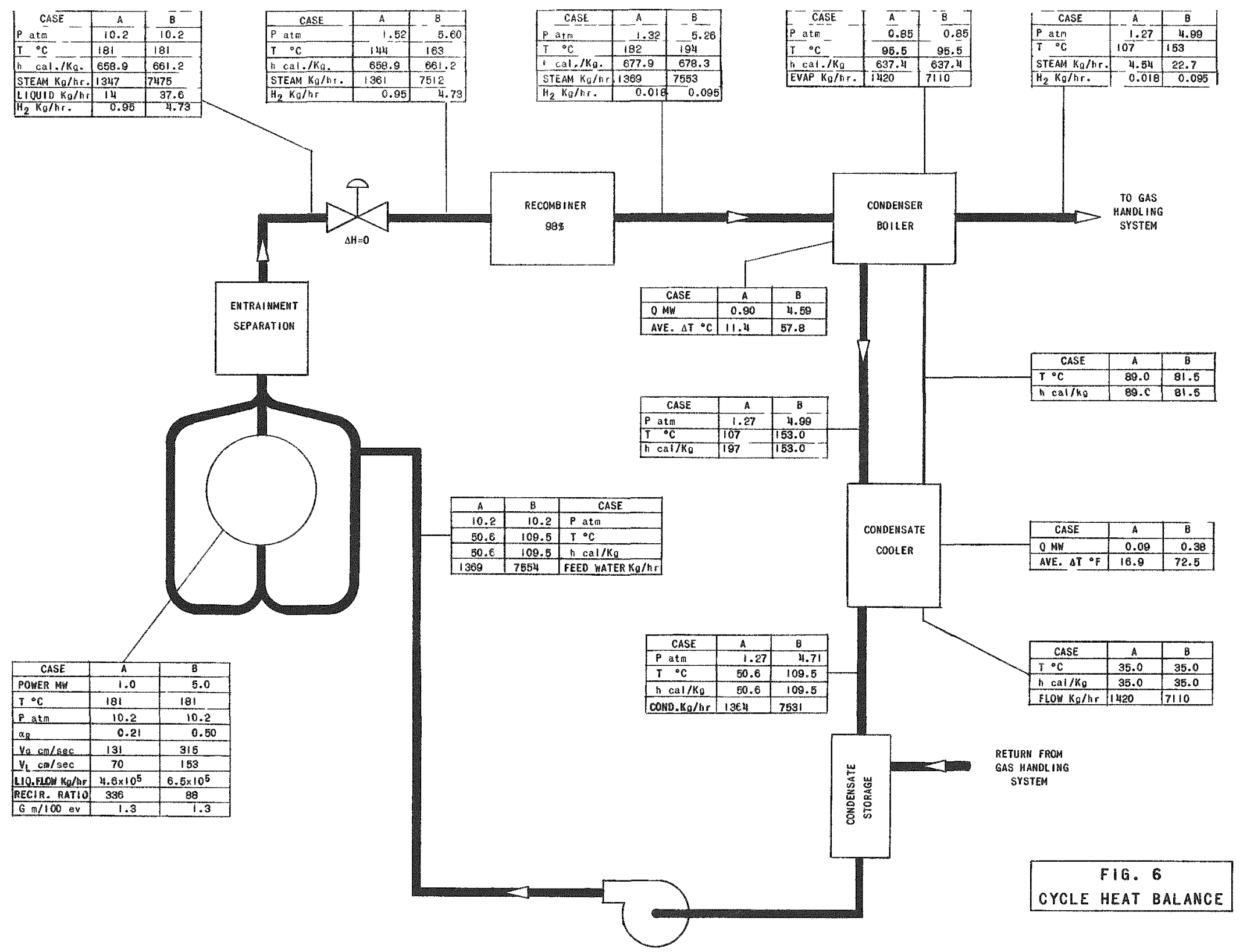


(2) pressure drops of $0.34,0.27$ and 0.27 atm for the recombiner, condenser boiler, and condensate cooler, respectively, at $5-\mathrm{Mw}$ and $0.21,0.05$, and 0 atm at $1-\mathrm{Mw}$ operation; and

(3) efficiency of the recombiner is $98 \%$ for both cases.

The purpose of the recombiner is to recombine the hydrogen and oxygen resulting from the radiolytic decomposition of water within the reactor, and thus to eliminate the explosion hazard. The recombiner was first located after the condenser boiler However, a thermodynamic analysis indicated that greater than $10 \%$ of the reactor steam must be carried with the radiolytic hydrogen and oxygen gases to prevent excessive temperature at the recombiner exit. Thus a large secondary condenser cooler would be required. With throttling of the reactor steam to eliminate moisture and to create a few degrees of superheat, a full-flow recombiner appears feasible and is incorporated in the design Recombination of the hydrogen and oxygen in this manner produces 15 to $40^{\circ} \mathrm{C}$ of superheat in the reactor, and the recombiner exit temperature can in fact be used as a measure of dissociation (Appendix B).

The estimated size of the catalytic bed is $60 \mathrm{~cm}$ in diameter by $120 \mathrm{~cm}$ in length of platinum-coated wire mesh Due to the absence of data. several assumptions were made in the design of the recombiner (Appendix B). To finalize the design, it is necessary to conduct confirmatory recombiner tests on existing experimental equipment.

It is recognized that iodine may poison the catalyst However, this problem was not investigated

From the recombiner, the steam passes to the condenser - boiler. The steam condenses within the tubes, on the shell side, cooling is provided by boiling water directly to the atmosphere The primary steam flow is controlled by a throttle valve.

The three terms which control heat transfer in the condenser-boiler are the heat transfer coefficient $U$, the transfer area $A$, and the temperature driving force $\Delta T$. For a condensing-boiling system, practice indicates heat transfer coefficients of about $2440 \mathrm{cal} /(\mathrm{hr})\left(\mathrm{m}^{2}\right)\left({ }^{\circ} \mathrm{C}\right)\left[\right.$ or $\left.500 \mathrm{Btu} /(\mathrm{hr})\left(\mathrm{ft}^{2}\right)\left({ }^{\circ} \mathrm{F}\right)\right]$. Thus the two variables are area and temperature difference. The temperature of the shell side is set by boiling at $96^{\circ} \mathrm{C}$ for NRTS atmospheric pressure conditions. The steam pressure controls the temperature on the primary side.

Two factors are considered in selecting the operating pressure of the condenser-boiler. An increase in the steam pressure also increases $\Delta T$, thus reducing the heat transfer area of the condenser-boiler for $5-\mathrm{Mw}$ operation. Conversely, the lower the pressure, the greater is the assurance of dry steam entering the recombiner (because the larger pressure 
drop across the valve preceding the recombiner produces steam withmore degrees of superheat). The assumption of $99 \frac{1}{2} \%$ quality on the high-pressure side of the throttle and the selection of $5.5^{\circ} \mathrm{C}\left(10^{\circ} \mathrm{F}\right)$ of superheat entering the recombiner as desirable for $5-\mathrm{Mw}$ operation lead to a condenser-boiler area of $27.9 \mathrm{~m}^{2}\left(300 \mathrm{ft}^{2}\right)$. Thus, the condenser-boiler component is based on a UA product of $68,100 \mathrm{cal} /(\mathrm{hr})\left({ }^{\circ} \mathrm{C}\right)\left[\right.$ or $\left.150,000 \mathrm{Btu} /(\mathrm{hr})\left({ }^{\circ} \mathrm{F}\right)\right]$. The condenser boiler removes about $90 \%$ of the heat.

The condensate is cooled by approximately $50^{\circ} \mathrm{C}$ in the condensate cooler. Carryunder of steam bubbles in the downcomer is reduced by use of subcooled feedwater. Also, the greater the subcooling, the greater is the reactor power output per kilogram of steam. The secondary cooling water for the condensate-cooler passes directly from the condensate-cooler to the condenser-boiler. This design eliminates the need for disposal of the cooling water from the condensate-cooler. However, this coupling essentially fixes the temperature of the effluent from the condensate-cooler. The flow rate of secondary cooling water is fixed by the heat removal rate (boiling rate) of the condenser-boiler To insure that the secondary cooling water leaving the condensate-cooler is not boiling, a UA product of about $4540 \mathrm{cal} /(\mathrm{hr})\left({ }^{\circ} \mathrm{C}\right)\left[\right.$ or $\left.10,000 \mathrm{Btu} /(\mathrm{hr})\left({ }^{\circ} \mathrm{F}\right)\right]$ is required, thus giving a heat transfer area requirement of about $4.6 \mathrm{~m}^{2}$ (or $50 \mathrm{ft}^{2}$ ). The condensate cooler removes about $8 \%$ of the heat.

The condensate storage tank serves as the buffer in the reactor and heat-cycle components. Any power change in the system is absorbed by a change of liquid level in the condensate storage tank. The details of the function and design of this tank are presented in Section III. E on the fuelhandling system.

The feedwater pump rating for $5-\mathrm{Mw}$ operation is $133 \mathrm{l} / \mathrm{min}$ at $4.76 \mathrm{~atm}$ head.

D. Gas-handling System

The functions of the gas-handling system are:

(1) receive and store the gaseous fission products released from the reactor:

(2) recombine the small amount of hydrogen and oxygen that passes through the full-flow recombiner;

(3) provide gas during noncritical conditions for injection in the reactor system to create natural circulation; and

(4) pressurize various components to provide the pressure differential for material transfer. 
The gaseous fission products, hydrogen, oxygen, and noncondensible gases, are removed from the primary steam cycle by continually bleeding steam from the condenser-boiler. The gaseous mixture first passes through the auxiliary recombiner. This unit has not been designed due to the uncertainty in the efficiency of the full-flow recombiner. However, it is small in size, and would be designed in the same manner as the full-flow recombiner. The steam bleed rate from the condenser-boiler should be sufficient to eliminate the explosion hazard of a hydrogen and oxygen mixture and to maintain a reasonable exit temperature from the auxiliary recombiner. Too high a bleed rate will unduly increase the size of the auxiliary condenser. The purpose of this condenser is to remove the steam, leaving only the fis sion and noncondensible gases

A cold trap to remove the water vapor is shown in the flow diagram (Fig. 1). It is being considered because water vapor may be undesirable in the gas - storage tanks.

No decision has been reached whether to remove fission gases from the gas-handling system in order to reduce the activity of the circulating gas or to let these gases accumulate throughout. Three methods of removal were considered: (1) charcoal-bed absorber, (2) solvent column, and (3) decay storage tank. The two preferred methods, i.e., charcoal absorption and decay storage, are shown in the flow diagram for the sake of completeness. Preliminary designs are presented for the charcoal bed and solvent column in Appendix C. Approximately $39 . \mathrm{l}$ of activated charcoal are required to absorb the xenon and krypton produced by 1000 hr of $5-\mathrm{Mw}$ operation. A solvent column to fulfill the same function is about $3 \mathrm{~cm}$ in diameter and $300 \mathrm{~cm}$ long (safety factor of two), packed with $\frac{1}{4}$-in. Raschig rings, and requires about $2500 \mathrm{l}$ of solvent during the life of the experiment. The major disadvantages of such a column are storage of the spent solvent and the possibility of solvent carryover into the reactor, where it could cause foaming.

Voids are produced during noncritical operation by injecting gas into the riser. The gas injection is accomplished by a closed, recirculating system. The gas leaves the reactor system through the steam-throttling valve, bypasses the condensers, recombiners, and absorbers, and enters directly into the low-pressure storage tank. From the low-pressure storage tank it is recompressed and accumulated in the high-pressure storage tank.

Gas from the high-pressure storage tank is also used to pressurize the expansion tank for material transfer, as discussed in the next section, and to inject voids into the downcomers for reactor control.

The estimated pressure requirements for these functions are as follows: 
1. Riser gas injection for circulation

2. Downcomer gas injection for control

3. Expansion tank pressurization for $\frac{\mathrm{atm}}{1.75}$

2.04

1

6.7

6.7

Since operations at the higher pressure are infrequent, it is possible to use bottled gas for these and to limit the delivery pressure of the compressor to $3.5 \mathrm{~atm}$. Since slurry circulation in the reactor demands the greatest mass flow rate of gas, the compressor must have a rating of at least $3000 \mathrm{l} / \mathrm{min}$ (STP). This is sufficient to produce a fluid velocity of about $40 \mathrm{~cm} / \mathrm{sec}$ in the reactor system, equivalent to a void fraction of about 0.1 . Helium, because of chemical inertness, is suggested as the circulating gas. The compressor is then likely to be a single-stage unit of about $25-\mathrm{kw}$ rating (see Appendix D for calculation of compressor sizes).

The particular design conditions for gas circulation, i.e., 0.1 void fraction at a reactor pressure of $175 \mathrm{~atm}$, dictate the procedures for reactor startup and shutdown. At startup, criticality is attained at 1.75 atm, the reactor is heated at low power to saturation temperature, and gas flow is reduced, causing gas voids to be replaced by steam voids. Pressure and power are then raised in turn to the desired power level at 10.2 atm. During routine shutdown, pressure and power are reduced to produce 0.1 void fraction at $1.75 \mathrm{~atm}$. The gas system is turned on, replacing steam voids with gas voids. The control rod is then fully inserted to complete the shutdown. The effect of gas-steam mixtures on the performance of the various gas-handling and heat-dissipation components should be analyzed in detail for these two transient conditions.

The volume and pressure level for the high and low-pressure tanks are not selected. The capacity of the high-pressure tank will more than likely be determined by emergency conditions. If the compressor is lost, the high-pressure tank should be able to perform the following operations:

(1) pressurize expansion tank to 2.04 atm when the tank is void of slurry and water;

(2) supply gas to circulate reactor liquid for $5 \mathrm{~min}$; and

(3) supply air to drain the reactor.

The low-pressure tank acts as a reservoir for the gas-handling system and therefore must be sized to allow for gas storage during any operational procedure. If a decay storage tank is incorporated into the 
final plant system, the gas stored there could be used, in case of an emergency, to supplement the gas inventory in the high-pressure tank. However, during normal system operations, the gas in the decaystorage tank is held until its activity is low enough to be expelled through the stack.

E. Fuel-handling System

\section{Introduction}

The fuel-handling system could consist of always safe tanks in which the slurry is suspended by mechanical mixing or gas sparging The major problem with mechanical mixing involves the problem of an always safe geometry. If one does not internally poison the tanks, the maximum pipe size is $8 \mathrm{in.}$, and $40 \mathrm{~m}$ of tank length are required to handle the slurry inventory. This means either very many tanks, each with its own mixer and instrumentation, or perhaps ten very long tanks. A very long tank requires supporting the mixer shaft on bearings internal to the tank with a resulting problem of maintenance Internal poisoning probably means boron steel mixer shafts and more baffles (also of a boron steel) than is desirable for good mixing.

In the case of gas sparging, internal poisoning by baffles probably raises less of a mixing problem The disadvantage here is the large amount of gas required. There is also the design and testing effort necessary to develop a tank with suitable gas injection to ensure material suspension and resuspension upon loss of gas supply or after shutdown during off-shift or weekend periods. There is no assurance that such a tank can be developed in a reasonable time

In order to obviate these problems, the design selected is one of a large coil of inclined loops in which the slurry is pumped. The expectation here is that, upon pump shutdown, the slurry settles in place. Upon pump startup, the water flowing over the slurry in the pipe resuspends it gradually This feature and the ability of the Argonne-developed oxide material to withstand attrition by the pump must be verified by operation of a loop mockup.

This design has other advantages

(a) Only one or possibly two sets of density instrumentation are required.

(b) By coupling this coil to an expansion tank, a constant inventory of water is maintained in the coil The maximum oxide concentration in this water is a function of the amount of oxide not in the reactor. The opportunity of adding a slug of highly concentrated slurry to the reactor at power (as from an isolated storage tank) is eliminated and it is easier to provide interlocks and operating procedures that will prevent too rapid addition of reactivity due to slurry transfer under any circumstances. 
The operations performed within the fuel-handling system may be divided into four types: (1) slurrystorage, (2) water storage, (3) reactor slurry concentration and dilution, and (4) reactor drain and fill.

The function of slurry storage is accomplished in the pipe coil. The coil consists of 4 -in. Schedule 10 pipe to preclude criticality under any conditions. Suspension of the slurry is maintained by a circulation pump which has a capacity of $750 \mathrm{l} / \mathrm{min}$.

The slurry is concentrated in storage by allowing settling to occur in the expansion tank. As the particles settle, they pass from the expansion tank into the coil where the recirculation suspends and evenly distributes the particles. Thus, the fluid in the upper portion of the expansion tank is clarified by virtue of the allowed settling. Clear water is transferred from the expansion tank to the condensate storage tank as needed.

A pressure differential is utilized as the driving force to transfer slurry to or from the reactor. The various pressure differentials are obtained by employing the storage coil pump and/or pressurized gas. The individual slurrytransfer operations aredescribed in subsequent paragraphs. Reactor slurry concentration is increased by adding slurry and reducing feedwater during power operation.

\section{Design Criteria}

The following preliminary criteria have been established to aid in the sizing and design of the storage system:

(a) The design pressure and temperature for the slurry storage system are:

$$
\begin{aligned}
& P=13.6 \mathrm{~atm} \\
& T=205^{\circ} \mathrm{C} .
\end{aligned}
$$

(b) The minimum and maximum operating levels in the steam separator are set at $17.8 \mathrm{~cm}$ and $30.4 \mathrm{~cm}$ above the lower crest of the separator. This yields slurry volumes of $1130 \mathrm{l}$ and $1280 \mathrm{l}$, respectively. The average volume is $1210 \mathrm{l}$.

(c) The oxide inventory is selected as that amount required to produce $5 \mathrm{Mw}$ under average conditions, plus $20 \%$ excess. The excess allows for fuel holdup in the storage system and the possibility of operation at slightly higher power levels.

When one considers voids, the volume distribution for $5-\mathrm{Mw}$ operation at minimum liquid level is $850 \%$ slurry and $280 \ell$ void, and at maximum liquid level is $980 \ell$ slurry and $300 \ell$ void. Thus, an average 
volume of $920 \mathrm{l}$ at $545 \mathrm{gm}$ oxide per $\mathrm{kg} \mathrm{H}_{2} \mathrm{O}$ plus $20 \%$ excess yields an oxide inventory of $507 \mathrm{~kg}$, consisting of $454.6 \mathrm{~kg} \mathrm{ThO}$ and $51.9 \mathrm{~kg} \mathrm{UO} 2.5$.

(d) The water inventory is selected as three average reactor volumes, or $3630 \ell$, at STP.

(e) The slurry-storage system must be capable of containing the entire inventory of water and oxide particles.

(f) The maximum slurry concentration in the slurry-storage coil is approximately $600 \mathrm{gm}$ oxide/ $l$ of slurry.

(g) The rate of concentration change in the reactor during critical operation is not to exceed $30 \mathrm{gm}$ of oxide $/(\ell)(\mathrm{min})$.

(h) The fluid velocities in the coil and connecting piping in the storage system are to be more than $150 \mathrm{~cm} / \mathrm{sec}$ to permit slurry resus pension and less than $450 \mathrm{~cm} / \mathrm{sec}$ to eliminate erosion effects.

(i) Gravity drain of the reactor system is not necessary.

(j) Normal reactor drain time is to be about one minute.

(k) After a drain, the reactor is rinsed three times.

(1) The decay heat in the storage system is removed by natural convection to the shield water.

(m) Only on-off valves are to be used in slurry lines.

\section{Design Details}

A schematic diagram of the fuel-handling system is presented in Fig. 7. The components and lines in the system are numbered and their design is discussed in subsequent paragraphs. The system can be broken down into four subsystems in accordance with the functions previously discussed.

a. Slurry-storage System
(1) Storage coil (1)
(2) Pump (2)
(3) Resistance coil (3)
(4) Expansion tank (4) 
b. Water-storage System

(1) Condensate storage tank (5)

(2) One-inch water transfer line and resistance coil (6)

(3) Expansion tank (4)

c. Concentration and Dilution System

(1) One-inch concentration increase line (8)

(2) One-inch concentration decrease line and resistance coil (9)

d. Primary Material Transfer System

(1) One-inch fill line (7)

(2) Four-inch drain line (10).

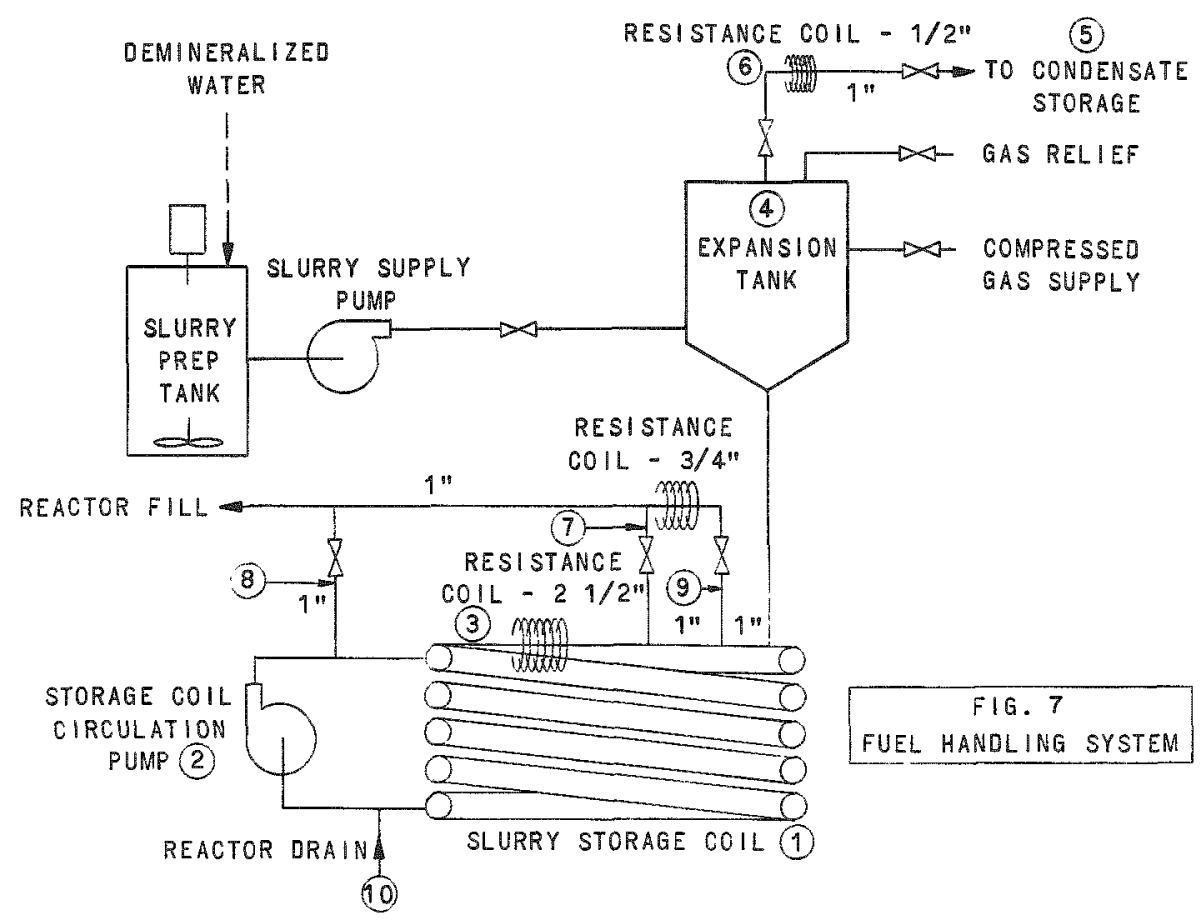

The storage coil (1), designed to withstand a pressure at $13.6 \mathrm{~atm}$ and a temperature of $205^{\circ} \mathrm{C}$, is constructed of 4 -in. Schedule 10 stainless steel pipe. The length of pipe is determined by the fuel inventory and the concentration requirement. To satisfy the design condition, $80 \mathrm{~m}$ of pipe are formed into eight loops, $3.5 \mathrm{~m}$ in diameter. The total volume of the storage coil and added resistance coil is $850 \hat{\psi}$. A different geometry may be used in the detailed design if it is more suitable from the standpoint of layout and fabrication. 
The storage coil pump (2) is a single-stage, centrifugal pump, which delivers $750 \mathrm{l} / \mathrm{min}$ at a pressure difference of 5.1 atm. The result ing fluid velocity in the storage coil is $154 \mathrm{~cm} / \mathrm{sec}$. The pump is operated during the fill operation, the drain operation, the concentration change operations, and when the slurry is being circulated in the coil.

The added resistance coil (3) in the slurry storage coil is designed so that required pressures for the various slurry transfer operations can be tapped off the storage system. The coil gives a pressure drop of 4.22 atm at a slurry flow rate of $750 \mathrm{l} / \mathrm{min}$. The design specifications are met by a 2 -in. Schedule 10 resistance coil with an equivalent lengthto-diameter ratio of 685 . One possible design is six full turns formed by $2 \rightarrow \mathrm{m}$ lengths of pipe between 180 -degree return bends.

The expansion tank (4) together with the storage coil is capable of containing the entire inventory of fuel and water, thereby insuring that the reactor can be drained at any time. The expansion tank has a volume of $3070 \mathrm{l}$. Therefore, the total capacity of the expansion tankand storage coil is $2 \%$ in excess of the total inventory of fuel and water. The design pressure and temperature of the tank are $13.6 \mathrm{~atm}$ and $205^{\circ} \mathrm{C}$, respectively. In the detailed design of the expansion tank, a larger tank neck may be needed to allow the slurry to settle into the coil in a reasonable time.

The condensate storage tank (5) is an integral part of the waterstorage system It acts as a reservoir for reactor feed and rinse water. The tank has a maximum and minimum operating volume of water. The minimum operating volume is $1190 \mathrm{l}$, which is $5 \%$ in excess of the clear water needed to carry out a rinse operation. The maximum operating volume of $1450 \mathrm{l}$ insures that at any reactor operating condition the storage coil has sufficient water to be completely full. The total condensate storage tank capacity is $1620 \mathrm{l}$, and the design pressure and temperature are $6.8 \mathrm{~atm}$ and $70^{\circ} \mathrm{C}$, respectively.

The 1 -in. water transfer line and resistance coil (6) join the expansion tank and condensate storage tank. The line is sized to transfer $52.3 \mathrm{l} / \mathrm{min}$ of water from one tank to the other under a pressure differential of $0.59 \mathrm{~atm}$. The hydrostatic analysis assumes that an average hydrostatic head of $130 \mathrm{~cm}$ of water exists during water transfer. The resistance coil is added in the line so that skin friction and not hydrostatic head is the controlling factor in determining flow. This coil insures that a reasonable flow between the tanks is established for any of the anticipated operating conditions. The $\frac{1}{2}-$ in. Schedule 10 coil of four $0.6-\mathrm{m}$ diameter loops is designed with an equivalent length-to-diameter ratio of 495 .

The fill line (7) is 1 -in. Schedule 10 pipe. The line branches from the slurry storage coil just after the resistance coil (3) so that the reactor is not filled too rapidly. 
Concentration of the slurry in the reactor is increased at operating conditions by using the 1 -in. concentration increase line (8). With a driving force of $0.32 \mathrm{~atm}$, a maximum concentration increase of approximately $30 \mathrm{gm}$ oxide $/(l)(\mathrm{min})$ is obtained.

The 1-in. concentration decrease line and resistance coil (9) are utilized during the diluting operation. A $\frac{3}{4}$-in. Schedule 10 resistance coil of ten $0.56-\mathrm{m}$ diameter loops, giving an equivalent length-to-diameter ratio of 2045 , results in a flow rate of $53 \mathrm{l} / \mathrm{min}$.

The 4-in. drain line (10) is used to drain the reactor. This line is tied into the reactor at the top of one of the 180-degree return bends. The line is placed on top of the bend so that the drain valve is not subject to caking due to settling slurry particles. The size of the drain line allows the reactor to be drained in approximately one minute. A rapid reactor drain is preferred in order to minimize settling within the reactor system during draining.

Instrumentation for the fuel handling system is indicated on the main flow diagram (Fig. 1).

\section{Operating Procedures}

\section{a. Reactor Fill}

The reactor is filled by transferring slurry from the storage coil to the reactor system. When the reactor is empty, the total fuel inventory is in the storage coil, and the concentration in the coil is about $600 \mathrm{gm}$ oxide/l of slurry. The concentration in the coil is decreased during the fill operation when the slurry is transferred from the coil to the reactor, and clear water drains from the expansion tank to the coil. By this method, the maximum obtainable concentration in the reactor is $350 \mathrm{gm}$ oxide $/ 2$ at ambient conditions. Concentrations greater than $350 \mathrm{gm} / 2 \mathrm{can}$ be reached only during power operation as described later. If an initial concentration lower than $350 \mathrm{gm} / 2$ is desired, a predetermined amount of clear water is first added to the reactor.

The pump in the slurry storage coil and the pressurized expansion tank supply the required driving force for slurry transfer. To insure that the pump is not subject to cavitation and to supplement the developed head, the expansion tank is pressurized to $2.04 \mathrm{~atm}$. Thus, the driving force of $1.19 \mathrm{~atm}$ allows $170 \mathrm{l} / \mathrm{min}$ of slurry to be transferred through the 1 -in. slurry fill line. With this driving force the reactor can be filled in about 7 min to the maximum initial concentration. Filling time for lower initial concentrations is shorter. 
Prior to the fill operation, the condensate storage tank should be filled to at least the minimum operating volume. Immediately after an unexpected drain this water is pumped into the reactor. It serves as a rinse to resuspend fuel particles not removed from the reactor during the draining operation.

\section{b. Normal Reactor Drain and Rinse}

A normal reactor drain is classified as the operation which transfers slurry from the reactor to the slurry-storage coil during routine system operations. Since the time is not an important variable, the drain system is designed to reduce thermal stresses and valve damage.

The drain operation is initiated after the reactor has been shut down, the reactor pressure is 1.75 atm, and the corresponding saturation temperature is $117^{\circ} \mathrm{C}$.

During the drain operation, the reactor is kept at an approximately constant pressure of $1.75 \mathrm{~atm}$. This is accomplished by closing the steam-throttle valve as the 4-in. slurry drain line is opened, and by injecting gas into the system to compensate for the draining slurry. During the drain operation the expansion tank is maintained at $0.85 \mathrm{~atm}$. Under the resulting pressure differential the slurry drains from the reactor in approximately one minute.

Immediately after the slurry is drained, the drain line is closed. and the reactor is filled to the minimum operating volume with water from the condensate storage tank. Natural circulation of the water 15 induced by gas injection to resuspend slurry particles that have been left in the system The rinse water is transferred from the reactor to the storage coil in the same manner that slurry is drained from the reactor If three rinses are employed and each drain eliminates $70 \%$ of the fuel parricles that remain in the reactor system, approximately $1 \%$ of the initial reactor fuel remains in the reactor after the third rinse is completed.

\section{c. Reactor Concentration Increase}

When the reactor is critical, the concentration of fuel can be increased even if the concentration in the storage coil is lower than that in the reactor. The automatic feedwater system regulates the feedwater flow so that the level of slurry in the separator remains relatively constant. To increase the concentration in the reactor, slurry is transferred from the storage coil. This disrupts the equilibrium slurry level, and the automatic feedwater control valve restricts the feedwater flow and restores the sys tem to equilibrium. Since fuel particles have been added to the system and the total volume has remained relatively unchanged, the slurry concentration in the reactor has been increased. 
A pressure differential of 0.32 atm allows slurry to be transferred through the 1-in. slurry-supply line to the reactor. The desired driving force is obtained by pressurizing the expansion tank to $6.7 \mathrm{~atm}$. With the slurry-supply line open, the storage coil pump circulates $850 \mathrm{l} / \mathrm{min}$ at a head of $4.94 \mathrm{~atm}$.

During the concentrating process the slurry additions should be carried out in steps, which will insure a reasonably accurate control of concentration change. However, with experience, it may be possible to eliminate the steps and concentrate at a steady rate. If the $I$-in slurry-supply line is opened for one minute at an initial slurry concentration of $300 \mathrm{gm}$ oxide/ $l$ in the reactor, this procedure increases the concentration by $16 \mathrm{gm}$ oxide/ $\ell$. The change is less when the initial concentration in the reactor is greater than $300 \mathrm{gm}$ oxide/l.

After the valve has been closed, time should be allowed for the concentration in the reactor to reach the new equilibrium level. When equilibrium has been reached, the new concentration is measured. If additional concentration is needed, the above step procedure is repeated until the desired result is obtained.

\section{d. Concentration Decrease}

The concentration is decreased by draining slurry from the reactor and replacing with an equal volume of clear water. During this process, the expansion tank is pressurized to 6.7 atm, and the storage coil pump is circulating $750 \mathrm{l} / \mathrm{min}$ at a head of $5.1 \mathrm{~atm}$. These conditions result in a pressure differential of $3.4 \mathrm{~atm}$ between the reactor and storage coil. At this driving force $53 \mathrm{l} / \mathrm{min}$ is transferred through the 1 -in. concentration-decrease line. This concentration-decrease operation is also a step procedure.

\section{e. Water Distribution}

The fuel-storage system is designed such that a constant inventory of water is maintained, eliminating the need for disposal of radioactive water during routine operations. During steady-state operation a constant amount of steam is produced and fed back into the reactor as condensate. During a concentration increase, the weight of steam which leaves the reactor is greater than the weight of the returning condensate. During a concentration decrease, less steam is produced than condensate returned. Clear water, otherwise produced in the expansion tank, is also needed for reactor-rinse operations. In accordance with the unsteady state requirements, water must be transferred between the condensate storage tank and the expansion tank. Since there are restrictions as to when such transfer can be made, the level in the condensate storage tank should be maintained in anticipation of these requirements. 
The restrictions stem from the fact that a pump is not provided between the two tanks, and water transfer is by means of pressure differential. No provision has been made for pressurizing the condensate storage tank, and, therefore, the pressure in the tank is dependent on the reactor power level. The pressure of the expansion tank depends upon the particular fuel-handling procedure in progress. For example, during the actual reactor-dilution process, the pressure in the expansion tank exceeds that in the condensate storage tank, even at a maximum power. Therefore, transfer of excess water from the condensate tank is not possible without stopping the dilution and depressurizing the expansion tank.

\section{F Miscellaneous Systems}

The slurry is prepared in a separate area and transferred to the fuel-handling system. The slurry-preparation area is not contaminated and thus is accessible during periods of reactor shutdown. A mixer can be used to disperse and suspend the fine fuel particles. The preparation is a batchwise operation.

Cooling water is supplied from an on-site well. Since the cooling process is a boiling operation, the cooling water must be demineralized. Cooling water requirements for the auxiliary condenser and charcoal bed have not been determined. This system also supplied makeup water to the shielding tanks

A stack is used to vent gases to the atmosphere. 


\section{CONTROL AND INSTRUMENTATION}

\section{A. Reactor Control}

The principal mode of reactor control, at least during preliminary operation, is a single, cruciform control rod, inserted in the riser section of the reactor vessel. The rod, made of $1 \%$ boron-stainless steel, is $58 \mathrm{~cm}$ wide, $0.63 \mathrm{~cm}$ thick, and $85 \mathrm{~cm}$ long. It is expected that the maximum control rod stroke will be $75 \mathrm{~cm}$. This permits the design of a tapered control rod which, in the down position, is inserted $20 \mathrm{~cm}$ into the $10 \mathrm{x} 24 \mathrm{~m}$. expander at the lower end of the core. Nuclear calculations are required to determine the extent of shutdown with the rod in the down position. One would not expect to make the core inlet subcritical for all slurry concentration, but only to protect the reactor against significant power production during the drainage step of the scram procedure. When the control rod is in the out position, the ratio of length to diameter for the core is equivalent to 1.5 , based on the analysis presented in Section VI. This provides a margin of error above the design ratio for length to diameter of 1.25. Further withdrawal does not appear warranted because it results in little increase in reactivity and because the total height of the reactor vessel would have to be increased to permit valid measurement of riser steam voids.

A final selection of a control rod drive has not been made. The major question is whether or not to put the moving parts of the drive inside or outside the pressure shell. If they are inside the pressure shell, the need for a high-pressure seal and the concern about fission product leakage is eliminated; however, slurry could possibly leak into the mechanism. Rather simple modifications, involving baffling or possibly flushing, could be tried to keep slurry out of the mechanism. Completely contained units such as the magnetic jack of the Navy design or a lead-screw drive, incorporating a collapsible nut, would be suitable and relatively inexpensive.

Other modes or reactor control are variation of fuel concentration and injection of gas into the downcomer. These have been described in earlier appropriate sections.

Details of the system of nuclear instrumentation have not been worked out. It is expected that the system might be patterned after BORAX V, since the requirements for remote transmission are compar able and since operation would likely be by personnel with prior experience on BORAX V.

\section{B. Scram and Alarm System}

A preliminary list of scram and alarm conditions for SLURREX is given in Table II. The number of scram circuits has been reduced deliberately because current design philosophy is based upon initiating draining of the reactor vessel as part of the scram procedure. The decision to drain is based on three reasons: 
(1) The behavior of the slurry is not sufficiently known to predict whether or not settling can be permitted in the reactor vessel, even for short periods of time.

(2) The gas system (see Section III-D) is not designed to maintain slurry suspension at full operating pressure (10.2 atm).

(3) Sufficient system analysis has not been performed to determine under what conditions of malfunction drainage is not required.

Table II

SCRAM AND ALARM CONDITIONS

\begin{tabular}{|c|c|c|}
\hline & Scram & Alarm \\
\hline 1. High Flux No. 1 & $\mathrm{x}$ & \\
\hline 2. High Flux No. 2 & $\mathrm{x}$ & \\
\hline 3. Short Period & $x$ & \\
\hline 4. Low Reactor Water Level & $\mathrm{x}$ & $\mathrm{x}$ \\
\hline 5. High Reactor Water Level & $\mathrm{x}$ & $\mathrm{x}$ \\
\hline 6. High Reactor Pressure & $\mathrm{x}$ & $\mathrm{x}$ \\
\hline 7. Low Reactor Pressure & & $\mathrm{x}$ \\
\hline 8. Low Air Pressure & & $\mathrm{x}$ \\
\hline 9. Low Feedwater Pressure & & $\mathrm{x}$ \\
\hline 10. Low Feedwater Storage Tank Level & & $\mathrm{x}$ \\
\hline 1. High Feedwater Storage Tank Level & & $\mathrm{x}$ \\
\hline 12. Reactor Slurry Flow Rate & & $\mathrm{x}$ \\
\hline 13. Storage System Slurry Flow Rate & & $\mathrm{x}$ \\
\hline 14. High Slurry Expansion Tank Level & & $x$ \\
\hline 15. Low Slurry Expansion Tank Level & & $\mathrm{x}$ \\
\hline 16. High Recombiner Temperature & & $\mathrm{x}$ \\
\hline 17. High Auxiliary Recombiner Temperature & & $\mathrm{x}$ \\
\hline I 8 High and Low Level - Raw Water Tank & & $\mathrm{x}$ \\
\hline $\begin{array}{l}\text { 19. High and Low Level - Demineralized } \\
\text { Water Tank }\end{array}$ & & $\mathrm{x}$ \\
\hline $\begin{array}{l}\text { 20. High Temperature - Cooling Water to } \\
\text { Condenser-Boiler }\end{array}$ & & $\mathrm{x}$ \\
\hline 21. Cooling Water Pump Off & & $x$ \\
\hline 22. Nuclear Instruments High Voltage Off & & $\mathrm{x}$ \\
\hline 23. High Air Activity - Stack & & $\mathrm{x}$ \\
\hline 24. High Air Activity - Armco Building & & $x$ \\
\hline
\end{tabular}

As further information is developed about the slurry and the anticipated behavior of the system, it may be possible to make drainage a manual operation as part of the remedial action prescribed in the operating manual for only certain scrams. Since startup with a full system is a much simpler 
procedure, one can then provide more signals calling for a scram. In an experimental reactor built in a remote location, one has considerably more 赵 latitude in this regard than in a commercial nuclear power station.

Since one can already visualize experiments involving transients resulting in wide swings in power, period, pressure, and reactor water level, all scram circuits are provided with key-operated bypass switches.

\section{Process Instrumentation}

Variables proposed for measurement are indicated on the main SLURREX flow diagram (see Fig. 1): density, liquid level, riser voids, flow, temperature, and pressure.

Density can be measured by means of differential pressure. For this purpose a radiation-resistant diaphragm type of different pressure unit was purchased for the mockup. This unit is a modification of the NaK-filled units used in EBR-II. Considerable savings can be attained by use of ordinary differential pressure taps instead of diaphragm units, and success with this has been reported by Westinghouse. (2) Trial in the mockup or in a separate heated tank of slurry was planned.

Liquid levels can be measured by a separate differential pressure unit, used in conjunction with the density-detection devices. Preliminary inquiries have also been made with respect to thermocouples probes and ultrasonic devices. A trial thermocouple probe was ordered for the mockup. In their present state of development, ultrasonic devices do not appear feasible because of problems associated with radiation resistance.

Riser voids are determined by comparison of differential pressure measurements in the riser and in the downcomer. By proper circuitry, this comparison could be made automatically, and a direct-reading instrument (at least at operating temperature) could be evolved.

The preferred method of flow measurement appears to be by magnetic flowmeters. These have no moving parts and negligible pressure drop, which is a requirement for downcomer measurements. However, the accuracy of magnetic flowmeters in a radiation environment is questionable, due to radiation damage of the insulating materials currently in use. Other components in the meter itself are used for calibration purposes and can be moved outside the radiation field. Preliminary tests by the Metallurgy Division (3) indicate that commercially available ceramic liners for magnetic flowmeters are of adequate corrosion resistance, after preliminary leaching, for use in SLURREX. 


\section{HEAT TRANSFER AND FLUID FLOW}

A. Hydraulic

The hydraulic equation for the SLURREX natural circulation system, derived in Appendix $E$, is

$$
\frac{213 \alpha(1-\alpha)^{2}}{31.6(1-\alpha)^{2}+1.17-\alpha^{2}}=\frac{V_{0}^{2}}{2 g_{c}}
$$

where $V_{0}$ is the fluid velocity, $\alpha$ is the void fraction, and $g_{c}$ a conversion factor.

The variation of $V_{0}$, the fluid velocity in the single-phase region of the 56.5-cm ID (24-in. Schedule 40) pipe, and $V_{d}$, the fluid velocity in the downcomer. with respect to void fraction, $\alpha$, is shown in Fig. 8. For a void fraction value of 0.76 , it is seen that $V_{0}$ attains a maximum value of $87 \mathrm{~cm} / \mathrm{sec}$.

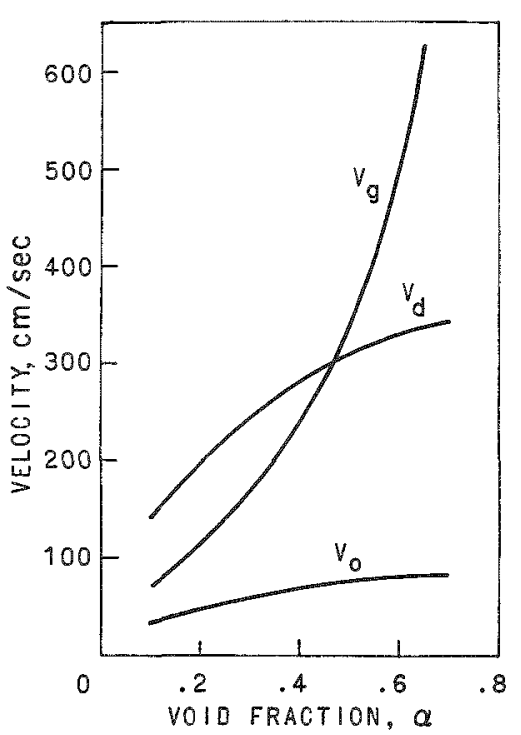

FIG. 8

TWO - PHASE STEAM VELOCITY AND CIRCULATION VELOCITY VS. VOID FRACTION

The following equations are used to calculate other hydraulic parameters:

$$
\begin{aligned}
& \text { Slip Ratio }=\frac{V_{g}}{V_{s}}=\frac{x}{l-x} \frac{1-\alpha}{\alpha} \frac{\rho_{s}}{\rho_{g}} \\
& V_{g}=V_{s} \times \text { (Slip Ratio) }
\end{aligned}
$$

where

$$
\begin{aligned}
\mathrm{V}_{\mathrm{g}}= & \text { velocity of the steam in the } \\
& \text { riser two-phase flow. } \\
\rho_{\mathrm{g}}= & \text { density of the steam. } \\
\mathrm{V}_{\mathrm{S}}= & \text { velocity of the slurry in the } \\
& \text { riser two-phase flow. } \\
\rho_{\mathrm{S}}= & \text { density of the slurry. }
\end{aligned}
$$

In the absence of other data, it has been assumed that the slip ratio data for steam-water systems are valid for steam-slurry systems. Experimental correlations of steam-water systems $(4)$ were used to evaluate $V_{g}$. A trial-and-error solution using Eqs. (2) and (3) and the slip ratio experimental correlations is required to determine $\mathrm{V}_{\mathrm{g}}$. The change of steam velocity with respect to void fraction is also presented in Fig. 8. 
The power output $P$ of the reactor is a product of the heat content change per pound and the steam mass flow rate:

$$
P(M w)=4.186 \cdot: V_{g} A \cdot g h \times 10^{6},
$$

where $A$ is the flow area and $\Delta h$ the enthalpy change.

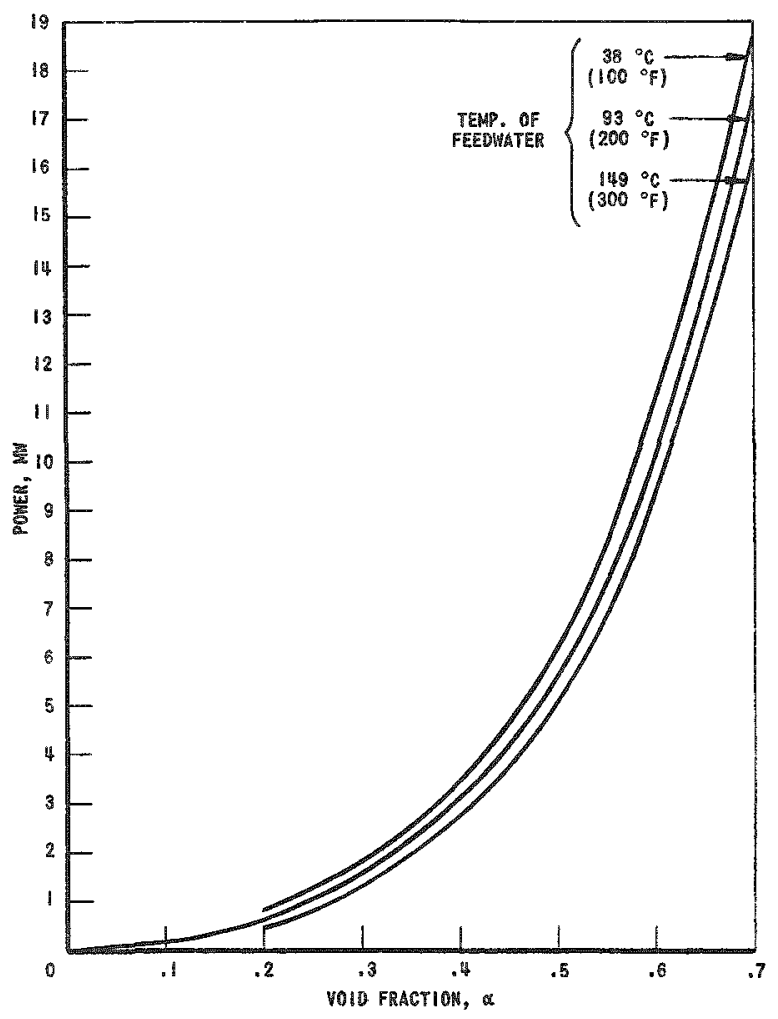

FIG. 8

FOWER OUTPUT VS. VOID FRACTIOH AT 10.2 ATH

The flow area is $2590 \mathrm{~cm}^{2}$ (24-in. Schedule 40 pipe), and the saturated steam density at $10.2 \mathrm{~atm}$ is $0.00533 \mathrm{gm} / \mathrm{cc}$. The value of $\mathrm{sh}$ in $\mathrm{Eq}$. (4) depends on the feedwater temperature returned to the reactor. Figure 9 presents power plotted against void fraction for three feedwater temperatures: $38^{\circ} \mathrm{C}, 93^{\circ} \mathrm{C}$, and $149^{\circ} \mathrm{C}$. The values of $\Delta \mathrm{h}$ are 625,570 , and $514 \mathrm{cal} / \mathrm{gm}$, respectively.

\section{B. Core Void Fraction Distribution}

A first approximation of the core void fraction distribution was made for $5-\mathrm{Mw}$ operation based on the following assumptions:

1. The heat generation rate per unit length is a sine function.

2. The length over which the nuclear reactions occur is $120 \mathrm{~cm}$.*

3. The feedwater temperature is $109.5^{\circ} \mathrm{C}$.

The equation for generation of heat $Q$ through the reactor length

$L$ is

$$
\frac{d Q}{d L}=C \sin \frac{\pi L}{120}
$$

*This active length is shorter than that developed in subsequent physics calculations (see Section VI). For the physics calculations it was ascertained that the nuclear reaction starts further down the expander than assumed here. For both sets of calculations the start of boiling and the end of the core occur at approximately the same corresponding points. The different active length is therefore expected to have an insignificant effect on the hydraulics and only a small effect on average void fraction. 
which must satisfy the boundary conditions that $d Q / d L$ equal zero at $L$ equal zero and at $L$ equals $120 \mathrm{~cm}$. Integration of $\mathrm{Eq}$. (5) yields

$$
Q(L)=\frac{120 C}{\pi}\left[1-\cos \frac{\pi L}{120}\right],
$$

where $C$ is a constant. The boundary conditions of $Q$ equals zero at $L$ equals zero and $Q$ equals $5 \mathrm{Mw}$ at $\mathrm{L}$ equals $120 \mathrm{~cm}$ yield a value for $C$ of $6.55 \times 10^{-2} \mathrm{Mw} / \mathrm{cm}$.

Before boiling can begin, the flowing slurry must be heated to the saturation temperature of $181^{\circ} \mathrm{C}$. This is accomplished at $\mathrm{L}$ equals $28 \mathrm{~cm}$. Between 28 and $120 \mathrm{~cm}, 2.08 \mathrm{~kg} / \mathrm{sec}$ of steam is produced.

The steam flow rate can be determined at any point if $Q(L)$ and the heat of vaporization are known. The velocity $\mathrm{V}_{0}$ for $5-\mathrm{Mw}$ operation is, from Figs. 8 and $9,76.5 \mathrm{~cm} / \mathrm{sec}$. The void fraction at any point $L$ is cal-

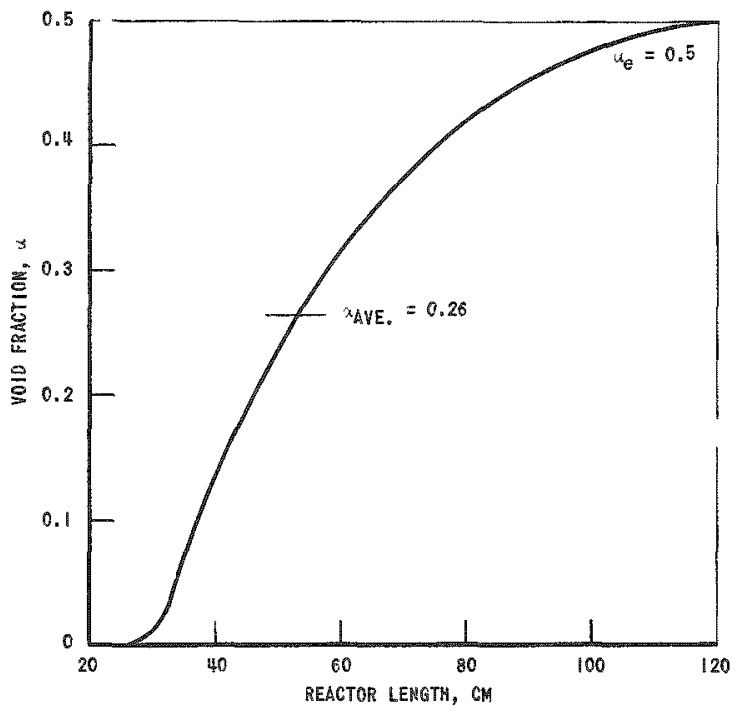

FIG. 10
VOID FRACTION VS. CORE LENGTH culated by iteration from Eqs. (6) and (2) and the experimental slip ratio data. The change in void fraction with length is illustrated in Fig. 10 . The maximum void fraction, referred to in this report as the riser void fraction, for $5 \mathrm{Mw}$ is 0.50 at $\mathrm{L}$ equals $120 \mathrm{~cm}$. The average void fraction, evaluated by determining the area under the curve of Fig. 10, is 0.26 for the $120-\mathrm{cm}$ reaction length. Thus, the average core void fraction is $52 \%$ of the riser void fraction.

\section{Heat Generation}

The energy removed from the reactor can be broken down into three parts:

(1) the heating of the subcooled feedwater to saturation temperature;

(2) the heat of vaporization; and

(3) the dissociation of water into hydrogen and oxygen.

The energy of the hydrogen cannot be realized until recombination occurs. For consistency, the following definition for calculating the SLURREX power output is used: the feedwater rate times the enthalpy difference be tween the exit steam from the full-flow recombiner and the feedwater (converted to megawatts). 
A heat cycle is illustrated in Fig. 6. For 5-Mw operation and $109.5^{\circ} \mathrm{C}$ feedwater, $13 \%$ of the energy is in subcooled heating of the feedwater, $84 \%$ in evaporation, and $3 \%$ in hydrogen recombination.

D. Power Density

The power density versus the core exit steam voids at 10.2 atm for the proposed SIURREX reactor vessel (separate riser and downcomers)

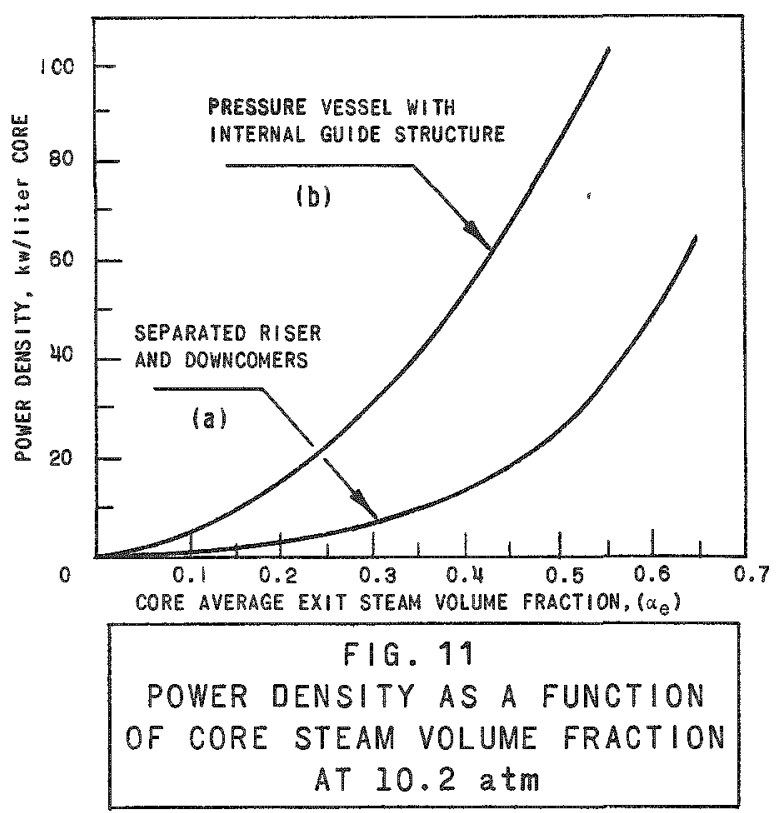
is shown as Curve (a) of Fig. 11. Increasing the recirculating coolant velocities results in an increase in power density for a constant core exit steam void. The recirculation velocity, which is a function of hydraulic resistance, could be increased by elimination of the separate riser and downcomer through use of a pressure vessel with an internal guide structure. The results for such a pressure vessel system with equivalent core and riser height are presented as Curve (b) in Fig. 11 .

Figure 12 shows the increase in power density resulting from increasing pressure for a given system geometry and steam void fraction at the core exit. This extrapolation is based on the experimentally determined change in slip ratio and on the increase in steam density with pressure. As a result of these theoretical considerations one can visualize for a natural-circulation boiling slurry reactor an available power density as high as $750 \mathrm{kw} / \ell$ at a pressure of 100 atm for a simple pressure vessel. From a practical standpoint, there is little doubt that the problem of steam separation would become the limiting factor long before this high power density was reached.

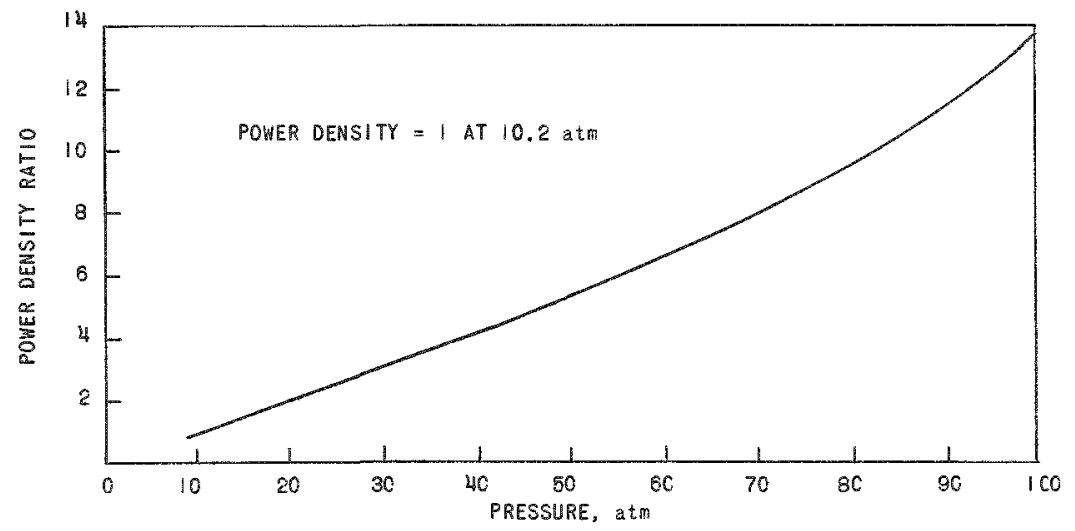

FIG. 12 POWER DENSITY AS A FUNGTION OF PRESSURE 


\section{PHYSICS}

A. Introduction

The diameter of the SLURREX core is determined by the dimensions of a 24-in. Schedule 10 pipe. This pipe size is sufficient to result in reasonable slurry concentrations for the desired operating conditions without reducing the velocity of the circulating slurry to an extent that particle settling is a problem. Since an analysis of the actual core shape would be difficult, preliminary criticality calculations have been performed on a right cylindrical core of this diameter $(59.6 \mathrm{~cm})$ to determine the effect of the following vaxiables:

(1) the ratio of length to diameter for the reactor:

(2) the per cent of uranium in the urania-ihoria slurry: and

(3) the average core void fraction (power output).

From these calculations a ratio of length to diameter and uranium content were selected as a design basis. The height of the actual core, i.e., how far the control rod must be withdrawn up the riser, has then been calculated for these conditions.

\section{B. Preliminary Criticality Calculations}

Table III gives material buckling $\left(\mathrm{B}_{\mathrm{m}}^{2}\right)^{(1)}$ values for various concentrations of $\mathrm{UO}_{3} \cdot \mathrm{H}_{2} \mathrm{O}$ and $\mathrm{ThO}_{2}$ at various water volume fractions. The calculations assume reactor operation at $185^{\circ} \mathrm{C}\left(500^{\circ} \mathrm{K}\right.$ neutron temperature) and 10.2 atm for all cases.

The values of $B_{m}^{2}$ were calculated by few-group diffusion theory, using four neutron energy groups: Group I, 1.35 to $10 \mathrm{Mev}$ : Group II, $9.12 \mathrm{kev}$ to $1.35 \mathrm{Mev}$; Group III, $0.4 \mathrm{ev}$ to $9.12 \mathrm{kev}$ : Group IV, 0 to $0.4 \mathrm{ev}$. The capture cross section for thorium in Group III was adjusted to agree with the effective resonance integral values computed by Dresner. (5)

The critical reactor slurry concentration was determined by graphical interpolation. Values of $\mathrm{B}_{\mathrm{m}}^{2}$ versus void fraction for each $\mathrm{ThO}_{2}$ concentration and varying $\mathrm{UO}_{3} \cdot \mathrm{H}_{2} \mathrm{O}$ concentrations were plotted. For average void fractions $*$ of $0,0.12,0.18,0.25$, and 0.32 , the relationship of $B_{m}^{2}$ to $\mathrm{UO}_{3} \cdot \mathrm{H}_{2} \mathrm{O}$ concentration for fixed $\mathrm{ThO}_{2}$ concentrations were obtained. From these relationships, the values of $\mathrm{B}_{\mathrm{m}}^{2}$ for fixed $\mathrm{ThO}_{2}$ concentrations and varying $\mathrm{UO}_{3} \cdot \mathrm{H}_{2} \mathrm{O}$ concentrations were determined.

$$
\text { *Void Eraction }=1-\left[\mathrm{V}_{\mathrm{f}}\left(\mathrm{H}_{2} \mathrm{O}\right)+\mathrm{V}_{f}\left(\mathrm{ThO}_{2}\right)+\mathrm{V}_{\mathrm{f}}\left(\mathrm{UO}_{3} \cdot \mathrm{H}_{2} \mathrm{O}\right)\right]
$$


Table III*

CALCULATED MATERIAL BUCKLINGS AND REFLECTOR SAVINGS FOR VARIOUS $\mathrm{UO}_{3} \cdot \mathrm{H}_{2} \mathrm{O}-\mathrm{ThO}_{2}-\mathrm{H}_{2} \mathrm{O}$ MIXTURES**

\begin{tabular}{|c|c|c|c|c|c|c|c|}
\hline \multirow{2}{*}{$\begin{array}{c}\text { Grams } \mathrm{ThO}_{2} \\
\text { per Liter } \\
\text { of Slurry }\end{array}$} & \multirow{2}{*}{$v_{f}^{\dagger}$} & \multicolumn{6}{|c|}{ Grams of $\mathrm{UO}_{3} \cdot \mathrm{H}_{2} \mathrm{O}$ per Liter of Slurry } \\
\hline & & 10 & 20 & 40 & 60 & 80 & 100 \\
\hline 200 & $\begin{array}{l}0.9 \\
0.8 \\
0.7 \\
0.6\end{array}$ & $\begin{array}{c}-0.00411 \\
- \\
-0.00260 \\
- \\
-0.00147 \\
- \\
-0.000606 \\
-\end{array}$ & $\begin{array}{l}0.00215 \\
2.1 \Uparrow \\
0.00239 \\
2.7 \\
0.00241 \\
3.5 \\
0.00225 \\
4.0\end{array}$ & $\begin{array}{l}0.00831 \\
8.6 \\
0.00719 \\
9.2 \\
0.00605 \\
10.0 \\
0.00485 \\
10.5\end{array}$ & $\begin{array}{l}0.0115 \\
9.2 \\
0.00962 \\
9.8 \\
0.00785 \\
10.6 \\
0.00612 \\
11.1\end{array}$ & $\begin{array}{c}0.0135 \\
- \\
0.0111 \\
- \\
0.00896 \\
- \\
0.00688 \\
-\end{array}$ & $\begin{array}{c}0.0149 \\
9.65 \\
0.0122 \\
10.25 \\
0.00972 \\
11.05 \\
0.00741 \\
11.55\end{array}$ \\
\hline 400 & $\begin{array}{l}0.9 \\
0.8 \\
0.7 \\
0.6\end{array}$ & $\begin{array}{c}-0.00594 \\
- \\
-0.00419 \\
- \\
-0.00282 \\
- \\
-0.00171 \\
-\end{array}$ & $\begin{array}{l}0.000489 \\
1.9 \\
0.000988 \\
2.5 \\
0.00125 \\
3.3 \\
0.00134 \\
3.8\end{array}$ & $\begin{array}{l}0.00703 \\
8.4 \\
0.00613 \\
9.0 \\
0.00520 \\
9.8 \\
0.00422 \\
10.3\end{array}$ & $\begin{array}{l}0.0105 \\
9.0 \\
0.00880 \\
9.6 \\
0.00722 \\
10.4 \\
0.00566 \\
10.9\end{array}$ & $\begin{array}{c}0.0127 \\
- \\
0.0105 \\
- \\
0.00846 \\
- \\
0.00654 \\
-\end{array}$ & $\begin{array}{c}0.0142 \\
9.45 \\
0.0116 \\
10.25 \\
0.00933 \\
10.85 \\
0.00715 \\
11.35\end{array}$ \\
\hline 600 & $\begin{array}{l}0.9 \\
0.8 \\
0.7 \\
0.6\end{array}$ & $\begin{array}{c}-0.00763 \\
- \\
-0.00564 \\
- \\
-0.00405 \\
- \\
-0.00272 \\
-\end{array}$ & $\begin{array}{l}-0.00104 \\
0.6 \\
-0.000308 \\
1.2 \\
0.000181 \\
2.0 \\
0.000478 \\
2.5\end{array}$ & $\begin{array}{l}0.00584 \\
7.1 \\
0.00516 \\
7.7 \\
0.00443 \\
8.5 \\
0.00362 \\
9.0\end{array}$ & $\begin{array}{l}0.00955 \\
7.7 \\
0.00806 \\
8.3 \\
0.00664 \\
9.1 \\
0.00522 \\
9.6\end{array}$ & $\begin{array}{c}0.0119 \\
- \\
0.00989 \\
- \\
0.00802 \\
- \\
0.00622 \\
-\end{array}$ & $\begin{array}{l}0.0136 \\
8.15 \\
0.0117 \\
8.75 \\
0.00899 \\
9.55 \\
0.00691 \\
10.05\end{array}$ \\
\hline 1000 & $\begin{array}{l}0.9 \\
0.8 \\
0.7 \\
0.6\end{array}$ & $\begin{array}{c}-0.00833 \\
- \\
-0.00634 \\
- \\
-0.00460 \\
-\end{array}$ & $\begin{array}{c}\text { Volumetr } \\
-0.00277 \\
- \\
-0.00186 \\
- \\
-0.00115 \\
-\end{array}$ & $\begin{array}{l}\text { cally not p } \\
0.00327 \\
1.5 \\
0.00290 \\
2.3 \\
0.00245 \\
2.8\end{array}$ & $\begin{array}{l}\text { sible } \\
0.00658 \\
2.1 \\
0.00549 \\
2.9 \\
0.00437 \\
3.4\end{array}$ & $\begin{array}{c}0.00873 \\
- \\
0.00714 \\
- \\
0.00559 \\
-\end{array}$ & $\begin{array}{l}0.0102 \\
2.55 \\
0.00831 \\
3.35 \\
0.00644 \\
3.85\end{array}$ \\
\hline
\end{tabular}

* Matexial buckling values are taken from ANL-6148, p. 36.(1)

** $185^{\circ} \mathrm{C}$ operating temperature; $500^{\circ} \mathrm{K}$ neutron temperature. Reflector savings calculated for water reflector, $50 \mathrm{~cm}$ thick.

$\dagger$ Volume fraction of water having density of $0.88 \mathrm{gm} / \mathrm{cm}^{3}\left(185^{\circ} \mathrm{C}\right)$. Note that void fraction $=1-\left[\mathrm{V}_{f}\left(\mathrm{H}_{2} \mathrm{O}\right)+\mathrm{V}_{\mathrm{f}}\left(\mathrm{UO}_{3} \cdot \mathrm{H}_{2} \mathrm{O}\right)+\mathrm{V}_{\mathrm{f}}\left(\mathrm{ThO} \mathrm{O}_{2}\right)\right]$.

तो Reflector savings in centimeters.

The reflector savings values(6) given in Table III were calculated for a water reflector, $50 \mathrm{~cm}$ thick, surrounding the core. The SNG Code for a cylinder $\left(S_{4}\right.$ approximation) was used to calculate the outer radius of 
the water reflector (a) at criticality. In adjusting the value of $\bar{a}$ to achieve the critical condition all radii were expanded or contracted proportionately. Since the reflector is many diffusion lengths thick, the changes in the reflector thickness resulting from this operation did not affect the value of the reflector saving. However, the assumed thickness of the steel reactor vessel was changed by the above operation. The maximum variation in the thickness of the steel was $2.8 \mathrm{~mm}$ compared to an actual thickness of $12.8 \mathrm{~mm}$. This relatively large difference gave a negligible effect in the reactor critical size as determined in a check calculation.

Three calculations of reflector savings have been performed with the SNG Code:

(1) $\mathrm{ThO}_{2}$ concentration was varied, with the $\mathrm{UO}_{3} \cdot \mathrm{H}_{2} \mathrm{O}$ concentration and volume fraction of water maintained at $40 \mathrm{gm} / l$ of slurry and $70 \%$, respectively.

(2) $\mathrm{UO}_{3} \cdot \mathrm{H}_{2} \mathrm{O}$ concentration was varied, with the $\mathrm{ThO}_{2}$ concentration and volume fraction of water maintained at $600 \mathrm{gm} / \ell$ of slurry and $70 \%$, respectively.

(3) Volume fraction of water was varied, with the $\mathrm{ThO}_{2}$ and $\mathrm{UO}_{3} \cdot \mathrm{H}_{2} \mathrm{O}$ concentrations maintained at 600 and $40 \mathrm{gm} / \ell$ of slurry. respectively.

By linearly combining the results of these calculations, it was possible to determine the value of the reflector savings to a reasonable degree of accuracy $(\approx 5 \%)$ for small changes in slury concentration.

The geometric buckling $\left(\mathrm{B}_{\mathrm{g}}^{2}\right)$ was calculated by the conventional equation for an equivalent bare cylindrical reactor:

$$
B_{g}^{2}=\left(\frac{2.405}{R^{1}}\right)^{2}+\left(\frac{\pi}{L^{1}}\right)^{2}
$$

where

$$
\begin{aligned}
R^{1} & =R+\text { reflector savings } \\
L^{1} & =\text { Reactor height }+(2)(\text { reflector savings }) \\
R & =\text { Reactor radius }=29.8 \mathrm{~cm} .
\end{aligned}
$$

Since the value of the reflector savings is dependent upon the composition of the slurry in the reactor core, values of $\mathrm{B}_{\mathrm{g}}^{2}$ were calculated for fixed $\mathrm{ThO}_{2}$ concentrations and varying $\mathrm{UO}_{3} \cdot \mathrm{H}_{2} \mathrm{O}$ concentrations for various ratios of length to diameter. For various $\mathrm{UO}_{3} \cdot \mathrm{H}_{2} \mathrm{O}$ concentrations and fixed $\mathrm{ThO}_{2}$ concentrations, void fraction, and ratio of length to diameter, $\mathrm{B}_{\mathrm{g}}^{2}$ was equated to $\mathrm{B}_{\mathrm{m}}^{2}$ by iteration in order to achieve the critical conditions. 
The results of the calculations for an average void fraction equal to $0.32 *$ and length-to-diameter ratios of $1.00,1.25$, and 1.50 are shown in Fig. 13 . Also shown in Fig. 13 are particle composition lines of $10 \mathrm{U} / 90 \mathrm{Th}$ and $8 \mathrm{U} / 92 \mathrm{Th}$ by weight $\left(93 \% \mathrm{U}^{235}\right)$. Figure 13 indicates that a reactor with a length-to-diameter ratio of 1.00 loaded with $8 \mathrm{U} / 92 \mathrm{Th}$ fuel never becomes critical.

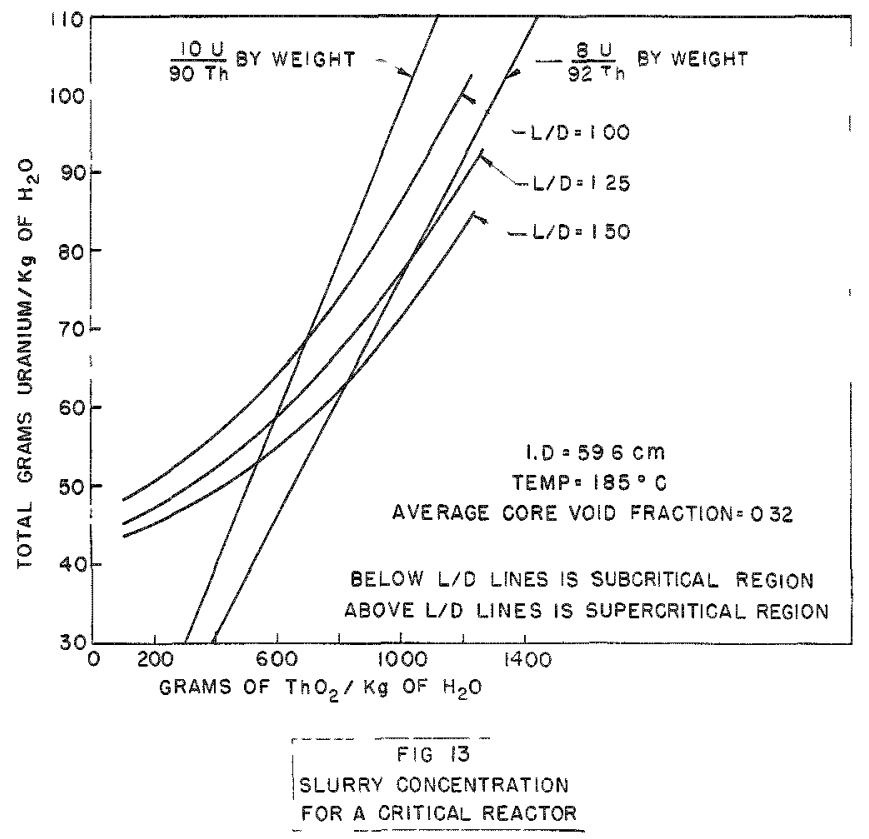

In order to reduce the uranium content of the fuel load and still provide a reasonable margin of excess uranium (excess reactivity) for operation at $5 \mathrm{Mw}$, a ratio of 1.25 for length to diameter and a particle composition of $10 \mathrm{U} / 90$ Th were selected as the parameters for further calculations. The effect of varying the average void fraction at critical operating conditions on the total grams of uranium ( $93 \%$ enriched) and $\mathrm{ThO}_{2}$ per $\mathrm{kg}$ of water is shown in Fig. 14. A change in the average void fraction from 0.25 to 0.32 increases the fuel load by a much larger fraction than an average void fraction change from 0 to 0.12 . From the points of intersection of the average void fraction-slurry concentration curves and the $10 \mathrm{U} / 90 \mathrm{Th}$ particle composition line (Fig. 14) one can determine the grams of solid per $\mathrm{kg}$ of water at critical operating conditions for the various average void fractions. Figure 15 is a plot of slurry concentration versus void fraction assuming that the fuel is $\mathrm{ThO}_{2}-\mathrm{UO}_{2.5}(93 \%$ enriched uranium).

*When these calculations were made the preliminary estimate of the average core void fraction at $5 \mathrm{Mw}$ was 0.32 . A more accurate value is 0.26 , as shown in Fig. 10. This variation of the average void affects only the displacement of the curves shown in Fig. 13 and not their general shape (see Fig. 14). Thus the selection of operating values for length-to-diameter and fuel ratios on this basis is valid. 


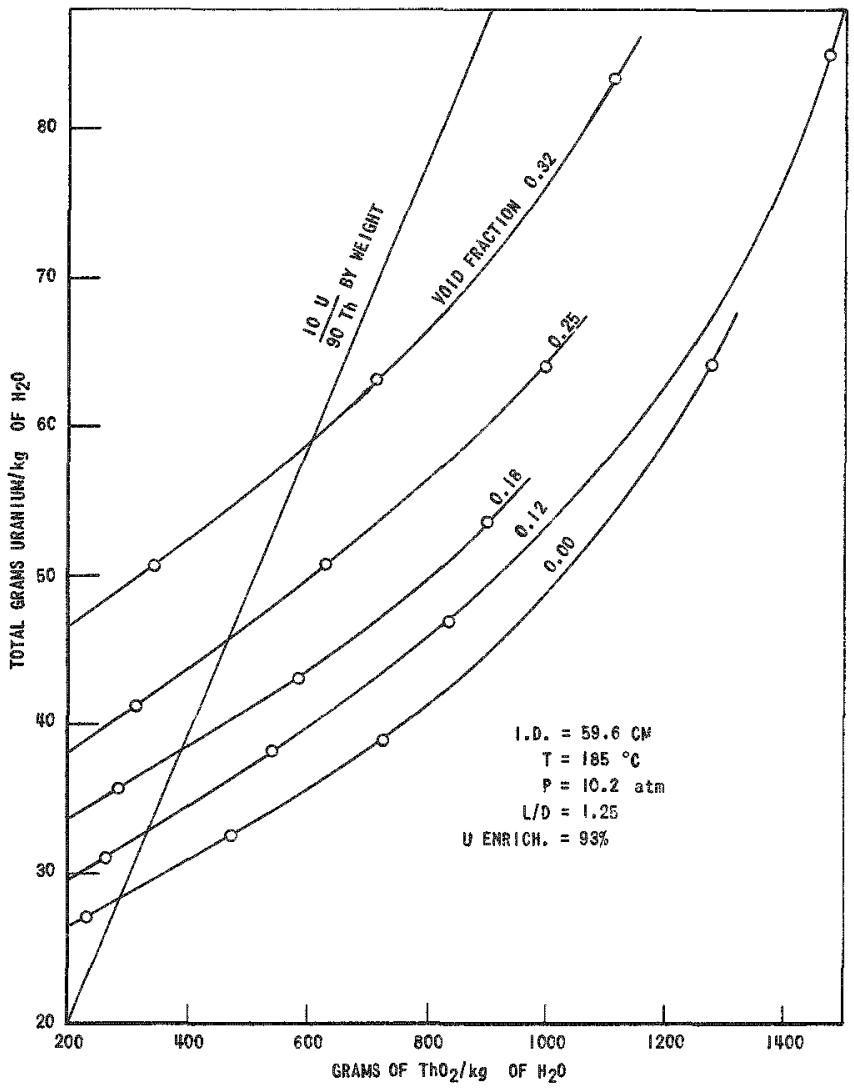

FIG. 14

URANIUA ARO THCRIA CCNCENTFATIOA AS A FUACTION OF VOID FRACTION

Figure 15 indicates that at design operating conditions the reactor requires $545 \mathrm{gm}$ of oxide per $\mathrm{kg}$ of water. Due to the large change in critical fuel load with void fraction (power level), it appears that a variation in fuel concentration offers a feasible method of controlling the SLURREX reactor.

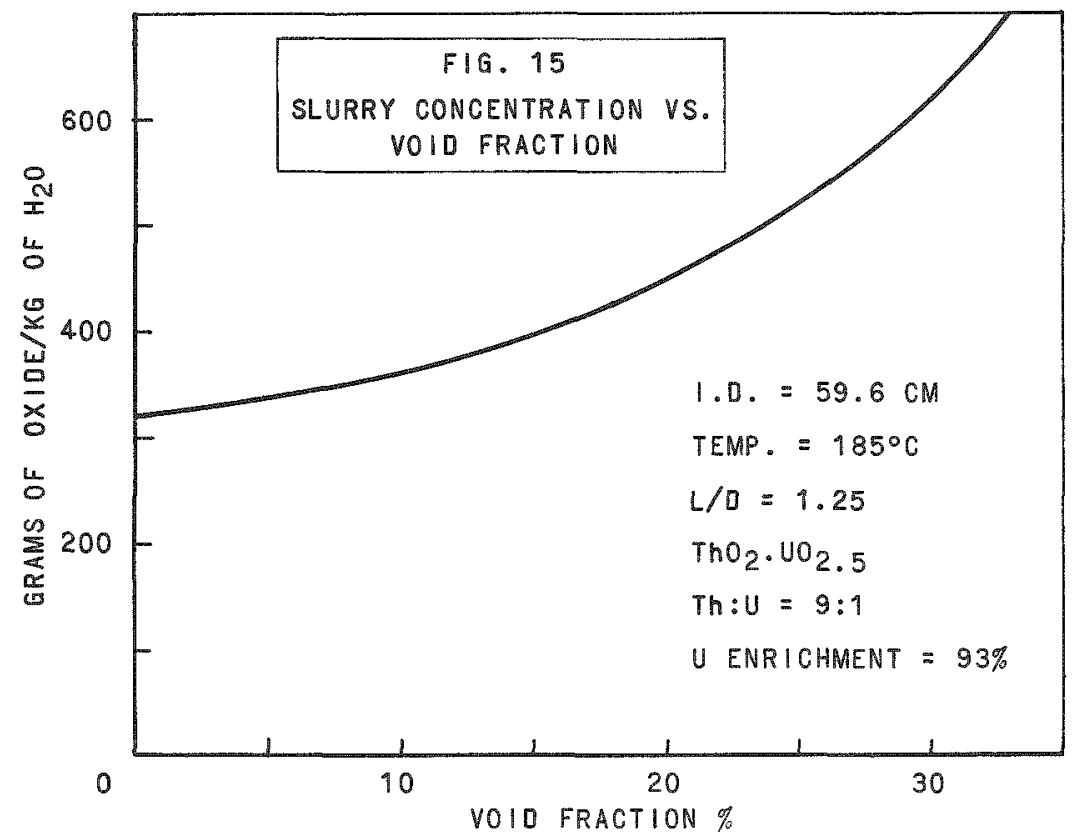


C. Determination of Core Height

The value of the actual core height ( $L^{\prime}$ on Fig. 16 ) was determined so that the total flux (volume weighted) of the SLURREX reactor equalled that of an equivalent cylinder having a value of 1.25 for the ratio of length to diameter. If one assumes that the values of the maximum flux $\left(\phi_{\mathrm{m}}\right)$ in the two reactors are equal and that the equivalent cylinder has a radius and reflector savings equal to $29.8 \mathrm{~cm}$ and $9.0 \mathrm{~cm}$, respectively, then $L^{\prime}$ can be calculated by trial and error. The value of the reflector savings is chosen as the average value for the expected slurry concentrations in the operating reactor.

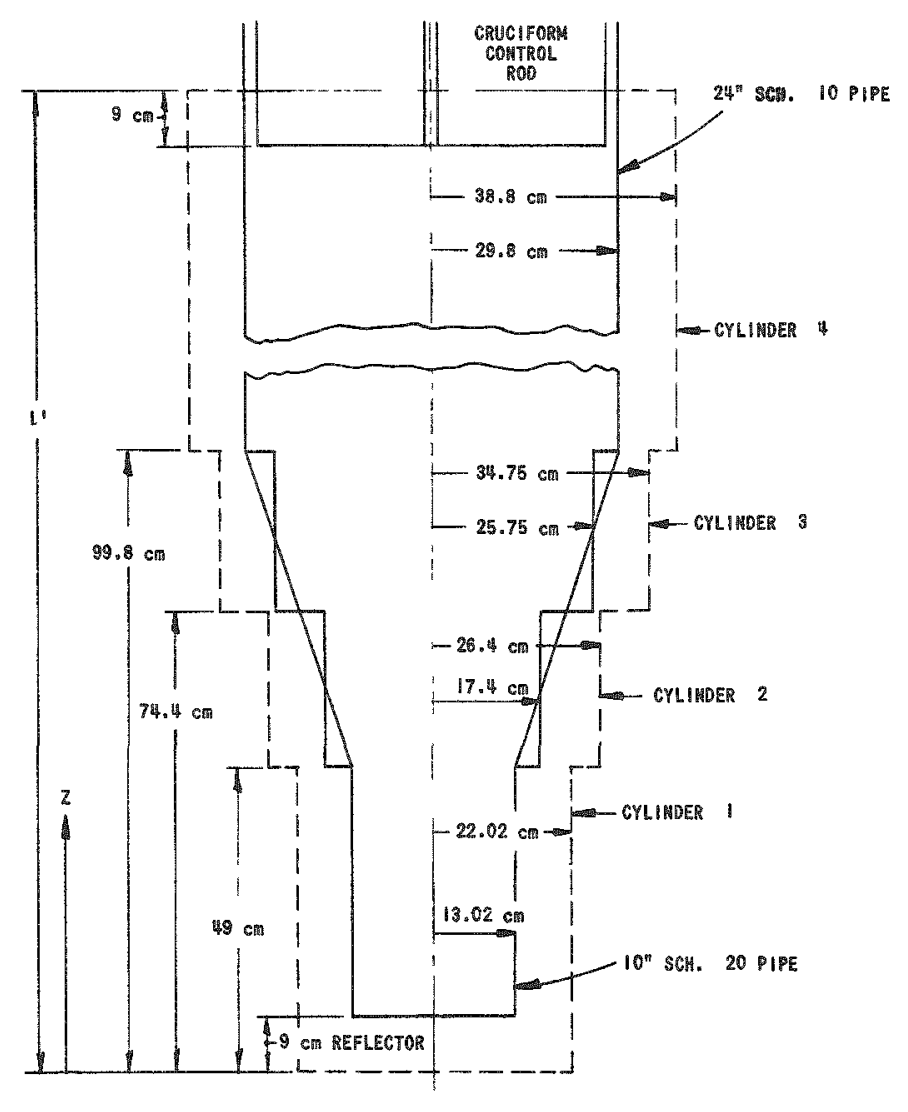

FIG. 16

CORE MODEL FOR CALCULATING AR EQUIVALENT CYLINDRICAL REACTOR

The total flux for the cylinder reactor $\left(\phi_{\mathrm{T}_{\text {cylinder }}}\right)$ is given by

$$
\phi_{T_{\text {cylinder }}}=\int_{9}^{68.6} \int_{0}^{29.8} \phi_{\mathrm{m}^{2}} 2 \pi r J_{0}\left(\frac{2.405 r}{R^{1}}\right) \cos \frac{\pi z}{L^{\prime}} d r d z \text {, }
$$


where

$$
\begin{aligned}
& R^{\prime}=\text { core radius }+ \text { reflector saving }=38.8 \mathrm{~cm} . \\
& L^{\prime}=(2) \text { (core radius) }(1.25)+\text { reflector saving }=83.6 \mathrm{~cm} \text {. }
\end{aligned}
$$

The core is reflected only on the bottom because the integration in the $z$ direction is carried $9 \mathrm{~cm}$ into the control rod to account for the heating which occurs in the riser.

If the SLURREX reactor is composed of four stacked cylinders as shown in Fig. 16, the total flux for the reactor $\phi_{T_{\text {reactor }}}$ can be given approximately by the summation of the fluxes in the four cylinders; this method of analysis leads to discontinuities in the flux pattern at the interfaces between cylinders, both in the $J_{0}$ and cos functions. These discontinuities do not affect greatly the value of $L^{\prime}$ or the heat production in the reactor for two reasons: (1) use of the average cylinder radius $\left(r_{2}\right.$ and $\left.r_{3}\right) *$ produces compensating errors in the flux pattern, and (2) the reflector tends to flatten the flux pattern within the core, thus reducing the error. More accurate results could be achieved by dividing the inlet enlarger section into cylinders having smaller height dimensions; however, approximations concerning the average void fractions are of such a nature that greater accuracy in this calculation is not warranted.

The value of $\left(T_{\text {reactor }}\right)$ is calculated by applying Eq. (8) to the four reflected cylinders which compose the reactor core:

$$
\begin{aligned}
T_{\text {reactor }}= & 2 \pi \phi_{\mathrm{m}}\left[\int_{z_{0}}^{z_{1}} \int_{0}^{r_{1}} r J_{0}\left(\frac{2.405 r}{R_{1}^{1}}\right) \cos \frac{\pi z}{L^{\prime}} d r d z+\int_{z_{1}}^{z_{2}} \int_{0}^{r_{2}} r J_{0}\left(\frac{2.405 r}{R_{2}^{i}}\right) \cos \frac{\pi z}{L^{\prime}} d r d z\right. \\
& +\int_{z_{2}}^{z_{3}} \int_{0}^{r_{3}} r J_{0}\left(\frac{2.405 r}{R_{3}^{\prime}}\right) \cos \frac{\pi z}{L^{\prime}} d r d z+\int_{z_{3}}^{z_{4}} \int_{0}^{r_{4}} r J_{0}\left(\frac{2.405 r}{R_{4}}\right) \cos \frac{\pi z}{L^{\prime}} d r d z
\end{aligned}
$$

where

$$
\begin{array}{ccccccc}
R_{1}^{\prime}=22.02 \mathrm{~cm} & R_{3}^{\prime}=34.75 \mathrm{~cm} & r_{1}=13.02 \mathrm{~cm} & r_{3}=25.75 \mathrm{~cm} & z_{0}=9.0 \mathrm{~cm} & z_{2}=74.4 \mathrm{~cm} \\
R_{2}^{\prime}=20.4 \mathrm{~cm} & R_{4}^{\prime}=38.8 \mathrm{~cm} & r_{2}=17.4 \mathrm{~cm} & r_{4}=29.8 \mathrm{~cm} & z_{1}=49.0 \mathrm{~cm} & z_{3}=99.8 \mathrm{~cm} \\
& z_{4}=L^{\prime} \mathrm{cm}
\end{array}
$$

If $\phi_{\mathrm{T}_{\text {cylinder }}}$ is set equal to $\phi_{\mathrm{T}_{\text {reactor }}}$, then the value of $\mathrm{L}^{\prime}$ can be determined. A value of $L^{\prime}=148.6 \mathrm{~cm}$ obtained for the dimensions listed above.

* The average radius for Cylinders 2 and 3 is determined by equating the volume of the cylinder with that of the truncated cone it replaces. 


\section{CHEMISTRY}

Development work by the ANL Chemical Engineering Division to produce an improved slurry material is being reported separately. (7) This work has resulted in an experimental method for fabricating spherical particles of thoria containing up to $10 \mathrm{wt}-\%$ urania (approximately $\mathrm{UO}_{2.5}$ ). The urania is so uniformly dispersed in this material that it is possible to fire the mixture to $1600^{\circ} \mathrm{C}$, the maximum firing temperature for thoria, without sintering. The resulting particle should be more resistant to abrasion and wear than materials fired at lower temperatures. These encouraging results have led to the selection of thoria-urania as the fuel for SLURREX.

The alternative of using pure urania has limited usefulness in future boiling slurry reactors because of the possibility of valence change of uranium at temperatures exceeding $200^{\circ} \mathrm{C}$. In a boiling system it is not possible to maintain a large excess of hydrogen. One cannot therefore surpress the uranium valence to plus four by this method, as has been proposed by the Dutch for their circulating slurry reactor.(8)

The chemical behavior of the slurry under reactor conditions is an uncertainty which can only be answered by actual experience. As outlined in a later section, some information in this regard will be obtained from SLURREX operation.

A related problem is the selection of structural materials. Eventually it is hoped to use carbon steel in boiling slurry reactors. However, short-term corrosion tests conducted by the Metallurgy Division on mild steel piping material in oxygenated water at $181^{\circ} \mathrm{C}$ produced considerable rust formation. Taking into account the uncertain effect of mild steel rust on the stability of the irradiated slurry and the possibility of continuing steel corrosion due to abrasive action of the slurry, the Metallurgy Division has recommended, on the basis of existing technology, the use of stainless steel for the reactor vessel.(9)

Other problems of a chemical nature, such as water decomposition and recombination and fission gas removal, have been evaluated in conjunction with the design of various SLURREX components. Appropriate supporting evidence is given in Appendices $B$ and $C$. 


\section{HAZARDS AND SITE SELECTION*}

Considerations as to the hazards associated with SLURREX operation have been limited to preliminary calculations to establish that SLURREX can with reasonable safety be built at the proposed site. This site is approximately $1200 \mathrm{~m}$ southeast of EBR-II at the National Reactor Testing Station. The prevailing winds are from the southwest. The site is also $4000 \mathrm{~m}$ north of U.S. Highway 20 and $16,000 \mathrm{~m}$ due west from the station's east boundary.

The site evaluation is predicted upon selection of a maximum credible accident. This accident is based upon the following majox premises:

(1) Because of the lack of experience with boiling slurry reactor operation, because of the broad experimental program planned for SLURREX, and because of only one solid barrier between fission products and the atmosphere, the maximum accident is considered to be a reactor disaster. This means an uncontrolled transient resulting in rupture of the primary system and major release of fission products to the atmosphere.

(2) The maximum energy release of such an uncontrolled transient is difficult to predict accurately. However, in the range of reason (from 100 to $10,000 \mathrm{Mw}-\mathrm{sec}$ ), the fission product release due to such a transient does not add significant dosage compared to that of long-term 5-Mw operation (see Fig. 17).

(3) Ten per cent is considered a reasonable upper limit for fission product release from such an accident because:

(a) Most of the fission products axe adsorbed to the surface of the fuel particles.

(b) The fuel particles are not expected to vaporize.

(c) Only about $35 \%$ of the water in the reactor system flashes when the pressure is completely released

(d) The water in the shielding tank will supply considerable quenching action.

(e) The fuel particles are marginal with regards to buoyancy in air, and for small energy releases should be readily trapped in and around any structure above the reactor tank.

(f) For sizeable energy releases it is possible that the entrapped particles could form a cloud having a height of approximately several hundred feet. Any particles released in such a case may be expected to remain

\footnotetext{
* Supporting calculations, where available, may be found in Appendix $F$.
} 
airborne at an altitude where the per cent fission product release is not important, since there is sufficient distance to an observer at ground level.

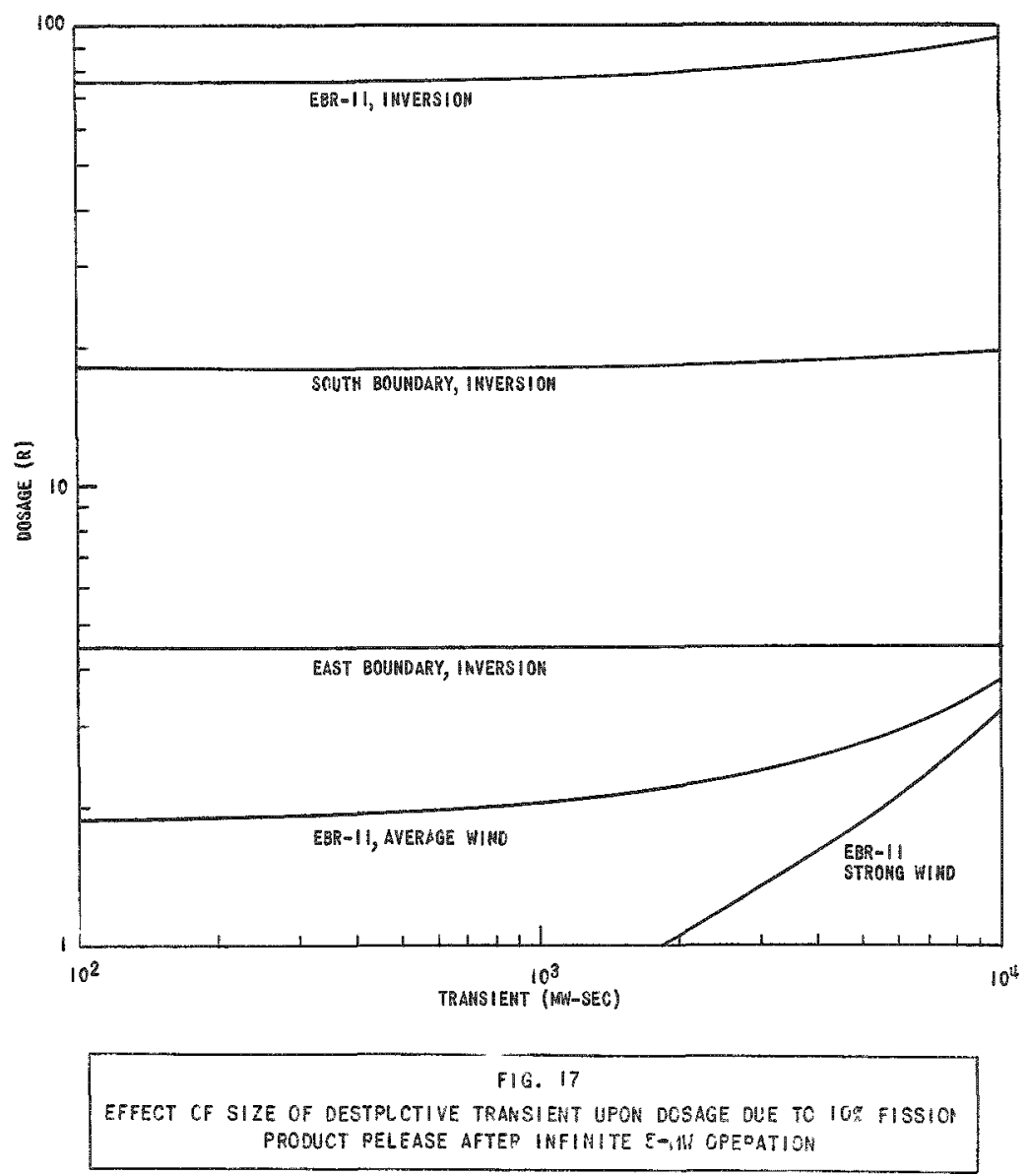

The external gamma dosage to an observer directly in the path of a cloud originating at ground level is plotted in Fig. 18 as a function of various weather conditions. The cloud contains a $10 \%$ fission product release after infinite $5-\mathrm{Mw}$ operation. The dosage is less than $0.3 \mathrm{r}$ at the site boundary under average and strong wind conditions. It exceeds $5 \mathrm{r}$ only under inversion conditions at Highway $20(18 \mathrm{r})$ and at EBR-II (75 r).

The nature of the inversion conditions results in a cloud which is small and travels slowly. Because of the small size of the cloud, an observer $10 \mathrm{~m}$ from the path of the center of the cloud receives only onehalf the dosage shown in Fig. 18. If he is $50 \mathrm{~m}$ away, he receives only one-fifteenth the dosage. The radioactive cloud at ground level takes 20 and $75 \mathrm{~min}$, respectively, to reach EBR-II and the southern site boundary. With proper integration of SLURREX into the NRTS Disaster Plan, this would provide sufficient time for evacuation of nonessential personnel at EBR-II and TREAT, or for clearing traffic on Highway 20. Even if evacuation of all personnel is not possible, significant reduction in dosage 
levels can be expected in many EBR-II operating areas due to the attenuating effect of the building walls and ceilings. If the ground level wind speed is higher than assumed, it is doubtful that the same meteorological constants would prevail. Changes in these constants result in reduced dosages. For example, at the same wind speed the meteorological constants used for average conditions give a dosage ten times less than the constants for inversion conditions.

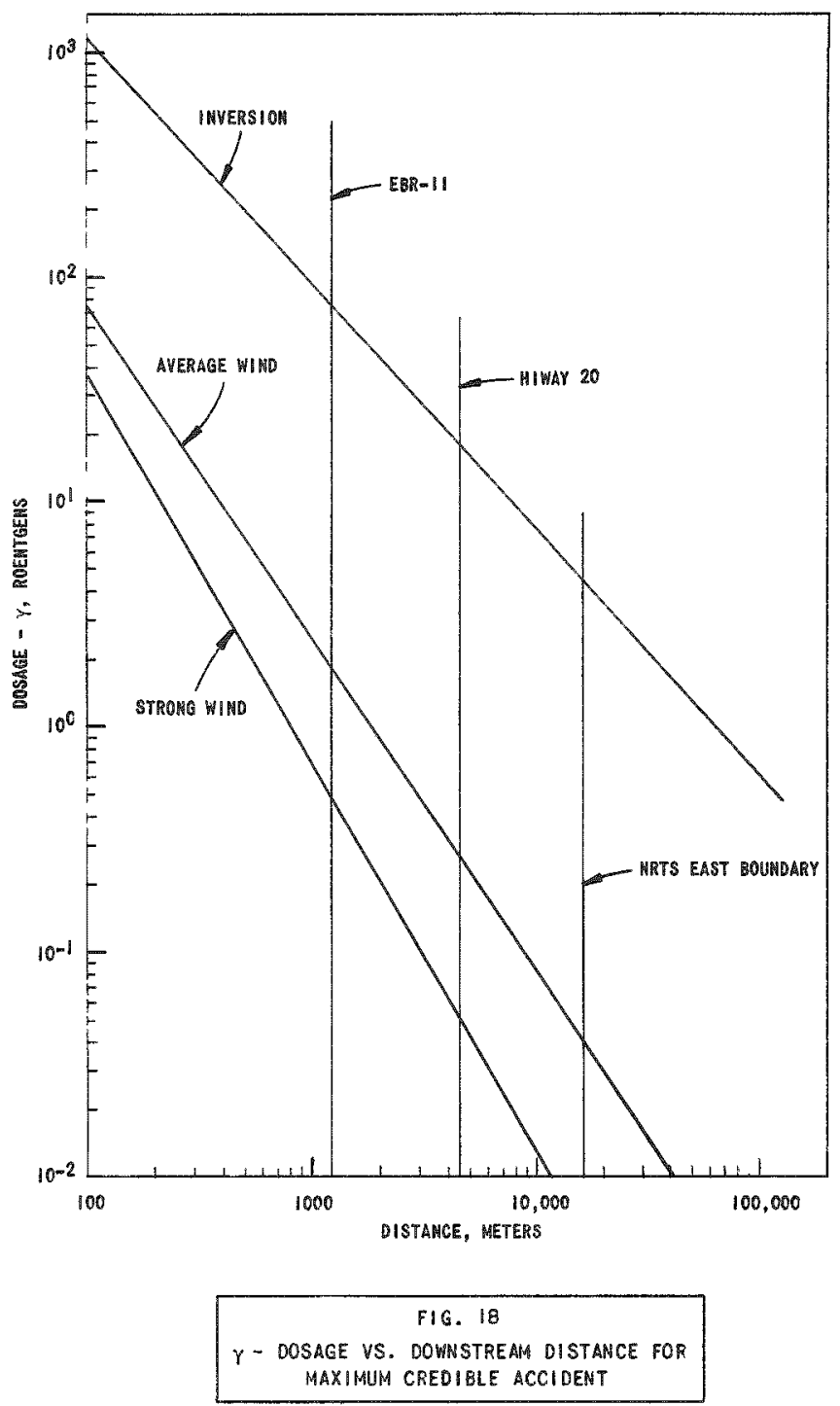

Because of the sensitivity of dosage to distance from the center of the cloud under prevailing inversion conditions, the radioactive cloud produces high dosage readings at the EBR-II area for only a few minutes, and any essential operating functions which are interrupted could be resumed after that time. 
As a result, the hazard to EBR-II operation should be essentially nil. For further protection, the emphasis on careful reactor management and operational control could, if deemed necessary, be augmented by some restrictions imposed by the weather. Specific illustrations of this are the following: One would not restrict steady-state operation at previously attained power levels. One would, however, apply weather restrictions to violent transients designed to test the effectiveness of void formation as a reactor shutdown mechanism. 


\section{PROPOSED SCHEDULE}

It is proposed that SLURREX would be ready for criticality 20 months after approval is given to initiate Title I design. A detailed schedule is given in Table IV.

Table IV

PROPOSED SCHEDUIE FOR SLURREX

\begin{tabular}{|l|l|}
\hline Approval Date & \multicolumn{1}{|c|}{ Start Title I Design } \\
\hline plus 2 months & Complete Title I Design \\
plus 3 months & Complete Preliminary Hazards Report \\
plus $3 \frac{1}{2}$ months & Start Title II Design \\
plus $7 \frac{1}{2}$ months & Complete Title II Design \\
plus 10 months & Start Congtruction \\
plus 15 months & Submit Final Hazards Report \\
plus $16 \frac{1}{2}$ months & Complete Construction \\
plus 18 months & Complete Operating Manual \\
plus 20 months & Critical \\
\hline
\end{tabular}




\section{EXPERIMENTAL PROGRAM}

The primary purpose of SLURREX is the demonstration of stable operation at design power, and justification for the experiment is based on this point. Important design information applicable to a more advanced reactor experiment to a prototype reactor or to large-scale reactor studies can be obtained in at least four other areas: general parameters, physics, hydrodynamics, and control characteristics. If SLURREX results substantiate values predicted during design (or if the variations from prediction are understood), considerable confidence for future design work will have been established.

On five other points of interest (vapor separation, gaseous fission product formation, water decomposition, slurry and structural material behaviors), the information obtained will for several reasons be more limited:

(1) These results will be a function of physical and chemical properties of the fuel slurry, and SLURREX is not meant to be a fuel-test facility.

(2) Some aspects, notably vapor separation and activity deposition, will be an unpredictable function of system geometry, which is not varied.

(3) Consistent with minimum expenditure, SLURREX is not a life test for structural materials and components.

Some limited specific plans for tests to be performed in the various areas are given in subsequent paragraphs. This listing is not complete; and no attempt has been made to evaluate the hazards associated with some of the proposed experiments:

\section{A. Reactor Stability and Safety}

1. Establish that reactor operates stably at design conditions.

2. Look for spurious power changes, as in HRT.

3. Check reactor response (without control rod scram) to rapid reactivity additions and potential accidents such as:
a. Ramp control rod withdrawal.
b. Rapid fuel addition.
c. Loss of condensate feedwater.
d. Loss of gas agitation during startup. 
B. Hydrodynamics

1. Measurement of exit voids and recirculation flow rate as a function of reactor power level.

2. Effect of change in slurry concentration.

This phase of the program would be in the nature of repeating parts of the mockup experimental program to determine if any variations from predicted values occur as a result of the nuclear environment, the increased temperature, and the slight change in geometry.

C. Physics

1. Measurement of rod critical position as a function of fuel concentration and possibly fission product buildup.

2. Determination of temperature and void coefficient.

3. Flux distribution

D. Response and Control Characteristics

1. Response to gradual reactivity changes such as normal rod movement, concentration change, and rate of gas agitation.

2. Measurement of transfer function.

3. Startup and control of reactor without use of control rod.

Response to gradual reactivity changes is closely allied to the basic stability of the reactor. If the system is sufficiently stable to operate at steady power, there are presumably rates of reactivity change which the system can handle satisfactorily. These could conceivably be too slow for a practical power plant. The information obtained on response and on transfer function would be applied to larger systems in an attempt to predict their stability.

E. Vapor Transport and Separation

1. Steam carryunder and liquid and slurry carryover, as a function of power

2. Activity and nature of downstream deposits. 
F. Radioactive Gas Evolution

1. Rate of gas release as a function of operating variables.

2. Nature of activity levels downstream.

It is advantageous to remove fission products from the slurry to improve neutron economy and to lessen the radioactive release due to a subsequent reactor disaster. The continuous release of these gases does increase the contamination of the steam system. Reliable information on fission product gas evolution is needed to determine future development in the area of fission product leaching.

\section{G. Water Decomposition}

1. Rate of water decomposition as a function of operating variables.

2. Feasibility of a full-flow recombiner.

The potential of the boiling slurry reactor concept is not seriously affected by the actual rate of water decomposition or by a failure to get consistent, reproducible results. The chances of getting irreproducible results (since changing slurry properties due to irradiation, corrosion products, etc, undoubtedly have an effect on decomposition rate) are in fact quite strong.

The failure of the full-flow recombiner to operate would reduce somewhat the capability of the system to remove heat, because it will be necessary to take the noncondensibles through the boiler-condenser for venting to atmosphere. This venting will require more stringent meteor ological restrictions on SLURREX operation.

\section{H. Slurry Behavior \\ 1. Tendency to cake. \\ 2. Slury carryover.}

If the slurry behaves satisfactorily under SLURREX operating conditions, one would increase slurry concentration. The concentrating operation would be carried out first by using all available enriched slurry while reducing core volume; then additional pure thoria or depleted uraniathoria from the mockup and precritical tests would be added to the system. This presumes that for larger reactors, slurry concentrations of, say, up to $1000 \mathrm{gm} / \mathrm{l}$ of water may be desirable from the standpoint of breeding. 
If no behavior problems are encountered with increased slurry concentrations, additives could be used to test one or more of the following:

a. fission product leaching;

b. change of rheological properties probably due to change in conductance; and

c. internal catalysis.

The avenue selected would depend upon the state of the art as well as the success of alternative schemes such as full-flow recombiner, and sidestream processing for fission products.

I. Structural Material Behavior

1. Postmortem examination of piping and components. 


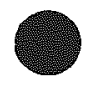


APPENDIX A

HALF-SCALE MOCKUP

\section{A. Introduction}

An analysis of the SLURREX natural circulation system determined the hydraulic equation (Eq. 1). From this equation the circulation velocity can be calculated if the core exit steam roids are known. However, this equation contains a degree of uncertainty since some of the hydraulic losses are guesses.

Generally, the performance of boiling reactors is dependent largely on the hydrodynamic characteristics of the reactor system, i.e., the amount of reactivity tied up in the core steam voids. Therefore, an atmospheric pressure mockup of the reactor vessel has been built to study the hydraulics and verify the derived hydraulic equation. Injected air is used to simulate steam voids. Operation of this mockup with slurry was also expected to aid in developing slurry-handling techniques, and in determining the effectiveness of the steam separator.

The vessels and pipe sizes of the mockup were scaled down to halfdiameter size while maintaining the full riser height. This reduces the slurry and air required to conduct an experimental program by a factor of four compared to a full-scale test program. The SLURREX reactor geometry was maintained in the mockup wherever practical so that similar hydraulic conditions would exist.

At the termination of the SLURREX project, the fabrication and erection of the mockup were essentially complete. The design, construction, and experimental program for the mockup are discussed in this appendix.

An elevation view of the mockup is shown in Fig. 19.

B. Half-scale Slurry Mockup Vessel

The half-scale slurry mockup vessel (Fig. 20) consists of five separately fabricated major subassemblies:

(1) riser:

(2) steam separator;

(3) right downcomer:

(4) left downcomer; and

(5) re-entry section. 


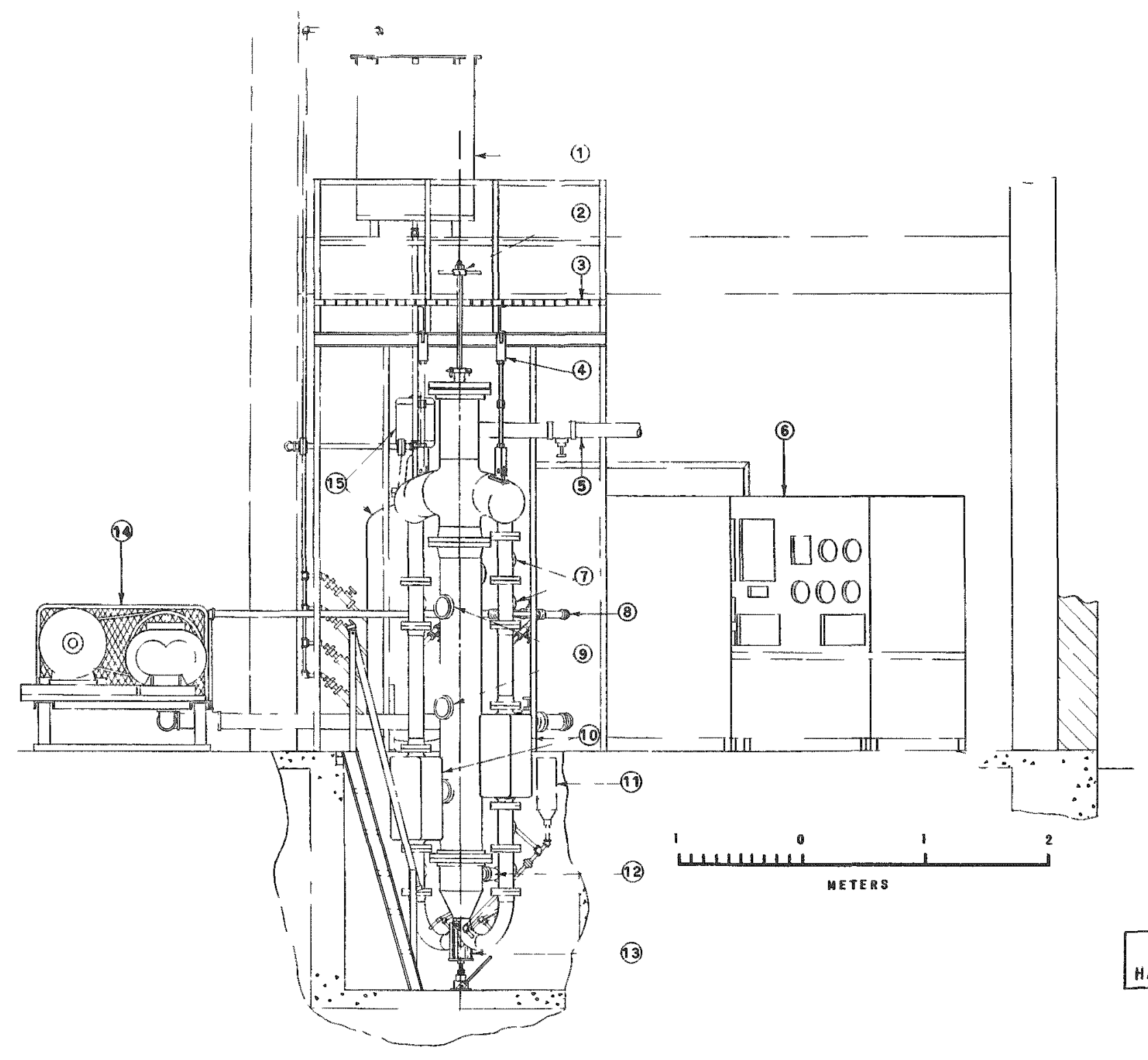

LEGEMD

1. hater storage tame

2. CORTROL ROD

3. MORKING PLATFORM

4. VESSEL SUPPORTS

5. ABR EXIT LINE

6. IISTRUMEMT PAREL

7. CMEMICAL teEs - IHSTRUMEGT POBTS

8. DoHACONER SECTIOHS - alr IMLETS

9. riser section - Instrument parts

10. MAGNETIC FLOW METERS

11. SLURRY COHCERtrator

12. RE-EHTRY SECtion - AIR IHLET

13. auxillakY vessel supports

14. BLOMER

15. Slurgy storage tahK amb mixer

FIG. 19

HALF-SCALE MOCK-UP FACILITY 


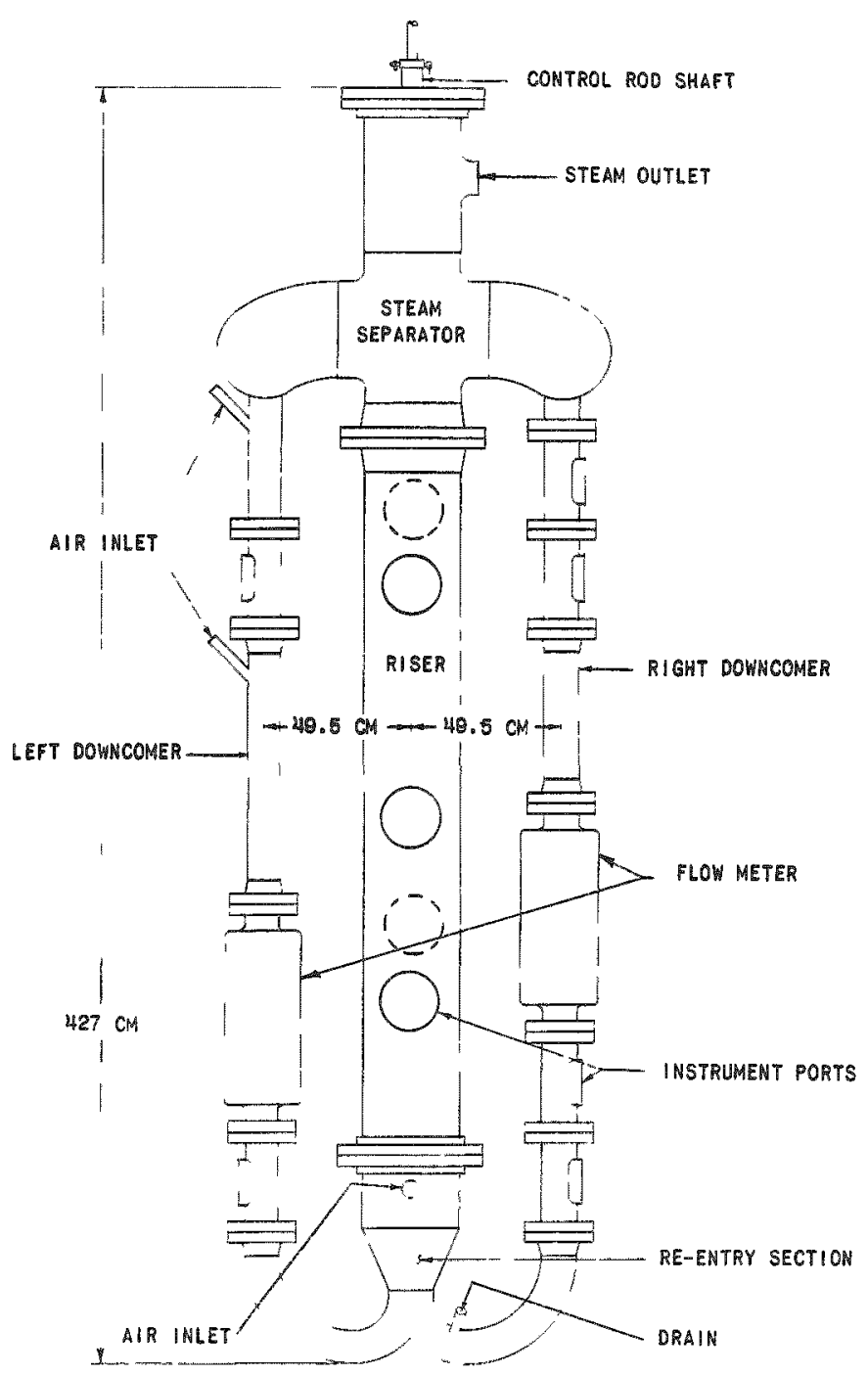

FIG. 20

HALF-SCALE SLURRY MOCK-UP VESSEL
The riser and steam separator sections consist of standard carbon steel, 12-in. Schedule 40 piping and fittings, with the exception of specially spun hemispherical heads at the two ends of the separator. The two downcomers and the re-entry section also consist of standard items in carbon steel, 4-in. and 6-in. Schedule 40 piping and fittings.

All permanent connections between subassembly components were made by means of heliarc consumable weld rings. In order to facilitate this type of weldment and to insure seal weld integrity, all fittings were end machined. This procedure reduced the possibility of setting up small flow restrictions and slurry collection pockets in the ressel. Instrumentation fittings were equipped with matching flanges to fit the shop-fabricated subassemblies. Each subassembly had 150-1b slip-on or weldneck flanges as required.

\section{Riser}

The riser (Fig. 2l) was made in two sections because of the weldment of simulated poison plates and control rod guides on the inner wall of the riser section. Weldment on the full length of these components would have required special jigging at considerable expense.

The upper section, approximately $122 \mathrm{~cm}$ in length, contains four $0.63-\mathrm{cm}$ thick, simulated poison plates, spaced at 90-degree interials, and welded perpendicularly to the pipe wall. Each plate is $92.7 \mathrm{~cm}$ long and $12.4 \mathrm{~cm}$ wide. 

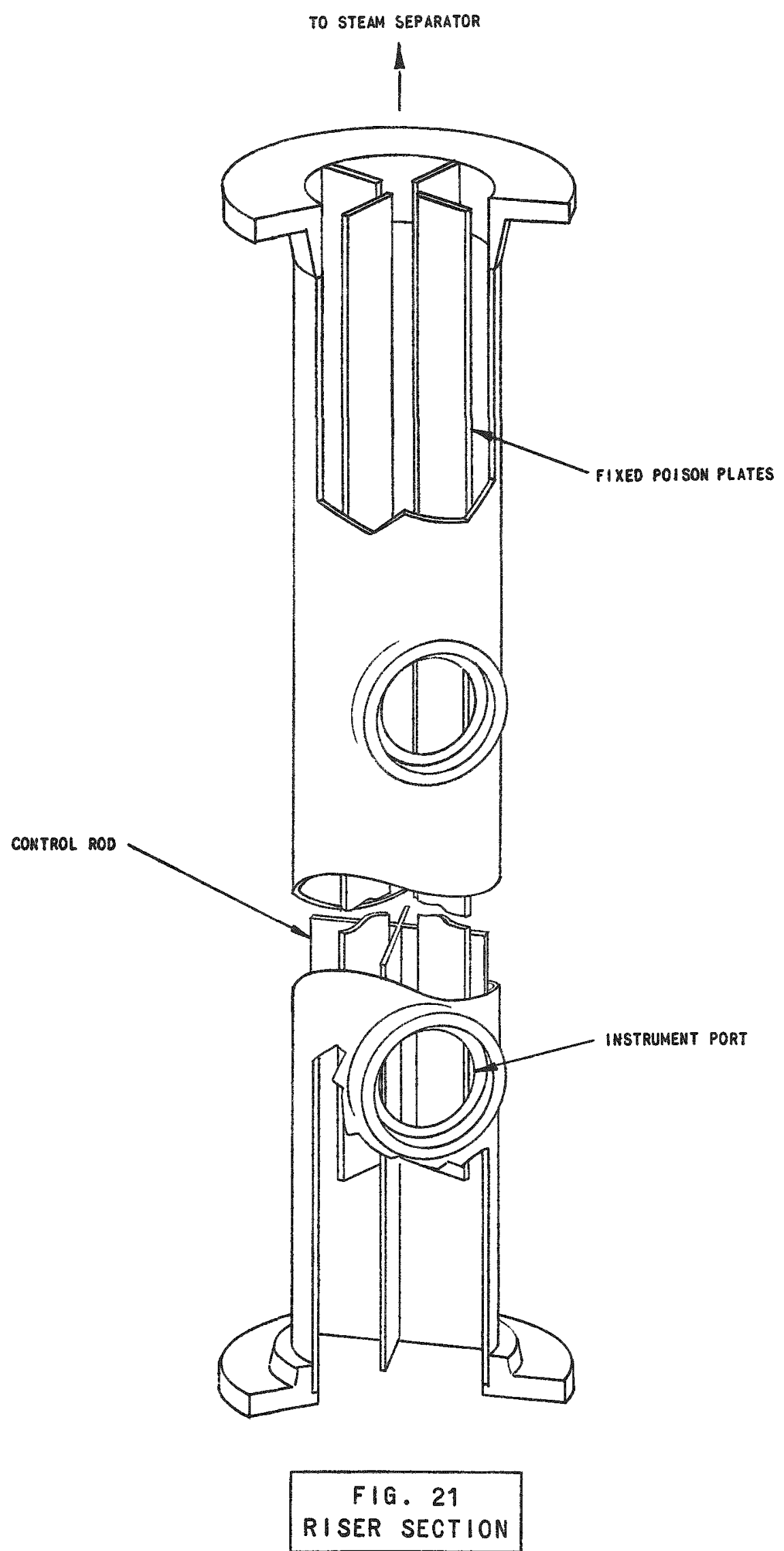
The lower subassembly, approximately $147 \mathrm{~cm}$ in length, also contains extensions of the four equally spaced simulated poison plates. Each extension is $110.2 \mathrm{~cm}$ long. The lower subassembly also contains four control rod channel guides welded perpendicular to the pipe wall and equidistant between poison plates. The guides are $71.1 \mathrm{~cm}$ in length and are intended to reduce lateral rod motion.

The upper and lower subassemblies were welded together, with poison plates in-line, to form the riser section. Five instrument openings for bolting diaphragm-type differential pressure cells are prorided in the riser section.

\section{Steam Separator}

The steam-separator subassembly (Fig. 22) consists of a riser flange connection welded to a cross with identical combinations of a shortradius ell and hemispherical head welded to each side of the cross. The end of the cross in line with the connector flange is welded to a reducing tee containing an outlet nozzle. All of the above are $12-\mathrm{in}$. Schedule 40 pipe and fittings and are assembled into a unit utilizing the consumable weld-ring technique. The hemispherical heads were bored out to take flanged sections of 4 -in. Schedule 40 pipe as a means of joining to the downcomers.

Each fitting in the separator contains four vertical simulated poison plates on about 5-cm centers. Assembly was accomplished by fabricating individual cartridges of poison plates contoured to fit the inside pipe periphery and then tack welding them to the individual fitting. Each cartridge was end machined to match the adjoining fitting and cartridge before weldment into a unit. Wherever possible throughout fabrication, weld beads between the poison plate cartridges and the pipe wall were kept to a minimum. All inside surfaces at the junctions were ground smooth in order to minimize places for slurry to settle.

The poison plate cartridge on the center of the cross can be removed to permit the removal of the control rod from the riser. This cartridge is designed with four supporting brackets which rest on and are bolted to four support pads welded to the inside of the flange connector of the cross. The poison plate cartridge within the cross includes a contoured plate to act as a steam deflector.

\section{Right Downcomer}

The right-hand downcomer (Fig. 20) consists of six components. Four of these are chemical tees for differential pressure instrumentation. One component is the magnetic flowmeter. The remaining fitting was 
fabricated after all other subassemblies were fitted in order to insure accuracy in alignment. A short section of one-inch line was included in this fitting to provide for air injection.

\section{Left Downcomer}

The left-hand downcomer (Fig. 20) consists of four components. Two of these are chemical tees, one is the magnetic flowmeter, and the remaining fitting again was used as a final assembly fitting.

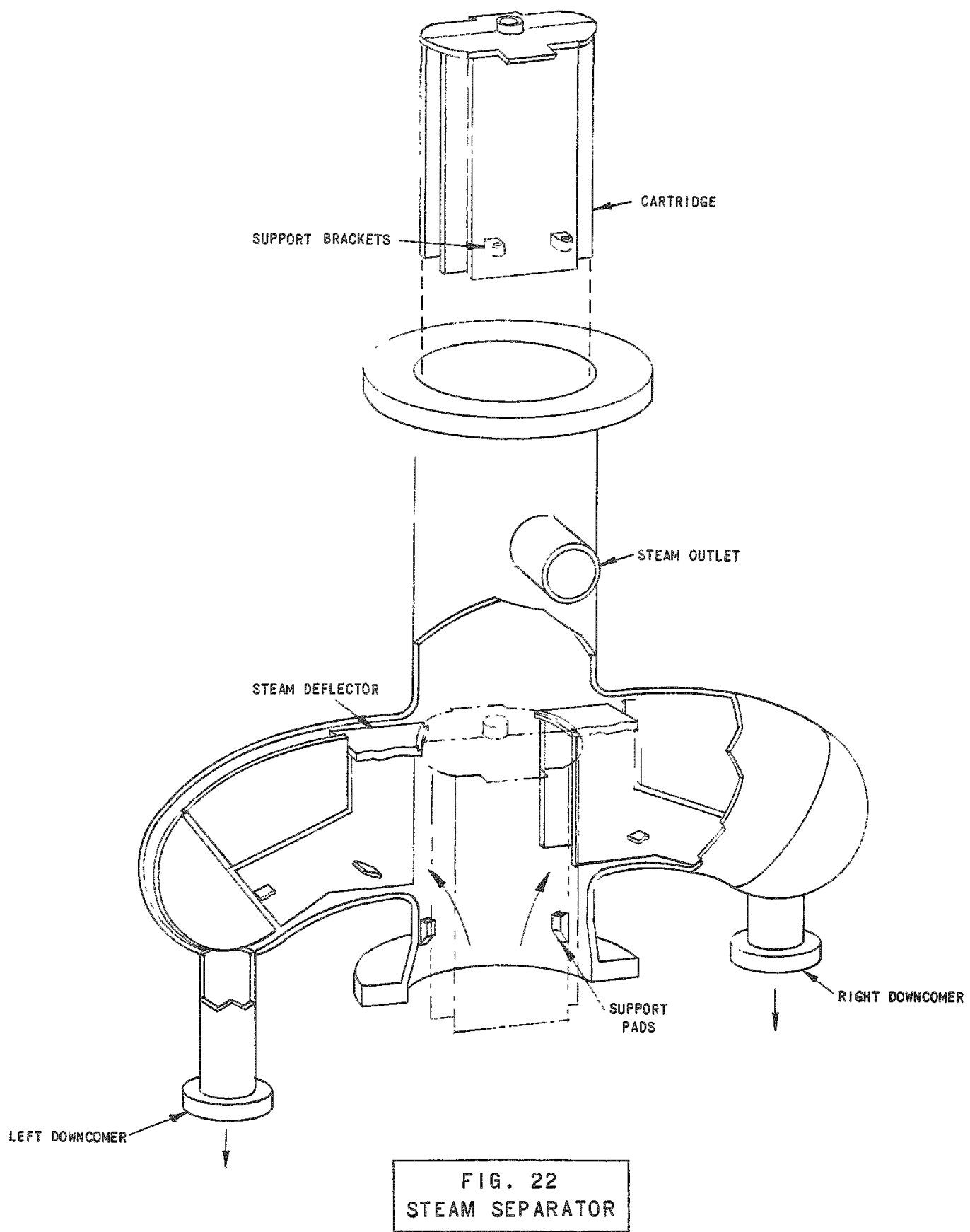




\section{Re-entry Section}

The central components of the re-entry section (Fig. 23) are a part of 5 to $4-i n$. Schedule 40 , long-radius ells, machined at matching ends, and welded together to form a Y-section. Two 4-in., Schedule 40, longradius ells were welded to the arms of the $Y$-section, and a $12-i n$. by $5-i n$. expander section was welded to the trunk of the $\mathrm{Y}$-section. The other end of these three fittings was flanged to provide for attachment to the riser and downcomers.

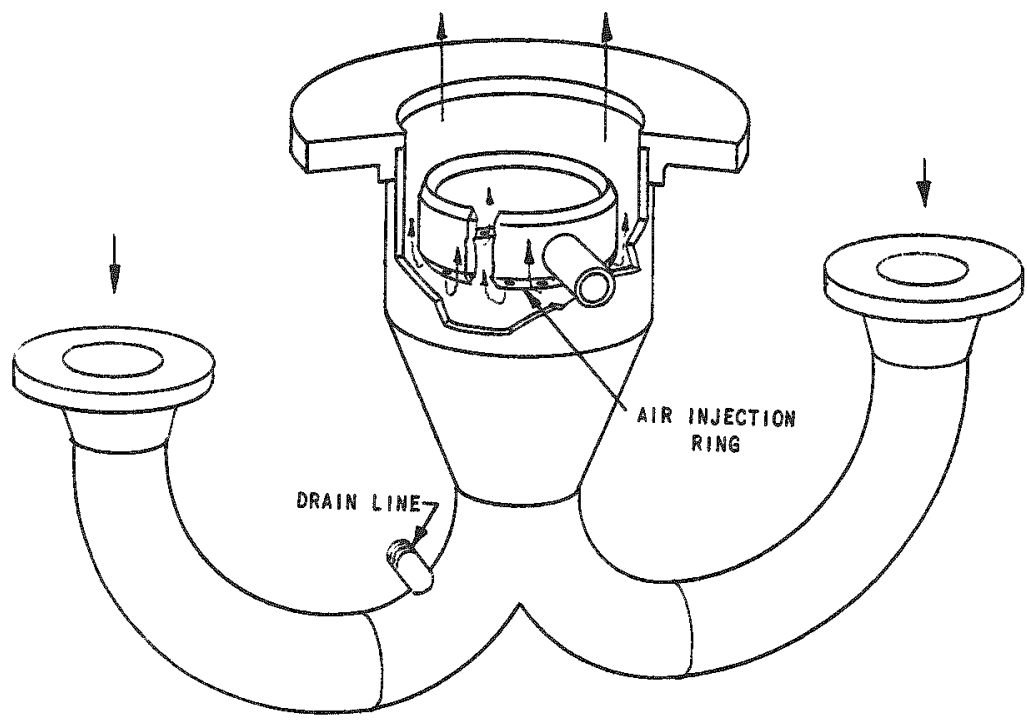

FIG. 23

RE-ENTRY SECTION

C. Air-injection System

A hollow air injection ring was welded to the inner wall of the 12 -in. pipe (see Fig. 23). The ring contains thirty-six equally spaced, drilled holes of $0.64-\mathrm{cm}$ diameter. A 2 -in. pipe outlet, seal welded to the pipe wall, was connected to an air-supply system, which also supplied the 2-in. diameter air-injection lines in the downcomers. The air is supplied by a Roots-Connersville blower with a capacity of $11,300 ?$ (STP)/min, discharging at 1.67 atm. Flow is measured by orifice sections in parallel $1 \frac{1}{2}-i n$. and 4 -in. pipes. The system contains the necessary valving to permit control of air flow to any or all of the air inlets.

D. Vessel Support Structure

The reactor vessel and support structure (see Fig. 19) is an assembly of floor-anchored, unistrut stanchion members, approximately $2.5 \mathrm{~m}$ square by $3.4 \mathrm{~m}$ high. This structure is built directly over a $1.8-\mathrm{m}$ by $1.8-\mathrm{m}$ concrete pit. This places about the lower two-fifths of the mockup vessel 
in the pit. Floor level installation was not possible because of headroom restrictions imposed by an overhead traveling crane. Angle-iron cross members bolted to the vertical supports supply additional strength and restrict overall structural twist.

A vertical unistrut superstructure to which two 6-in. channel iron members have been bolted will provide the main support for the slurry mockup vessel. The top of the structure supports a working platform consisting of portable sections of safety tread grating. The platform is provided with railing of unistrut construction to insure personnel safety. Permanent ladders allow easy access to the upper platform and the pit.

\section{E. Auxiliary Equipment}

\section{Control Rod}

The control rod is a cruciform, 28- cm by $28-\mathrm{cm}$ blade. Four sections of $032-\mathrm{cm}$ thick, $122-\mathrm{cm}$ long, mild steel sheets were bent to form right-angled sections and spot welded together to form the cross. An extension shaft threaded through a fitting in the center of the cross extends through the steam separator section. A blind flange at the top of the vessel has an alignment hole and collar through which the shaft protrudes. A series of holes (for a cotter pin) through the upper portion of the shaft permits manual rod withdrawal by one-inch increments.

\section{Bolt-removal Tool}

The bolt-removal tool is designed to fit down into the steam separator section to connect or disconnect the attachment bolts for the cross poison plate cartridge.

\section{Auxiliary Vessel Support Equipment}

It is planned to run a series of experiments which will require the removal of selected sections of the riser and downcomers. In order to facilitate dismantling of these sections, an auxiliary vessel support and lift has been designed to attach to supports welded to both sides of the reentry section (see Fig. 19). This consists of a small, heavy-duty "U" stand supported by a hydraulic jack.

When a change of vessel geometry is contemplated, slight jack pressure upward removes the load from all flanged connections. Loosening and subsequent removal of the flange bolts can be accomplished easily. 


\section{Portable Lifting Jig}

In order to raise or lower the heavy riser and re-entry sections, a portable lifting jig was designed to fit under the flanges. A yoke with two chains is lowered by using the traveling crane. The chains, provided with hooks, are linked with a pair of eyebolts in the portable lifting jig.

F. Slurry Equipment

\section{Slurry Storage Tank and Mixer}

The slurry storage tank is to be fabricated from 30-in. carbon steel Schedule 10 pipe, $138 \mathrm{~cm}$ in length with dished head ends, for an overall length of $182 \mathrm{~cm}$. The top of the tank is equipped with an 8-in., 150-1b raised face slip-on flange machined and ground to fit at the top of the dished head. The mixer is bolted to this flange (see Fig. 19). The two other ports are for viewing and lighting. These ports are Lenape-type saddles machined and ground to the contour of the dished heads. Four heavy angle-iron legs welded to the tank wall provide off-the-floor support.

The tank contains four full-length, vertical baffle plates tack welded to the inner tank wall studs. Clearances between the baffle plate and the tank wall permit full peripheral flow during mixing. An instrument port, also fabricated from a Lenape saddle, is welded to the tank near the bottom. A 1 -in. Schedule 40 withdrawal pipe, extending through the top of the dished head to the bottom of the tank, is welded to supporting brackets inside the tank. The lower end of this pipe section is contoured to fit the dished head. The tank is designed but has not been fabricated.

The mixer is a Chemineer Model VMA-20, equipped with twin 7-in diameter, three-blade, marine-type propellers. All contact parts are Type 304 stainless steel. The purpose of the mixer is to lift the thorium oxide solid particles from the bottom of the tank and maintain them in a suspended state to form a uniform slurry. It can be operated even during filling and emptying of the tank.

\section{Slurry Concentrator}

The slurry concentrator (see Fig. 19) is a clear plastic cylinder, coned at one end, provided with necessary fittings to permit installation into the system. The slurry concentrator is used to study visually the rate at which clear water can be produced via slurry settling in a still arm. The concentrator is approximately $61 \mathrm{~cm}$ in length and $15.2 \mathrm{~cm}$ in diameter. 


\section{G. Instrumentation}

A three-section instrument panel is located near the mockup facility (see Fig. 19). This panel contains essentially all the recording, controlling, and indicating equipment required for test operation. The major trans mitters supplying these instruments are the following:

\section{Item 1 - Taylor Transaire Differential Transmitter} Model No. 206TN195

This diaphragm-type instrument has an operating range from 0 to $100 \mathrm{in}$. of water and is equipped with flanges for flush mounting into chemical tees or Lenape saddles. Two such transmitters, each consisting of two diaphragms, are mounted in tandem in the right downcomer. Starting from the top, the first and third and the second and fourth chemical tees provide a $203-\mathrm{cm}$ center-to-center distance for measuring slurry density from which oxide concentration can be calculated. Calibration of these cells is performed during the water tests. Another pair of diaphragms, also on $203-\mathrm{cm}$ centers, is mounted in the left downcomer (see Fig. 19).

The riser has five Lenape saddles to accommodate a pair of trans mitters for measuring riser density (which permits calculation of riser voids) over a $182-\mathrm{cm}$ length. Three other transmitters were purchased for installation in the slurry storage tank to check for uniformity of oxide distribution.

Item 2 - Taylor Transaire Differential Pressure Transmitter Model No, XSPDP2

This NaK-filled unit with $0-50$ in. operating range is designed to be used in a radiation field. Another port is provided in the riser to accommodate the $76-\mathrm{cm}$ measuring length of this possible SLURREX prototype instrument.

\section{Item 3 - Two Fischer and Porter 10D1416A Magnetic Flowmeters}

These are 4-in., Teflon-lined, and equipped with standard 150-1b flanges. The tube is Type 316 stainless steel. Variable range settings are from $0-3$ fps to $0-30 \mathrm{fps}$ and flow ranges from $0-150$ to $0-1200 \mathrm{gpm}$. These flowmeters measure the circulation velocity in the downcomers.

Item 4-Gamma-ray Attenuation Instrument

This is an Argonne-designed instrument used for measuring voids in the riser section. 


\section{Item 5 - Orifice Assembly}

This assembly consists of orifices with flanges, etc., for the $1 \frac{1}{2}$ - in. and 4 -in. lines, and is used to measure flow rate $(\mathrm{cm})$ in the air injection system.

H. Hydraulic Experimental Program

The hydraulic experimental program is broken down into six subprograms and is presented in Table $V$. The check marks in the first and second horizontal groups of the table specify what fluid and what riser section are used for each subprogram. The third, fourth, fifth, and sixth horizontal groups give the function of each subprogram, and the seventh group shows how the void fraction is measured.

Table V

PROPOSED HYDRAULIC EXPERIMENTAL PROGRAM

\begin{tabular}{|c|c|c|c|c|c|c|c|}
\hline \multicolumn{2}{|c|}{ Subprogram } & 1 & 2 & 3 & 4 & 5 & 6 \\
\hline \multirow{2}{*}{ Fluid } & Water & & & & & & \\
\hline & Slurry & & & & & & \\
\hline \multirow{2}{*}{ Riser } & $\begin{array}{l}\text { Four fixed } \\
\text { poison plates } \\
\text { and control rod }\end{array}$ & & & & & & \\
\hline & $\begin{array}{l}\text { Plain 12-in. } \\
\text { pipe }\end{array}$ & & & & & & \\
\hline \multicolumn{2}{|c|}{$\begin{array}{l}\text { Determine hydraulic loss } \\
\text { coefficients } A \text { and } B\end{array}$} & & & & & & \\
\hline \multicolumn{2}{|c|}{$\begin{array}{l}\text { Additional flow resistance } \\
\text { by adding orifice plates in } \\
\text { the downcomer }\end{array}$} & & & & & & \\
\hline \multicolumn{2}{|c|}{ Variation of void height } & & & & & & \\
\hline \multicolumn{2}{|c|}{$\begin{array}{l}\text { Air injection into the } \\
\text { downcomers }\end{array}$} & & & & & & \\
\hline \multirow{2}{*}{$\begin{array}{l}\text { Void } \\
\text { deter - } \\
\text { mination }\end{array}$} & $\begin{array}{l}\text { Differential } \\
\text { pressure cells }\end{array}$ & & & & & & \\
\hline & $\begin{array}{l}\text { Gamma-ray } \\
\text { attenuation }\end{array}$ & & & & & & \\
\hline
\end{tabular}


form

The hydraulic equation as developed in Appendix E has the general

$$
\frac{H \alpha(1-\alpha)^{2}}{A(1-\alpha)^{2}+B-\alpha^{2}}=\frac{v_{0}^{2}}{2 g_{C}}
$$

For the mockup, the effective hydrostatic height $\mathrm{H}$ is $272 \mathrm{~cm}$; the hydraulic loss coefficients, $A$ and $B$, are 56.7 and 1.67 , respectively. Subprogram No. 1 will verify the values of $A$ and $B$, while subprograms Nos. 2 and 3 will demonstrate how $A$ and $B$ vary when flow resistance is added or removed. The effect of riser length will be determined in subprogram No. 4 . The effect of air injection in the downcomer will be studied in subprogram No. 5. Since sufficient SLURREX fuel has not been prepared, subprogram No. 6 may be run with a cheaper, substitute material. 


\section{APPENDIX B}

\section{PRELIMINARY CONSIDERATIONS IN THE DESIGN}

OF A CATALYTIC RECOMBINER

\section{A. Introduction}

In the SLURREX reactor, the water which serves as moderator and fuel particle carrier is subject to decomposition because of fission fragment and recoil particle collisions with the water molecules, and from radiation action on the water molecules. Since the fuel particles are very small (of the order of 10 microns in diameter), essentially all the fission fragments escape from the particle into the water. Thus, the rate of production of hydrogen for SLURREX will be much greater in magnitude than that for an heterogeneous type of reactor. This production rate is usually expressed by a $G$ value, given in molecules of hydrogen produced per 100 ev of absorbed energy.

The $G$ values have been calculated $(10)$ for various slurry particle diameters where $G$ is defined as the number of molecules of $\mathrm{H}_{2}$ produced per $100 \mathrm{er}$ of original fission fragment energy. The calculations were made as a function of: (1) the diameter of spherical slurry particles; (2) the fraction of fission fragments escaping from the particles; (3) the average value of the fraction of initial kinetic energy retained by the fission fragments after escape; (4) the number that strike a second slurry particle after escaping from the first; and (5) the amount of radiolytic gas that is produced by fission fragments. These calculated values, plotted in Fig. 24, represent the maximum $G$ values, since credit is not taken for any possible internal recombination.

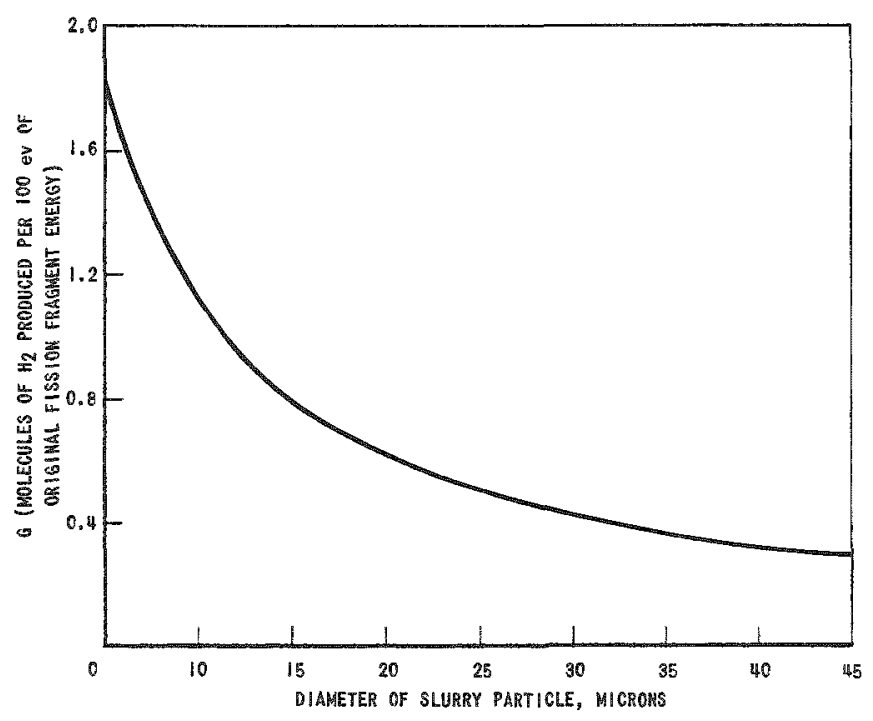

FIG. 24 HYDROCEN PROOUCTION VS. DIAMETER OF SLURRY PARTICLE 
Values of $\mathrm{G}\left(\mathrm{H}_{2}\right)$ have been experimentally determined at Oak Ridge National Laboratory in in-pile tests. $(11,12,13)$ These tests were carried out in light water with autoclaves sealed in air at 200 to $300^{\circ} \mathrm{C}$ and with $650^{\circ} \mathrm{C}$-fired thorium oxide at concentrations of 285 to $850 \mathrm{gm} \mathrm{ThO} / \mathrm{kgH}_{2} \mathrm{O}$ (245 to $700 \mathrm{ThO}_{2} / l$ of slurry at $10.2 \mathrm{~atm}$, saturation). The $\mathrm{G}$ value for hydrogen produced was about 0.8 . The experiments were conducted in the ORNL Graphite Reactor at a flux of $4.2 \times 10^{11} \mathrm{n} /\left(\mathrm{cm}^{2}\right)(\mathrm{sec})$ with the light water slurry of $\mathrm{ThO}_{2}$ containing about $2.4 \%$ uranium oxide, $93 \%$ enriched in $\mathrm{U}^{235}$. The mixed oxides were prepared by coprecipitation of the thorium and uranium oxalates at $10^{\circ} \mathrm{C}$, followed by calcination at $650^{\circ} \mathrm{C}$. The experiments were conducted in small, dash-pot-stirred stainless steel autoclaves. Slurries of $900^{\circ} \mathrm{C}$-fired oxide in light water gave the same experimental results. $(14,15)$

The particle size was in the range from 1 to 4 microns. Based on total energy absorbed, the theoretical $G$ value is about 1.5 as compared to the experimentally determined $G$ value of 0.8 . The difference between the theoretical and experimentally determined values is probably due to internal recombination caused by (1) mixed radiations, (2) slurry particles acting as catalyst, and ( 3 ) the container possibly acting as a catalyst.

\section{B. Hydrogen and Oxygen Production Rates in SLURREX}

The $G$ value for SLURREX is estimated by dividing the reactor sys tem into three regions and then adding the contribution from each region.

\section{Region of Subcooled Heating}

Based on operating conditions of 10.2 -atm saturation and $109^{\circ} \mathrm{C}$ feedwater, $13 \%$ of the total power is generated in this region. The average slurry particle size is 10 to 15 microns in diameter, which corresponds to a theoretical $G$ value of 0.95 as based on total energy absorbed. The net recombination value $-\mathrm{G}\left(\mathrm{H}_{2}\right)$ is about 2.3 molecules of hydrogen re combined per $100 \mathrm{ev}$ mixed radiations energy absorbed. The decomposition value is 0.4 and the recombination value is $2.7 .(16)$ The mixed radiation energy contribution to the total power is about $7 \%$. Thus, the recombination $G$ value in this region is about 0.16 as based on the total energy absorbed. The catalytic activity of the slurry particles under the proposed SLURREX operating conditions is considered negligible, based on an extrapolation of the experimental data by ORNL. (17)

The $G$ value contribution for Region I is $13 \%$ of 0.79 , or 0.10 .

\section{Boiling Region}

It has been shown in the operation of BORAX III that there is less internal recombination due to mixed radiations in a boiling reactor.(18) The hydrogen and oxygen gases are stripped from the aqueous phase into 
the steam bubbles before radiation-induced recombination of the free radicals can occur. The hydrogen and oxygen gases in the steam bubbles are also separated from the very small catalytic activity of the slurry particles. This stripping effect tends to reduce internal recombination. Thus, the assumption is made that radiation and particle catalytic recombination are negligible in the boiling region. The $G$ values are, therefore the theoretical value of 0.95 for fission fragment energy and 0.4 for mixed radiation. The $G$ value contribution for Region II is $81 \%$ of 0.95 plus $6 \%$ of 0.4 , which equals 0.80 .

\section{Riser and Downcomers}

The energy contribution to the total power in this region is from delayed neutrons and físsion product decay. The maximum possible contribution to the $G$ value for this section is only 0.01 . This is based on the as sumption that $\frac{1}{2} \%$ of the total power is absorbed in this region and that the radiation net recombination occurs at the maximum of 2.3 . Thus, it is as sumed that the $G$ value contribution from Region III is negligible.

The sum of the three regions gives a $G$ value of 0.9 molecule of hydrogen produced per 100 ev of total energy absorbed. This represents the best estimate of a hydrogen production $G$ value for SLURREX.

In order to be conservative in the system design, the $G$ value selected for SLURREX reference design is 1.3 molecules of hydrogen produced per $100 \mathrm{ev}$ of total energy absorbed. This is based on (1) no credit for internal recombination of any type, and (2) an allowance for particle size degradation to a range of $5-7$ microns.

The rate of production of radiolytic hydrogen and oxygen in stoichiometric amounts is given by

$$
W=\beta E G
$$

where

$$
\begin{aligned}
& W=\text { Gas production rate, } \mathrm{kg} / \mathrm{hr} \\
& E=\text { Rate of energy absorption } \\
& G=\text { Molecules of hydrogen produced per } 100 \text { ev of total } \\
& \quad \text { absorbed energy } \\
& \beta=\text { Conversion factor. }
\end{aligned}
$$

For a reactor operating at $\mathrm{P} \mathrm{Mw}$,

$$
E=\left(2.247 \times 10^{22}\right)\left(\mathrm{P} \times 10^{6}\right)=2.247 \times 10^{28} \mathrm{P} \mathrm{ev} / \mathrm{hr}
$$


The conversion factors $($,$) ) are$

$$
\dot{p}_{\mathrm{H}_{2}}=\frac{2.016}{\left(6.023 \times 10^{23}\right) 1000}=3.347 \times 10^{-27} \frac{\mathrm{kg} \text { hydrogen }}{\text { molecule hydrogen }}
$$

and

$$
\beta_{\mathrm{O}_{2}}=\frac{16.000}{\left(6.023 \times 10^{23}\right) 1000}=26.56 \times 10^{-27} \frac{\mathrm{kg} \text { oxygen }}{\text { molecule hydrogen }} .
$$

Thus,

$$
W(\text { hydrogen })=0.752 \mathrm{PG}\left(\mathrm{kg} \mathrm{H} \mathrm{H}_{2} \text { per hour }\right)
$$

and

$$
W \text { (oxygen) }=5.97 \mathrm{PG}(\mathrm{kg} \mathrm{O} \text { per hour })
$$

C. First Sizing of the Catalytic Recombiner

The operating conditions of the full-flow recombiner are shown in the cycle heat balance (Fig. 6). A first approximation of the recombiner size is based on the data trends indicated in Figs. 25 and 26 . These data were taken from preliminary runs of a pilot plant recombiner(19) and should be verified.

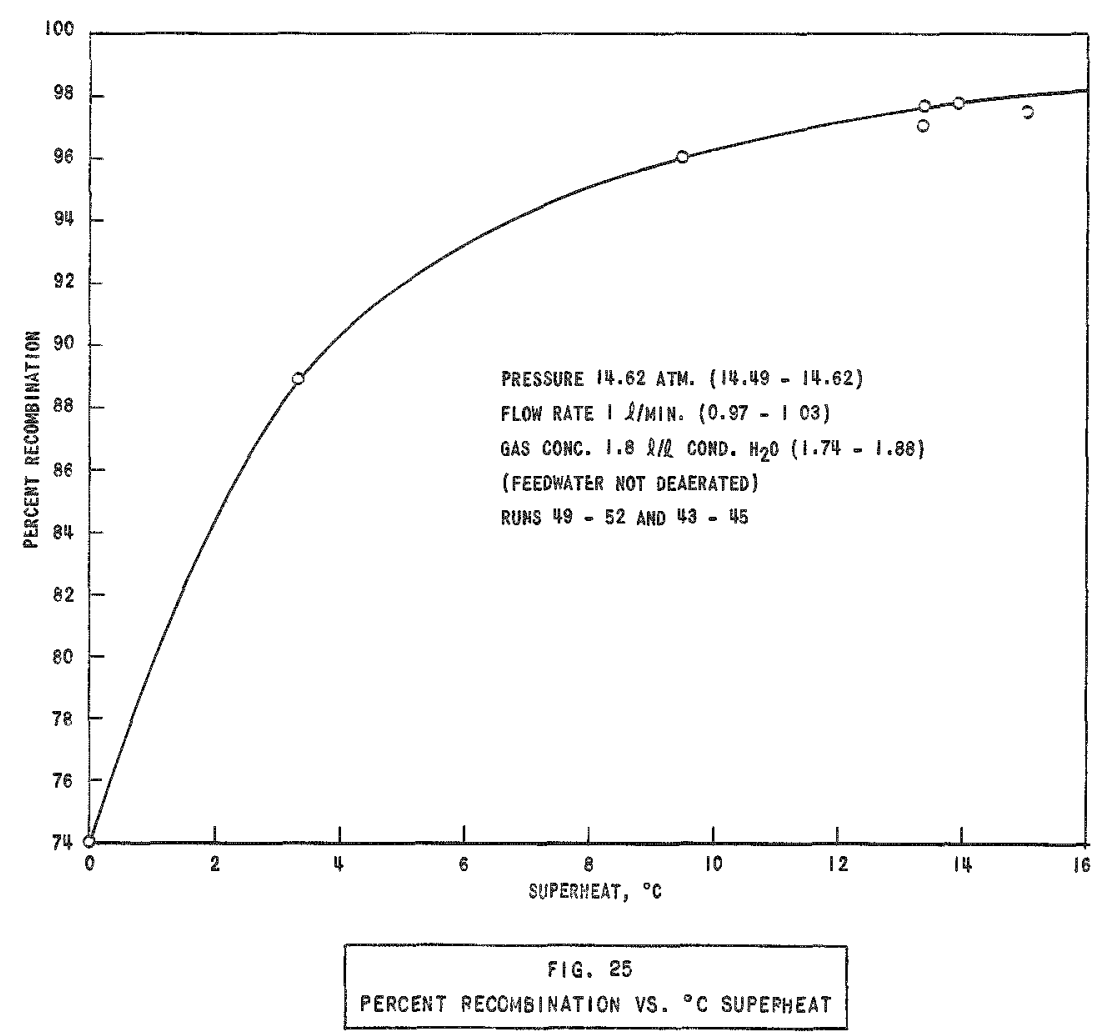




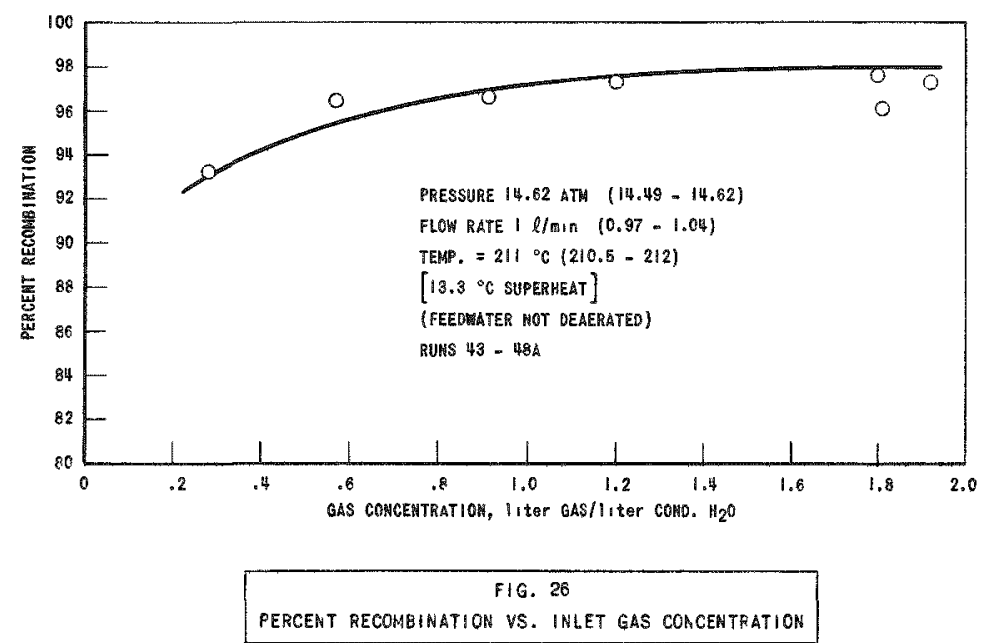

The primary factors determining the extent of recombination are the gas concentration in $l / l$ of condensed water (at recombiner conditions) and the degree of superheat. The gas-to-condensate ratio in SLURREX is $2.6 \mathrm{l} / \mathrm{l}$ of condensate. From Fig. 25 , at $5.5^{\circ} \mathrm{C}$ superheat and a gas-tocondensate ratio of 1.8 , a $92.5 \%$ recombination efficiency can be expected. From Fig. 26, one would expect some increase in efficiency with increas ing gas-to-condensate ratio. The higher ratio in SLURREX plus a safety factor (to be applied later) on effective bed volume should make it possible to attain the desired $98 \%$ recombination efficiency.

It then becomes a case of appropriately scaling up the pilot recombiner, which consists of a platinum-coated wire mesh ( $93.8 \%$ voids) enclosed in a cylinder of $81-\mathrm{cm}^{2}$ cross-sectional area and $9.5-\mathrm{cm}$ length. If one maintains the same mass velocity $\left[10.6 \mathrm{gm} /(\mathrm{min})\left(\mathrm{cm}^{2}\right)\right]$, the resulting SLURREX recombiner diameter is $124 \mathrm{~cm}$. If one also holds the space velocity* the same (1.3 $\mathrm{min}^{-1}$ based on the volume of condensate), the recombiner length will be the same as that of the pilot unit resulting in an unsatisfactory geometry. One then compromises by reducing the diameter to $61 \mathrm{~cm}$ and overly compensating in length by an increase to $122 \mathrm{~cm}$ to obtain a lower space velocity. These dimensions yield a bed volume of $356 \ell$ (with a safety factor of 3.3 ) and a space velocity of $0.4 \mathrm{~min}^{-1}$.

D. Recombiner Exit Temperature as a Means of Determining Hydrogen Production Rate

The heat reaction in the recombiner per gram mole of water formed can be calculated by the conventional procedures of physical chemistry. This calculation is based on $98 \%$ recombiner efficiency,i.e., a slight excess of reactants are carried along, and on the reaction taking place at

* Space velocity is defined as the volumetric flow rate of reactants divided by the volume of recombiner, i.e., the reciprocal of contact time. 
recombiner inlet conditions to yield products at outlet conditions. The mode of calculation is graphically illustrated below:

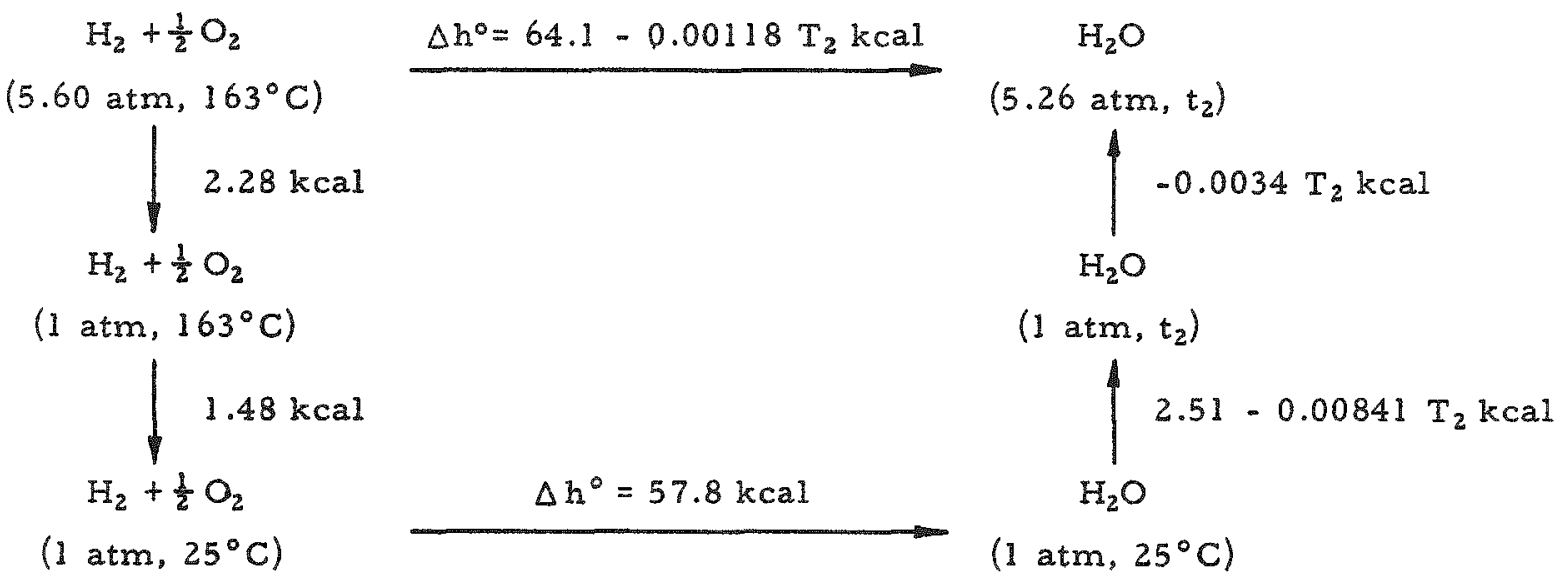

The values for standard heat of reaction and specific heat are taken from Ref. (20).

If $h_{1}$ is the inlet steam enthalpy, $h_{2}$ the exit steam enthalpy, and $x$ the weight of steam $/ g$-mole of water formed, an enthalpy balance across the recombiner yields:

$$
\mathrm{xh}_{1}=\mathrm{xh} \mathrm{h}_{\mathrm{2}}+\Delta \mathrm{h},
$$

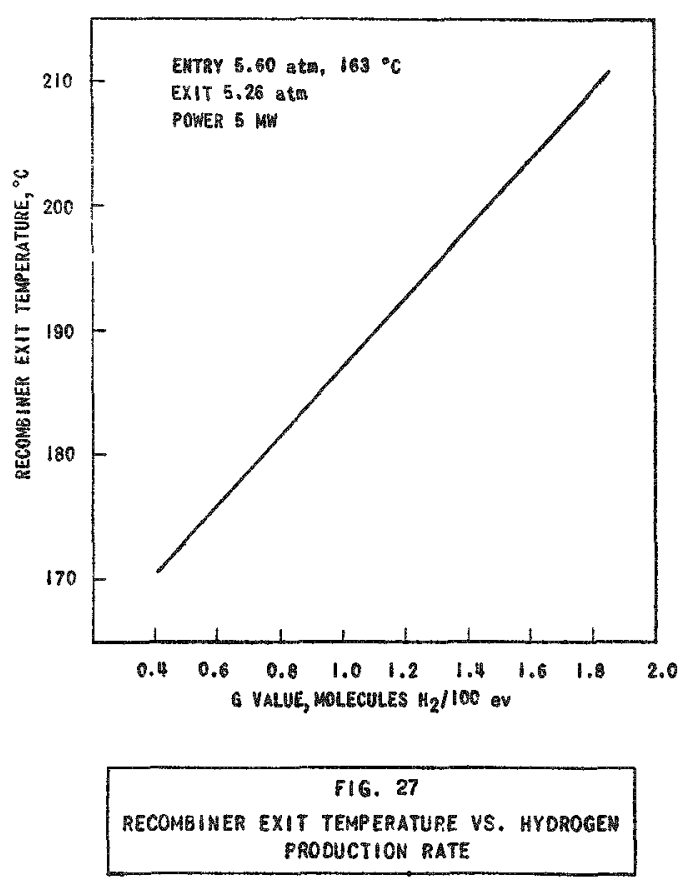

where $\mathrm{x}$ is inversely proportional to hydrogen production rate, which has been shown to be a function of $G$ value (see Eq. 11). Combination of the various equations yields the following expression for outlet enthalpy:

$h_{2}-1190.1=G\left(26.8-0.00288 t_{2}\right)$

where $t_{2}$ is in ${ }^{\circ} \mathrm{F}$ and $\mathrm{h}_{2}$ is in $\mathrm{Btu} / \mathrm{lb}$ to allow use of the steam tables. The value of $P_{2}$ is 77.3 psia. Figure 27 is a plot of recombiner outlet temperature in ${ }^{\circ} \mathrm{C}$ for a range of $G$ values from 0.5 to 2.0 . Except for minor changes due to slight var iation in inlet conditions (see Fig. 6), these results are independent of reactor power level. 


\section{APPENDIX C}

\section{SYSTEMS FOR REMOVING XENON AND KRYPTON}

A. Introduction

If the production rate of xenon and krypton equals $0.387(21)$ and $0.013(22)$ atoms/fission, respectively, then for a $5000 \mathrm{Mw}-\mathrm{hr}$ design life of SLURREX, the production of xenon and krypton is $48.3 \mathrm{gm}$ and $1.02 \mathrm{gm}$, respectively. At STP the respective volumes are $8010 \mathrm{cc}$ and $269 \mathrm{cc}$. Preliminary designs have been prepared for alternate schemes of gas absorption in a solvent bed or a charcoal bed.

\section{B. Solvent Column Design}

Steinberg and Manowitz(23) reported the results of an investigation concerning the solubility of xenon and krypton in various solvents. The results of this laboratory work have produced two desirable solvents:

Amsco 123-15 (American Mineral Spirits Solvent No, 140) and Ultrasene (Atlantic Refining Co. solvent), both kerosene-base organics. These solvents reportedly have: (1) the highest measured affinity for xenon; (2) good selectivity for xenon over other gases such as helium; (3) a high boiling range, 185 to $255^{\circ} \mathrm{C} ;$ (4) low vapor pressure at ordinary temperature, of the order of $1 \mathrm{~mm}$ or less: (5) high flash point, 60 to $80^{\circ} \mathrm{C}$ : (6) low cost, of the order of $\$ 0.25$ to $\$ 0.40 / \mathrm{gal}$; and (7) stability to radiation as shown by experience in irradiated fuel-processing plant solvent extraction operations. (24)

Solubility data and mass transfer coefficients obtained by these authors have been used in conjunction with standard equations to design a packed column. Such a column, $150 \mathrm{~cm}$ high by $2.5 \mathrm{~cm}$ diameter, packed with $\frac{1}{4}$-in. Raschig rings, removes $100 \%$ of the xenon and about $99.8 \%$ of the krypton. The column has negligible pressure drop and is not subject to flooding. About 25002 of solvent is required during the life of the plant.

The advantages of the solvent column are that the operational characteristics can be predicted with greater accuracy than those for a charcoal bed and the possibility of an explosive or uncontrollable chemical reaction is reduced greatly.

The two disadvantages of the solvent column are the disposal of the used solvent and the possibility of solvent carryover into the reactor vessel, resulting in the formation of foam. Preliminary calculations indicate that for an otherwise acceptable solvent the end-of-life concentration of organic in the reactor could reach $1000 \mathrm{ppm}$ if all the solvent made its way into the reactor. 
The complexity of operation and the disadvantages of the solvent column lead to the conclusion that a charcoal bed is the preferred method of fission product disposal.

C. Charcoal Bed Design

Investigations $(25,26,27)$ have shown the gas-adsorbing capacity of charcoa1, V, is related to the partial pressure $\mathrm{p}$ (of xenon or krypton) by the equation

$$
V=K p^{-n}(\text { at constant temperature) }
$$

Thus it is seen that the bed size will be small if the partial pressure of adsorbed gas is high. It is desired in this design, however, to adsorb all of these gases. To do this effectively, a carrier gas must be used such that the fraction of xenon and krypton is very small. It has been deter mined $(28,29)$ that helium is the best carrier gas available, since it is only very slightly adsorbed by the charcoal. Oak Ridge reports $(30)$ that Columbia $G$ brand charcoal has the highest capacity factor (cc gas adsorbed) gm charcoal) of those tested.

Two equations (31) relate the decay heat of fission gas to time after fission.

$$
q=5 \times 10^{4} t^{-1.25} \text { for } 0.5<t<20 \mathrm{hr}
$$

and

$$
q=7.7 \times 10^{4} t^{-1.4} \text { for } 20<t<1000 \mathrm{hr}
$$

If the gases are passed, after one-half hour, to the charcoal bed, the average heat generation rate over the reactor lifetime may be computed:

$$
q_{a v}=\int q d t / \int d t
$$

Thus, for $833 \mathrm{hr}$ at $6 \mathrm{Mw}$,

$$
q_{a v}=\frac{5 \times 10^{4} \int_{0.5}^{20} t^{-1.25} d t+7.7 \times 10^{4} \int_{20}^{833} t^{-1.4} d t}{833}=620 \mathrm{Btu} /(\mathrm{hr})(\mathrm{gm})
$$

or

$$
\mathrm{qav}_{\mathrm{v}}=182 \mathrm{watts} / \mathrm{gm} \text { of fission gas. }
$$


For a system pressure of 2 atm, a flow rate for xenon, $F_{X e}$, of $0.161 \mathrm{cc} / \mathrm{min}$ (at $6-\mathrm{Mw}$ reactor power), and a bed wall temperature of $30^{\circ} \mathrm{C}$, the amount of charcoal and hence the bed volume can be calculated as a function of maximum temperature of the bed ( $I_{\max }$ ) and the helium flow rate $\left(F_{H e}\right)$. As a specific example, $T_{\max }=140^{\circ} \mathrm{C}$ and $F_{H e}=10 \mathrm{cc} / \mathrm{min}$ are used. Thus,

$$
\bar{p}_{X e}=2 \operatorname{atm} \times 760 \mathrm{~mm} \mathrm{Hg} \times \frac{F_{X e}}{F_{X e}+F_{K r}+F_{H e}}=24.6 \mathrm{~mm} \mathrm{Hg*}
$$

For the conditions stated, the average bed temperature $\left(T_{a v}\right)$ is $85^{\circ} \mathrm{C}$. Then, $\mathrm{n}=0.99$ and $\mathrm{K}=0.18,(26)$ and, from Eq. (14),

$$
\mathrm{V}=0.18(24.6)^{0.99}=4.28 \mathrm{cc} / \mathrm{gm}
$$

To adsorb $8010 \mathrm{cc}$ of xenon, there will be required $8010 / 4.28=1870 \mathrm{gm}$ of charcoal. If the bed density is $0.48 \mathrm{gm} / \mathrm{cc},(26)$ the theoretical required bed volume is $3880 \mathrm{cc}$.

The theoretical bed volume as a function of maximum bed temperature and carrier flow rate is plotted in Fig. 28.

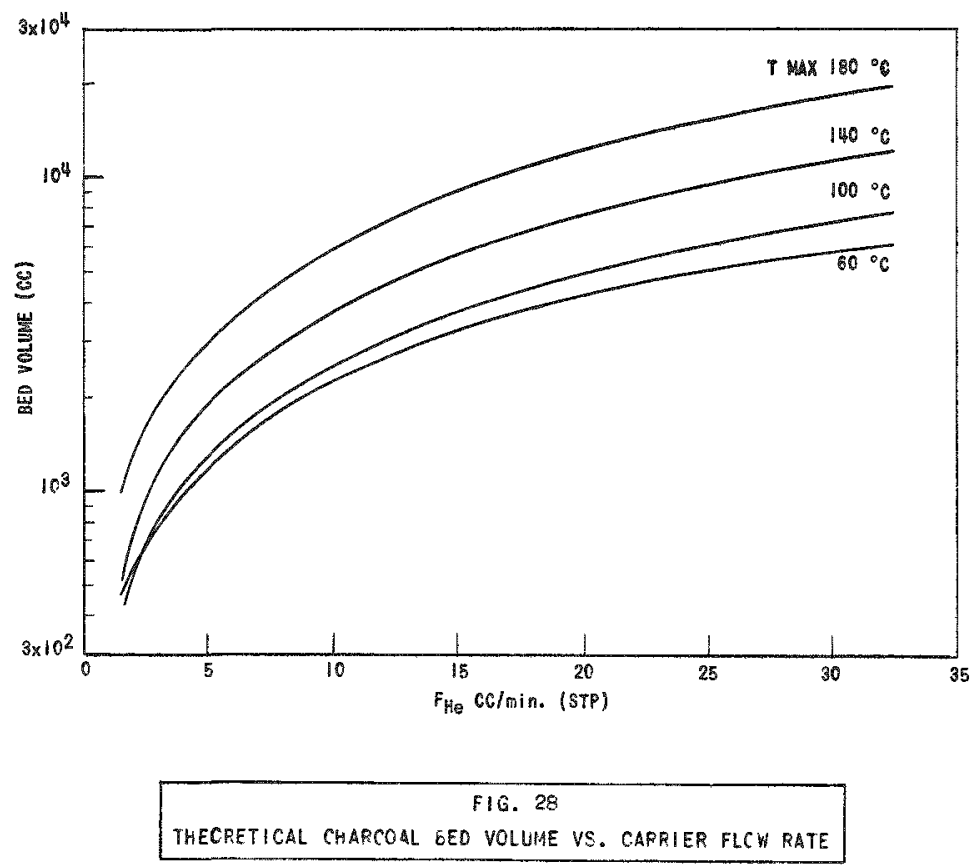

For preliminary sizing one arbitrarily introduces a safety factor of 10 to account for krypton adsorption, helium adsorption, $\mathrm{H}_{2} \mathrm{O}$ adsorption,

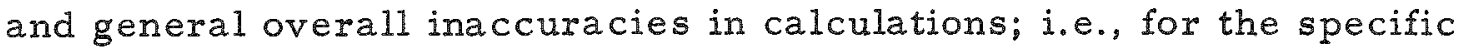
example, the bed volume (B.V.) is $38,800 \mathrm{cc}$.

${ }^{*} \mathrm{~F}_{\mathrm{H}_{2} \mathrm{O}}$ is neglected, assuming a low inlet temperature. 
The mass of the charcoal is given by

$$
M=\left(B \cdot V_{0}\right)(\rho) \quad \text {, }
$$

where $\rho$ is the density of the charcoal. If $\rho=0.48 \mathrm{gm} / \mathrm{cc}$, then $\mathrm{M}=18,700 \mathrm{gm}$.

The volumetric rate of heat production is given by

$$
q_{v}=\frac{182 \text { watt }}{g m} \times \frac{48.3 \mathrm{gm}}{38.800 \mathrm{cc}}=0.227 \mathrm{watt} / \mathrm{cc}
$$

This rate of heat production is based on uniform adsorption throughout the bed. The optimism of this assumption is counteracted by the high contunu. ous power $(6 \mathrm{Mw}$ ) assumed for the life of the core.

Fox heat production in a cylindracal tube, it can be shown that

$$
T_{\max }-T_{0}=q_{v} R^{2} / 4 k
$$

whene $T_{0}$ is the wall temperature and $k$ the thermal conductivity. This equation can be solved for $R$. Vielding

$$
R=\sqrt{4 k\left(T_{\max }-T_{0}\right) / q_{v}}
$$

For $\mathrm{k}=1.38 \times 10^{-3} \mathrm{watt} /(\mathrm{cm})\left({ }^{\mathrm{C}} \mathrm{C}\right)$

$$
R=\sqrt{\frac{(4)\left(1.38 \times 10^{-3}\right)(140-30)}{0.227}}=1.63 \mathrm{~cm}
$$

The tube radius $R$ is plotted as a function of maximum bed temperature and carrier flow xate in Fig. 29 with and without a safety factor for bed volume.

Once the bed volume and tube radius are known the number $\mathrm{N}$ of tubes and linear velocity $v$ through the tubes may be computed for a given *ube length. For 30 i-cm long tubes.

$$
N=38800 /(\pi)(1.63)^{2}(305)=15.2(15 \text { tubes })
$$

and

$$
\checkmark=(10.2)(305) / 38800=0.08 \mathrm{cc} / \mathrm{min}
$$

At these low velocities the pressure drop through the tube bundle is negli gible ( $<$ I psi). 


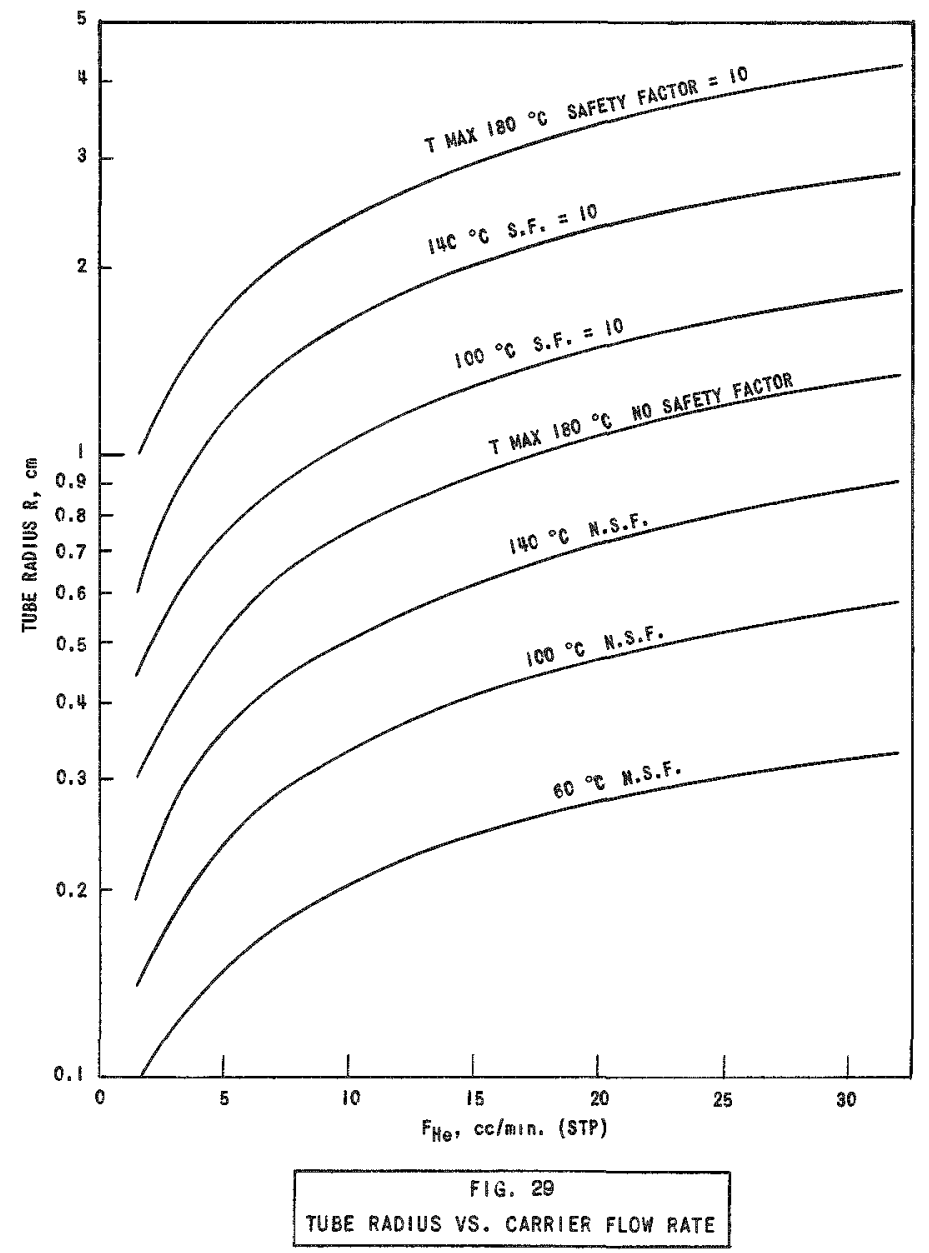

The flow rate of krypton is $0.005 \mathrm{cc} / \mathrm{min}$ (at $6-\mathrm{Mw}$ power) and $\bar{p}=1520 \times \frac{0.005}{10.2}=0.76 \mathrm{~mm} \mathrm{Hg}$

At $85^{\circ} \mathrm{C},(26)$

$$
K=0.035
$$

and

$$
\mathrm{n}=1
$$

Ther efore

$$
V_{K r}=(0.035)(0.76)^{1}=00296 \mathrm{cc} / \mathrm{gm}
$$

requiring, for $269 \mathrm{cc}$ of $\mathrm{Kr}$,

$$
269 / 0.0269=10,000 \mathrm{gm} \text { charcoal }
$$


It was previously calculated that there would be $18,700 \mathrm{gm}$ of charcoal, thus representing a bed size $46 \%$ in excess of that theoretically required (based on krypton).

The bed design must be checked for occurrence of breakthrough. An adsorber will remove essentially all xenon and krypton present in the gas stream until breakthrough loading is reached. At breakthrough, the exit gas concentration will rise, approaching the inlet concentration as a limit.

An equation for breakthrough time $t_{b}$ is $(32,33)$

$$
t_{b}=0.33 \frac{(V)(M)}{F},
$$

where the ratio of breakthrough time $t_{b}$ to time of maximum effluent concentration $t_{\max }$ is taken as 0.33 .

For the illustrative case, the breakthrough time for xenon is $2760 \mathrm{hr}$, and for krypton $560 \mathrm{hr}$. The bed will retain all the xenon, but not all the kxypton for an 833-hour life. This is also time for the five other representative charcoal bed designs shown in Table VI. To retain all the krypton, a larger safety factor is required.

Table VI

PARAMETERS OF REPRESENTA TIVE CHARCOAL BED DESIGNS

\begin{tabular}{|c|c|c|c|c|c|c|c|c|c|}
\hline & $\begin{array}{c}T_{\max } \\
\left({ }^{\circ} \mathrm{C}\right)\end{array}$ & $\begin{array}{c}F_{\text {He }} \\
(\mathrm{cc} / \mathrm{min})\end{array}$ & $\begin{array}{c}\left(\mathrm{B.V} \times \mathrm{x}^{-3}\right) \\
(\mathrm{cc})\end{array}$ & $\begin{array}{c}\mathrm{R} \\
(\mathrm{cm})\end{array}$ & $\mathrm{N}$ & $\begin{array}{c}\mathrm{V} \\
(\mathrm{cm} / \mathrm{min})\end{array}$ & $\begin{array}{c}\text { \% Excess } \\
(\text { ba sed on Kr })\end{array}$ & \multicolumn{2}{|c|}{$\mathrm{t}_{\mathrm{b}}(\mathrm{hr})$} \\
\hline 1 & 180 & 30 & 182.0 & 4.2 & 11 & 0.05 & 30 & 487 & 2810 \\
2 & 180 & 5 & 31.2 & 1.7 & 11 & 0.051 & 39 & 497 & 5010 \\
3 & 60 & 30 & 56.5 & 1.04 & 52 & 0.163 & 37 & 565 & 2730 \\
4 & 60 & 30 & 12.7 & 0.49 & 55 & 0.125 & 49 & 740 & 2830 \\
5 & 120 & 15 & 47.0 & 1.66 & 18 & 0.099 & 48 & 577 & 1325 \\
6 & 140 & 10 & 38.8 & 1.63 & 15 & 0.08 & 46 & 560 & 2760 \\
\hline
\end{tabular}

The effect of water vapor, use of a different carrier gas, and of irradiation on the performance of the charcoal bed has been examined. Oak Ridge reports (34) Columbia-G charcoal is 35 to $45 \%$ more effective when dry than when containing $7 \%$ water. In the illustrative example, the carrier gas at $25^{\circ} \mathrm{C}$ will bring in during the life of the plant an amount of water equivalent to much less than $1 \%$ of the weight of charcoal. From the standpoint of bed performance, a cold trap is therefore not needed. 
Few data are available concerning the adsorbing capacities for other gases. It has been determined(35) that hydrogen is about two-thirds as effective as helium, whereas the gases argon, nitrogen, oxygen, and dry air are about one-third as effective. These figures are not exact (especially under varying conditions of temperature and pressure) and should be applied conservatively.

Most radioactive decay in the bed will be beta. Amphlett and Greenfield(25) irradiated some bed samples with 1-Mev electrons (corresponding to $600 \mathrm{hr}$ of irradiation at $\mathrm{l}$ watt $/ \mathrm{cc}$ ). They report no noticeable effect on adsorbing ability of charcoal for either krypton or xenon at these levels of radiation. It may thus be concluded that the beta decay will have no serious effect on the adsorbing capacity of the bed.

D. Nomenclature

B. V. = bed volume, $c c$

$F \quad=$ flow rate, $\mathrm{cc} / \mathrm{min}(\mathrm{STP})$

$\mathrm{K} \quad=$ dimensionless constant $=\mathrm{f}(\mathrm{T})$

$\mathrm{k}=$ thermal conductivity of helium-filled charcoal bed, watt $/{ }^{\circ} \mathrm{C}$

$\mathrm{M} \quad=$ mass of bed, gm

$\mathrm{N} \quad$ number of tubes

n = dimensionless constant $=f(T)$

$\mathrm{p} \quad=$ partial press, $\mathrm{mm} \mathrm{Hg}$

$q=$ rate of heat production, watt/gm fission product

$\mathrm{q}_{\mathrm{v}}=$ volumetric rate of heat production, watt/cc charcoal

$\mathbf{R}=$ tube radius, $\mathrm{cm}$

$t=5$ times after físsion, hr

$\mathrm{t}_{\mathrm{b}}=$ retention, holdup, or breakthrough time, hr

$t_{\max }=$ time for concentration in effluent stream to reach inlet concentration, min

$\mathrm{T}_{\max }=$ maximum bed temperature, ${ }^{\circ} \mathrm{C}$

$\mathrm{T}_{\text {ay }}=$ average bed temperature, ${ }^{\circ} \mathrm{C}$

$\mathrm{T}_{0} \quad=$ wall temperature, ${ }^{\circ} \mathrm{C}$

$\mathrm{V}=$ adsorbing capacity of charcoal, cc adsorbed/gm charcoal

$\mathrm{v} \quad=$ linear velocity through tubes, $\mathrm{cm} / \mathrm{min}$

$\rho=$ bed density, $\mathrm{gm} / \mathrm{cc}$ 


\section{COMPRESSOR RATING FOR THE GAS HANDLING SYSTEM}

The relationship of superficial velocity $\left(V_{0}\right)$ versus exit void fraction $\left(\alpha_{x}\right)$, given in Equation (1), is corrected for a longer effective $r$ iser

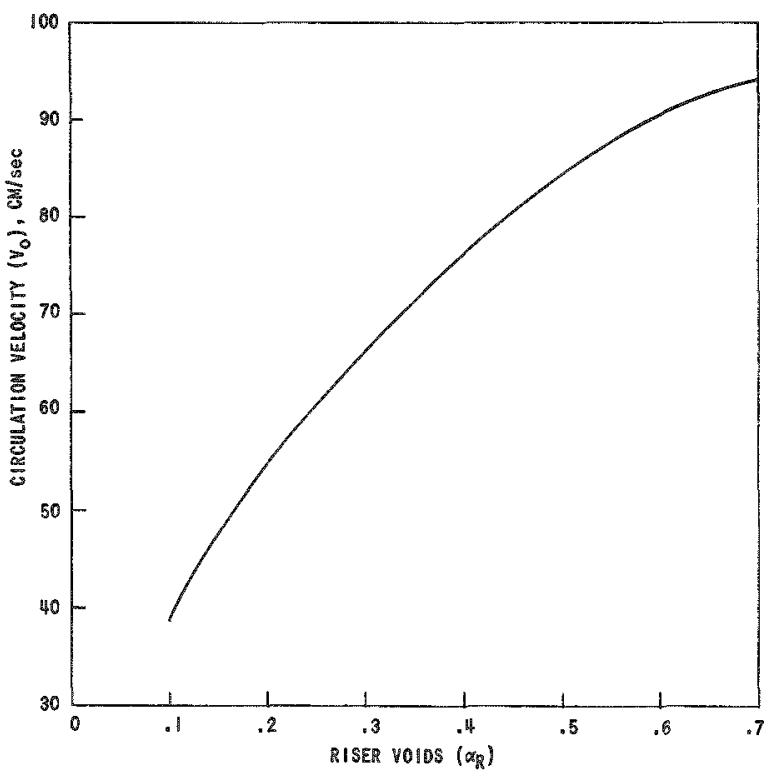

FIG. 30

CIRCULATION VELOCITY $\left(V_{0}\right)$ VS. VOIOS IN RISER DURING GAS IMJECTION section $(254 \mathrm{~cm})$. This increase results from gas injection at a point lower than the start of steam formation during power operation. The corrected relationship is plotted as Fig. 30 .

Volumetric gas flow rates required to obtain a given $\mathrm{V}_{0}$ were calculated, based on the experimental slip ratio correlation of Marchaterre and Petrick(36) for air-water systems at atmospheric pressure. A correction factor was applied to reflect the small decrease in slip ratio observed by them with increasing pressure in steamwater systems. The compressor intake volumetric flow rate,measured at ambient conditions of $0.85 \mathrm{~atm}$ and $21^{\circ} \mathrm{C}$, is plotted in Fig. 31 as a function of superficial velocity at three delivery pres-

sures: $2,3.5$, and $10.2 \mathrm{~atm}$. Of these, that at $2 \mathrm{~atm}$ is the minimum acceptable for the gas-injection function of the gas-handling system; 10.2 atm represents the maximum pressure requirement for all functions of the gas-handling system; 3.5 atm is selected as a compromise allowing some operating margin and smaller storage tanks (than for $2 \mathrm{~atm}$ ), while still permitting a single-stage compressor. In all three cases, the outlet temperature is assumed as $21^{\circ} \mathrm{C}$, since upon injection into a cold core the gas will attain ambient temperature. The actual exit temperatures from the compressor are $85^{\circ} \mathrm{C}, 134^{\circ} \mathrm{C}$, and $119^{\circ} \mathrm{C}$ for $2,3.5$, and $10.2 \mathrm{~atm}$, respectively. This assumes interstage cooling to $21^{\circ} \mathrm{C}$ for the two-stage compressor required for the 10.2 -atm case.

The power requirements of the compressor were calculated using the standard equation for an adiabatic, $n-s t a g e$ compressor (assuming per. fect interstage cooling for the two-stage unit). The gas constant of 1.3 for a diatomic gas and a compressor efficiency of $70 \%$ were utilized. The results are plotted in Fig. 32 . 


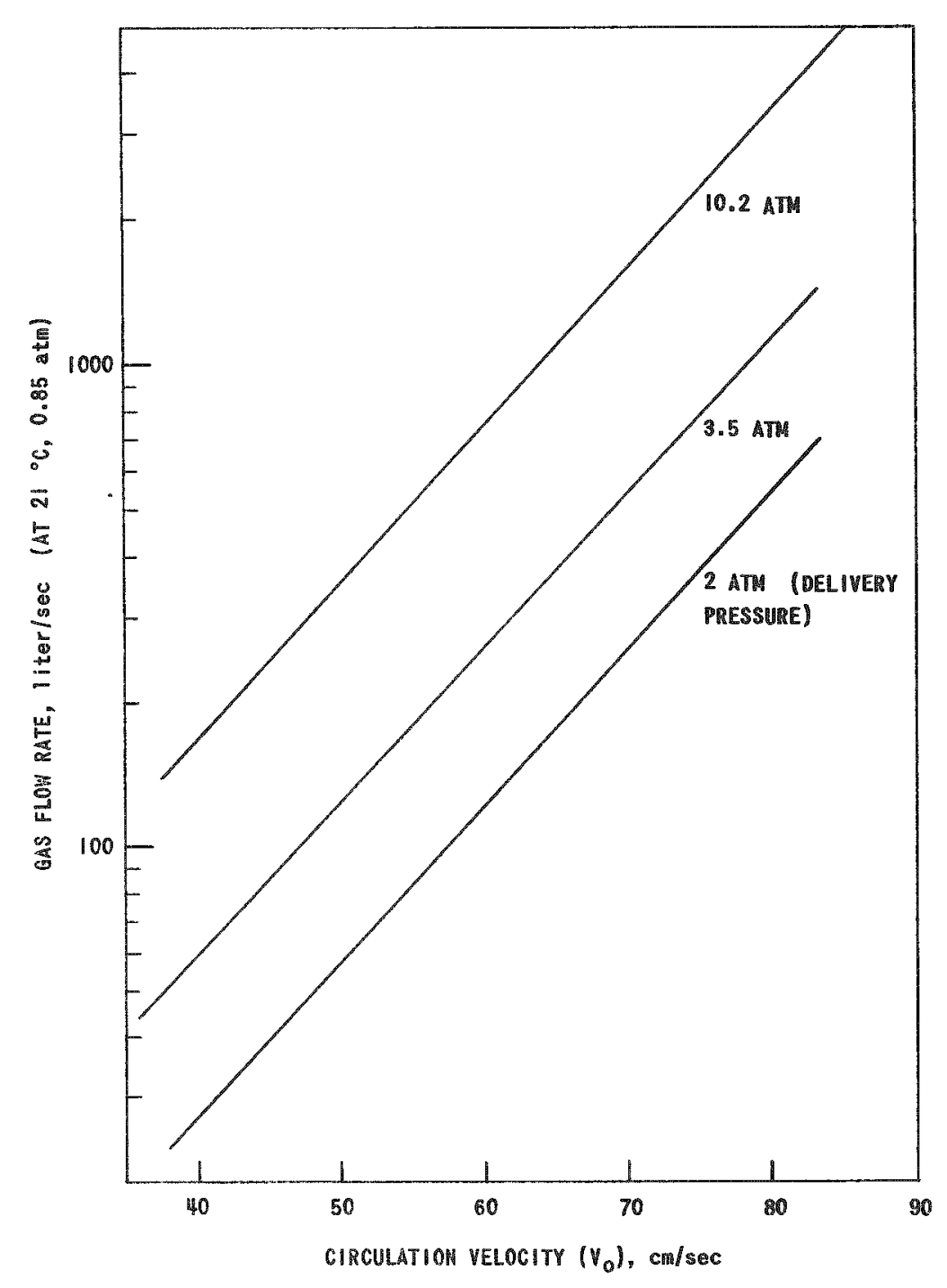

FIG.31

GAS FLOW RATE AT COMPRESSOR INTAKE VS. CIRCULATION VELOCITY $\left(V_{0}\right)$

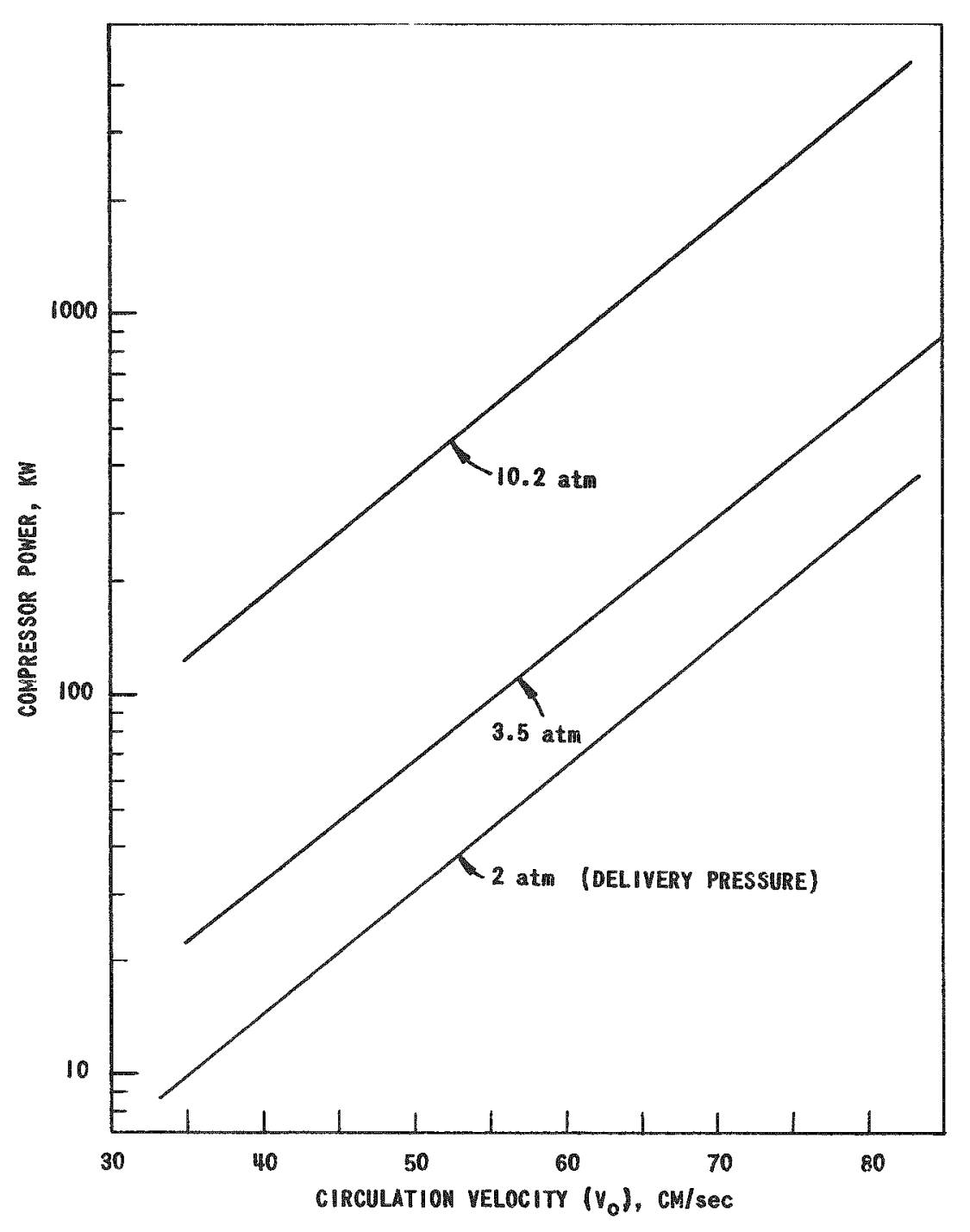

FIG. 32

CCMPRESSCR POWER VS. CIRCULATION VELOCITY $\left(V_{0}\right)$ 
In a natural circulation system the pressure drop around a closed loop is equal to zero. Therefore, the summation of the frictional, acceleration, and hydrostatic head components around the closed loop must be equal to zero.

$$
\oint d P=0=\oint \rho d L+\oint \rho \frac{V d V}{g_{C}}+\oint \rho d H_{f}
$$

where $P$ is the pressure, $p$ the density, $V$ the velocity, and $H_{f}$ a head loss.

The flow geometry of the SLURREX reactor system is presented in Fig. 33. The closed loop consists of reactor core, riser, crossover, downcomer, and the 180-degree return $Y$ fitting.

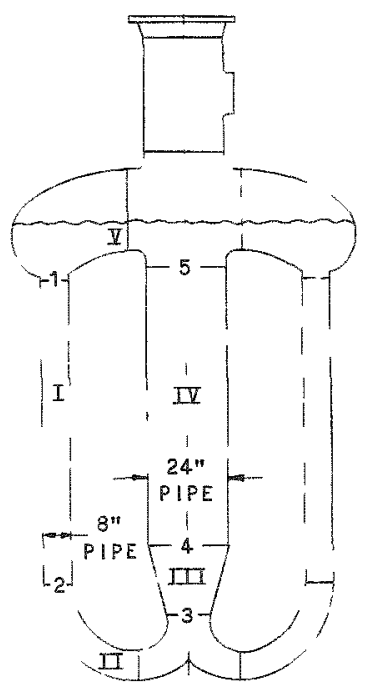

FIG.33 SECTIONAL BREAKDOWN FOR HYDRAULIC ANALYSIS OF REACTOR VESSEL Summation of the hydrostatic head components around the closed loop results in an expression which contains the density difference between the downcomer and the two-phase flow of the core and riser:

$-\oint \rho d L=\left(\rho_{D}-\rho_{R}\right) L_{R}+\left(\rho_{D}-\bar{\rho}_{C}\right) L_{C}$

where the subscripts $D, C$, and $R$ refer to the downcomer, core, and riser, respectively, the bar denotes an average value, and $L$ the effective length. It is the density difference or driving force which causes the natural circulation. The acceleration and frictional components can be defined as the resistance forces which balance the driving force.

Hydraulic resistances or losses are generally defined as a multiplier $(\mathrm{K})$ times the velocity head $\mathrm{V}^{2} / 2 \mathrm{~g}_{\mathrm{c}}$. The velocity term to be used in this expression will be $V_{0}$, which is defined as a superficial velocity for the riser, determined by dividing the mass flow rate in $\mathrm{gm} /(\mathrm{sec})\left(\mathrm{cm}^{2}\right)$ by the density of the saturated liquid. Summation of the frictional and acceleration components yields

$$
\oint \rho \frac{V d V}{g_{C}}+\oint \rho d H_{f}=\rho_{s}\left(\Sigma K_{C}+\Sigma K_{D}\right) \frac{v_{0}^{2}}{2 g_{c}},
$$


where $\rho_{S}$ is the slurry density, $\Sigma K_{C}$ is the summation of the multipliers that are constant, and $\Sigma K_{D}$ is the summation of the multipliers that vary with respect to $V_{0}$.

Combination of Eqs. (22), (23), and (24) results in the following equation:

$$
\left(\rho_{D}-\rho_{R}\right) L_{R}+\left(\rho_{D}-\bar{\rho}_{C}\right) L_{C}=\rho_{S}\left(\Sigma K_{C}+\Sigma K_{D}\right)\left(V_{0}^{2} / 2 g_{C}\right)
$$

The average density of the core and the density of the riser are defined respectively as

$$
\bar{\rho}_{\mathrm{c}}=\bar{a}_{\mathrm{c}} \rho_{\mathrm{g}}+\left(1-\bar{a}_{\mathrm{c}}\right) \rho_{\mathrm{s}}
$$

and

$$
\rho_{R}=\alpha_{R} \rho_{g}+\left(1-\alpha_{R}\right) \rho_{s},
$$

wherec is the void fraction and the subscript g refers to the steam.

Due to the high recirculation ratio, the cold feedwater lowers the average downcomer temperature only by about $1^{\circ} \mathrm{C}$; thus, the slurry density in the system is essentially constant and $\rho_{D}=\rho_{s}$. The high recirculation ratio also causes the concentrating effect of the water removal due to steam formation to be negligible. Combining Eqs. (25), (26) and (27), and assuming $\alpha, \mathrm{g}$ products to be negligible, there is obtained

$$
\alpha_{R} L_{R}+\bar{a}_{C} \dot{L}_{C}=\left(\Sigma K_{C}+\Sigma K_{D}\right)\left(V_{0}^{2} / 2 g_{C}\right) \text {. }
$$

Note that the density cancels out of the equation.

For the SLURREX system as shown in Fig. 5, the effective length of the riser is $132 \mathrm{~cm}$. The core conditions are assumed as an effective length $\left(L_{C}\right)$ equal to $122 \mathrm{~cm}$ and an average core void fraction $\left(\bar{\alpha}_{c}\right)$ equal to $\left(\frac{2}{3}\right) \alpha_{R}$. Thus, Eq. (28) reduces to

$$
\left(\frac{2}{3}\right) \alpha_{R}=\left[\sum \mathrm{K}_{\mathrm{C}}+\Sigma \mathrm{K}_{\mathrm{D}}\right]\left(\mathrm{v}_{0}^{2} / 2 \mathrm{~g}_{\mathrm{C}}\right)
$$

The frictional and accelerations losses will be determined by breaking down the reactor system into sections as shown in Fig. 33 . The system geometry is: (1) flow area of the core and riser is $2590 \mathrm{~cm}^{2}$ (24-in. Schedule 40 pipe): (2) flow area of the downcomers is $644 \mathrm{~cm}^{2}$ (two 8 -in. Schedule 40 pipes): and (3) flow area of the core entrance is $508 \mathrm{~cm}^{2}(10-$ in. Schedule 40 pipe). The velocity relationships by mass balance are $V_{D}=4.02 V_{0}$ and $V_{(10: 1)}=5.10 V_{0}$ 
Section 1, Points I to II

The hydraulic losses in this section are due to the contraction and fluid acceleration caused by the area reduction from the steam separator into the downcomer. It is estimated that the velocity head in the steam separator is about one and the contraction coefficient is about 0.1. Thus, the loss for Section 1 is

$$
\text { Loss }=\frac{V_{D}^{2}}{2 g_{C}}-\frac{V_{0}^{2}}{2 g_{C}}+0.1 \frac{V_{D}^{2}}{2 g_{C}}=16.8 \frac{V_{0}^{2}}{2 g_{C}}
$$

where

$$
\mathrm{K}_{\mathrm{Cl}}=16.8 \text {. }
$$

Section 2, Points II to III

This section has a frictional loss for flow in the downcomer. An average Reynolds number of $2.5 \times 10^{6}$ was selected. The friction factor does vary with velocity and density and, therefore, with Reynolds number. However, the range of conditions is in the relatively flat portion of the Reynolds pressure drop correlation; thus the friction factor tends to remain constant. The loss for Section 2 is

$$
\text { Loss }=\frac{f L_{D}}{D_{D}} \frac{V_{D}^{2}}{2 g_{C}}=5.8 \frac{V_{0}^{2}}{2 g_{C}} \text {, }
$$

where

$$
\mathrm{K}_{\mathrm{C} 2}=5.8 \text {. }
$$

Section 3, Points III to IV

The losses in this section are due to the fittings of the 180 -degree return $Y$ and the acceleration and contraction caused by the area reduction from the two downcomers to the $25.4-\mathrm{cm}$ ID (10-in. Schedule 40) pipe. The fitting loss coefficient (37) was determined to be 0.3 , and the contraction was estimated to be 0.1 . The loss for Section 3 is

$$
\text { Loss }=0.3 \frac{V_{D}^{2}}{2 g_{C}}+\frac{V\left(10^{\prime \prime}\right)}{2 g_{C}}-\frac{V_{D}^{2}}{2 g_{C}}+0.1 \frac{V^{2}\left(10^{\prime \prime}\right)}{2 g_{c}}=17.4 \frac{V_{0}^{2}}{2 g_{c}} \text {, }
$$

where

$$
\mathrm{K}_{\mathrm{C} 3}=17.4
$$


Section 4, Points IV to V

This section has the deceleration recovery for the expansion from the 25.4-cm ID (10-in. Schedule 40) pipe to the 57.5-cm ID (24-in. Schedule 40) pipe. The average expansion angle of 41 degrees gives a recovery coefficient of $0.93 .(38)$ The loss (gain) for Section 4 is

$$
\text { Los } s=\frac{V_{0}^{2}}{2 g_{c}}-\frac{V^{2}\left(10^{\prime \prime}\right)}{2 g_{c}}+0.93 \frac{\left[V\left(10^{\prime \prime}\right)-V_{0}\right]^{2}}{2 g_{c}} \text {, }
$$

where

$$
K_{C 4}=-9.4
$$

Section 5, Points V to VI

It is assumed that boiling does not begin until the fluid is in Section 5. The losses in this section are acceleration due to void formation and two-phase frictional flow loss. The acceleration loss is based on a momentum balance, yielding.

$$
\text { Loss }=\frac{V_{0}}{g_{C}}\left(\frac{V_{0}}{1-\alpha}-V_{0}\right)=\frac{2 \alpha}{1-\alpha} \frac{V_{0}^{2}}{2 g_{c}},
$$

where

$$
K_{D l}=\frac{2 \alpha}{1-\alpha}
$$

The calculation of the frictional loss in the riser is complicated by the existence of four fixed poison vanes and a cruciform control rod. The average Reynolds number for the two-phase flow is about $3.5 \times 10^{6}$, based on an equivalent diameter of $15.5 \mathrm{~cm}$. The loss for two-phase flow friction is

$$
\text { Loss }=\frac{\mathrm{fL}_{\mathrm{P}}}{\mathrm{D}_{\mathrm{e}}} \frac{1}{(1-\alpha)^{2}} \frac{\mathrm{V}_{0}^{2}}{2 \mathrm{~g}_{\mathrm{C}}}=\frac{0.17}{(1-\alpha)^{2}} \frac{\mathrm{V}_{0}^{2}}{2 g_{\mathrm{C}}}
$$

where

$$
K_{D 2}=\frac{0.17}{(1-\alpha)^{2}}
$$


Section 6, Points VI to I

It is assumed that the flow losses from Point VI to Point I are equal to the gradient in the liquid level from Point VI to Point I and thus cancel out from the hydraulic equation.

The summation of the $\mathrm{K}_{\mathrm{C}}$ coefficients is 32.6 , and the summation of the $K_{D}$ coefficients is

$$
K_{D}=\frac{1.17-\alpha^{2}}{(1-\alpha)^{2}}-1 .
$$

Once the system geometry is selected, as it has been in Fig. 5 , the $\mathrm{K}_{\mathrm{C}}$ 's are constant and the $K_{D}$ 's are a function only of void fraction.

Substitution of $\Sigma K_{C}$ and the $\Sigma K_{D}$ into Eq. (29) yields the hydraulic equation of the SLURREX natural circulation system, from which the circulation velocity can be computed:

$$
\frac{213 \alpha(1-\alpha)^{2}}{31.6(1-\alpha)^{2}+1.17-\alpha^{2}}=\frac{v_{0}^{2}}{2 g_{c}} \text {. }
$$

Since the completion of this hydraulic analysis, additional calculations and design decisions have resulted in the use of different core voids and pipe thicknesses (and hence ID). These changes do not affect the validity of the method of analysis, but would result in somewhat different constants. 
DOSAGE CALCULATIONS

A. Method of Determining Dosage

The nomograms in AECU-3066(39) have been used in conjunction with Sutton's meteorological constants given in Table VII.

Table VII

SUTTON'S METEOROLOGICAL CONSTANTS

\begin{tabular}{|l|l|l|l|}
\hline & $\begin{array}{c}\text { Average } \\
\text { Meteorological } \\
\text { Conditions }\end{array}$ & $\begin{array}{l}\text { Inversion } \\
\text { Conditions }\end{array}$ & $\begin{array}{c}\text { Strong Wind } \\
\text { Conditions }\end{array}$ \\
\hline Stability Index, $\mathrm{n}$ & 0.25 & 0.50 & 0.25 \\
Diffusion Parameter, ${ }^{\circ} \mathrm{C}$ & $0.20(\mathrm{~m})^{1 / 8}$ & $0.05(\mathrm{~m})^{1 / 4}$ & $0.20(\mathrm{~m})^{1 / 8}$ \\
Wind Velocity, $\mathrm{m} / \mathrm{sec}$ & 3 & 1 & 15 \\
\hline
\end{tabular}

B. Cyclic Operation

The decay after a daily $6 \mathrm{hr}$ at $5 \mathrm{Mw}$ for an infinite number of days is assumed to follow the decay shown in Curve (B) of Eig. 34. This is based on the following:

(1) At 10 sec after shutdown, the decay power is the same as for infinite 5-Mw operation.

(2) The decay power after one day is the same as for infinite $1.25-\mathrm{Mw}$ operation (i.e., decay from then on depends only on integrated power for each day and not on the daily mode of operation). Curve $D$ in Fig. 34 shows this is valid even for daily bursts of integrated power equal to daily constant power operation (as illustrated by Curve A). as $t^{-0.31}$.

(3) Between $10 \mathrm{sec}$ and one day after shutdown, the power decays

These assumptions yield a pessimistic upper limit to the dosage from cyclic operation. The decay power at $10 \mathrm{sec}$ is actually somewhat lower than assumed. Based on the shape of Curve (D), Curve (B) actually will show greater initial slope than $t^{-0.31}$ and will approach Curve (A) assymptotically at some time less than one day. In addition, the reduction in dosage is based on the time after shutdown when the cloud first reaches the particular location, rather than on the time the center of the cloud passes the location. 


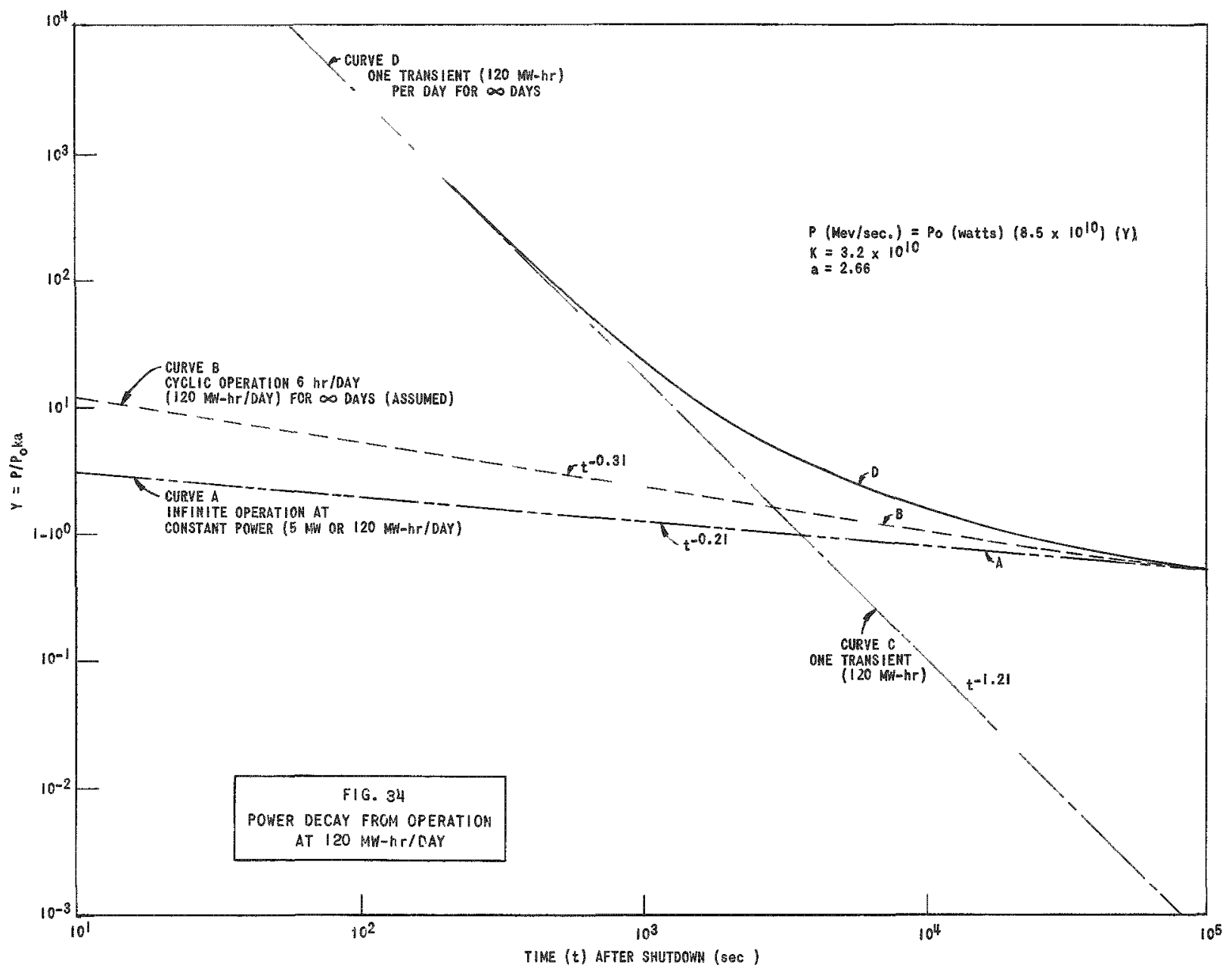

Values from Curves (B) and (C) are reduced by the appropriate factor, since the curves represent daily energy release equal to continuous 5-Mw operation. Curves (A), (C), and (D) are based on the work of Butler and Grotenhuis. (40)

The reduction in dosage due to the above assumptions for cyclical operation are given in Table VIII.

Table VIII

REDUCTION FACIOR FOR DOSAGE TO CYCLIC OPERATION

\begin{tabular}{|l|l|l|l|}
\hline Location (km) & 1.2 & 4.4 & 16 \\
\hline & & & \\
\hline & \multicolumn{2}{|c|}{ Reduction Factors } \\
Average & 0.55 & 0.45 & 0.35 \\
Strong Wind & 0.7 & 0.6 & 0.5 \\
Inversion & 0.45 & 0.35 & 0.3 \\
\hline
\end{tabular}


C. Results of Dosage Calculations

Table IX gives, for $10 \%$ and $50 \%$ fission product release, the dosages resulting at the various locations under the various weather conditions from infinite 5-Mw operation. Table $X$ gives the same for cyclical operation, i.e., daily 6-hour cycle at $5 \mathrm{Mw}$ for an infinite number of days. Table XI gives the same for one $1000 \mathrm{Mw}$-sec transient.

Table IX

DOSAGE FROM 5-Mw STEADY-STATE OPERATION*

\begin{tabular}{|c|c|c|c|c|c|c|}
\hline Location (km) & \multicolumn{2}{|c|}{1.2} & \multicolumn{2}{c|}{4.4} & \multicolumn{2}{c|}{16} \\
\hline Fission Product Release & $10 \%$ & $50 \%$ & $10 \%$ & $50 \%$ & $10 \%$ & $50 \%$ \\
\hline Average & 1.85 & 9.3 & $\begin{array}{l}0.27 \\
0.05\end{array}$ & $\begin{array}{l}1.35 \\
0.26\end{array}$ & $\begin{array}{l}0.04 \\
0.01 \\
4.4\end{array}$ & $\begin{array}{l}0.19 \\
0.03 \\
\text { Strong Wind }\end{array}$ \\
Inversion & 75 & 375 & 18 & 90 & 4.4 \\
\hline
\end{tabular}

Table X

DOSAGE FROM 5-MW CYCLIC OPERATION*

\begin{tabular}{|c|l|l|l|l|l|l|}
\hline Location (km) & \multicolumn{2}{|c|}{1.2} & \multicolumn{2}{c|}{4.4} & \multicolumn{2}{c|}{16} \\
\hline Fission Product Release & $10 \%$ & $50 \%$ & $10 \%$ & $50 \%$ & $10 \%$ & $50 \%$ \\
\hline Average & 1.0 & $\begin{array}{l}5.0 \\
1.7\end{array}$ & $\begin{array}{l}0.12 \\
0.03 \\
6.3\end{array}$ & $\begin{array}{l}0.6 \\
0.15\end{array}$ & $\begin{array}{l}0.01 \\
\text { NEG. } \\
1.4\end{array}$ & $\begin{array}{l}0.07 \\
0.01 \\
6.5\end{array}$ \\
\hline Strong Wind & $\begin{array}{l}0.35 \\
\text { Inversion }\end{array}$ & 34 & 170 & 6.3 & 12 \\
\hline
\end{tabular}

Table XI

DOSAGE FROM $1000 \mathrm{Mw}$-sec TRANSIENT*

\begin{tabular}{|c|c|c|c|c|c|c|}
\hline Location (km) & \multicolumn{2}{|c|}{1.2} & \multicolumn{2}{c|}{4.4} & \multicolumn{2}{c|}{16} \\
\hline Fission Product Release & $10 \%$ & $50 \%$ & $10 \%$ & $50 \%$ & $10 \%$ & $50 \%$ \\
\hline Average & 0.19 & 0.95 & 0.01 & 0.05 & NEG. & NEG。 \\
Strong Wind & $\begin{array}{l}0.27 \\
\text { Inversion }\end{array}$ & $\begin{array}{l}1.4 \\
0.9\end{array}$ & $\begin{array}{l}0.01 \\
0.14\end{array}$ & $\begin{array}{l}0.07 \\
0.7\end{array}$ & $\begin{array}{l}\text { NEG. } \\
0.01\end{array}$ & $\begin{array}{l}\text { NEG。 } \\
0.05\end{array}$ \\
\hline
\end{tabular}

* All table values are in roentgens. 


\section{Effect of Distance on Dosage}

By referring to the original nomogram, (39) the effect of distance of the observer from the path of the cloud has been calculated for inversion conditions at the three locations. The results in terms of reduction factors based on zero distance are given in Table XII.

Table XII

\section{REDUCTION FACTOR DUE TO DISTANCE FROM CLOUD PATH DURING INVERSION}

\begin{tabular}{|c|c|c|c|}
\hline Location $(\mathrm{km})$ & 1.2 & 4.4 & 16 \\
\hline & & & \\
\hline & \multicolumn{3}{|c|}{ Reduction Factors } \\
$10(\mathrm{~m})$ & 1.8 & 1 & 1 \\
$50(\mathrm{~m})$ & 15 & 3 & 1.2 \\
$100(\mathrm{~m})$ & 35 & 10 & 2 \\
\hline
\end{tabular}

E Maximum Cloud Height

From AECU-306́ page 83, Eq. $(6-11),(39)$ one can calculate cloud height under night=time conditions

$$
z_{\max }=\left(\frac{Q_{n}}{2 C_{p} \rho \pi^{3 / 2} C^{3} \theta_{a}}\right)^{0.270}
$$

where

$$
\begin{aligned}
& Q_{n}=\text { heat liberated }=100 \mathrm{Mw}-\mathrm{sec} \text { or } 2.39 \times 10^{7} \mathrm{cal} \\
& C_{p}=\text { specufic heat }=0.25 \mathrm{cal} /(\mathrm{gm})\left({ }^{\circ} \mathrm{C}\right) \\
& \rho=\text { air density }=1.1 \times 10^{3} \mathrm{gm} / \mathrm{m}^{3} \\
& \theta_{a}^{\prime}=\text { gradient of potential temperature }=10^{-2}{ }^{\circ} \mathrm{C} / \mathrm{m} \\
& C=\text { diffusion coeficient }\left(\mathrm{m}^{1 / 8}\right)=0.3 \text { for stable conditions. }
\end{aligned}
$$

$z_{\max }$ is then $110 \mathrm{~m}$. Based on the discussion in AECU-3066, (39) the cloud height under daytime conditions would be considerably greater. 


\section{APPENDIX G \\ PHYSICAL PROPERTIES OF AQUEOUS THORIA SLURRIES}

Density, $\mathrm{ThO}_{2}$ vol $\%$, $\mathrm{ThO}_{2}$ wt $\%$, and heat capacity of $\mathrm{ThO}_{2}-\mathrm{H}_{2} \mathrm{O}$ slurries as a function of thoria concentration are plotted in Figs. 35 to 38 . A theoretical density for $\mathrm{ThO}_{2}$ of $9.69 \mathrm{gm} / \mathrm{cc}$ was used. The individual volumes of $\mathrm{ThO}_{2}$ and $\mathrm{H}_{2} \mathrm{O}$ were assumed additive for determining the slurry density. For a $\mathrm{ThO}_{2}$ concentration (C) expressed as $\mathrm{gm}^{\mathrm{ThO}} \mathrm{O}_{2}$ per liter of slurry,

$$
\rho_{\mathrm{s}}(\mathrm{gm} / \mathrm{cc})=\frac{\mathrm{C}+\rho_{\mathrm{H}_{2} \mathrm{O}}[1000-(\mathrm{C} / 9.69)]}{1000}
$$

which simplifies to

$$
\rho_{\mathrm{s}}(\mathrm{gm} / \mathrm{cc})=0.001 \mathrm{C}=0.000103 \rho_{\mathrm{H}_{2} \mathrm{O}} \mathrm{C}+\rho_{\mathrm{H}_{2} \mathrm{O}}
$$

The equation becomes linear once $\rho_{\mathrm{H}_{2} \mathrm{O}}$ is known.

$$
\begin{aligned}
& \mathrm{ThO}_{2} \text { vol } \%=\mathrm{C} / 96.9 . \\
& \mathrm{ThO}_{2} \text { wt }-\%=\frac{\mathrm{C}}{0.01 \mathrm{C}-0.00103 \rho_{\mathrm{H}_{2} \mathrm{O}} \mathrm{C}+10 \rho_{\mathrm{H}_{2} \mathrm{O}}} .
\end{aligned}
$$

Heat capacities of $\mathrm{ThO}_{2}$ were calculated from the equation.

$$
\mathrm{C}_{\mathrm{p}}\left[\text { in } \frac{\mathrm{cal}}{(\mathrm{gm} \mathrm{mole})\left({ }^{\circ} \mathrm{K}\right)}\right]=16.45+2.346 \times 10^{-3} \mathrm{~T}=\frac{2.124 \times 10^{5}}{\mathrm{~T}^{2}}
$$

The heat capacity values for the slurry were obtained from weight averages of the heat capacity of the individual water and thoria. A molecular weight of 264.12 was used for $\mathrm{ThO}_{2}$.

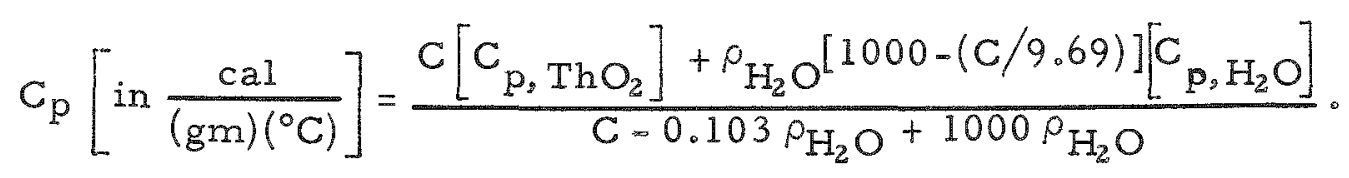




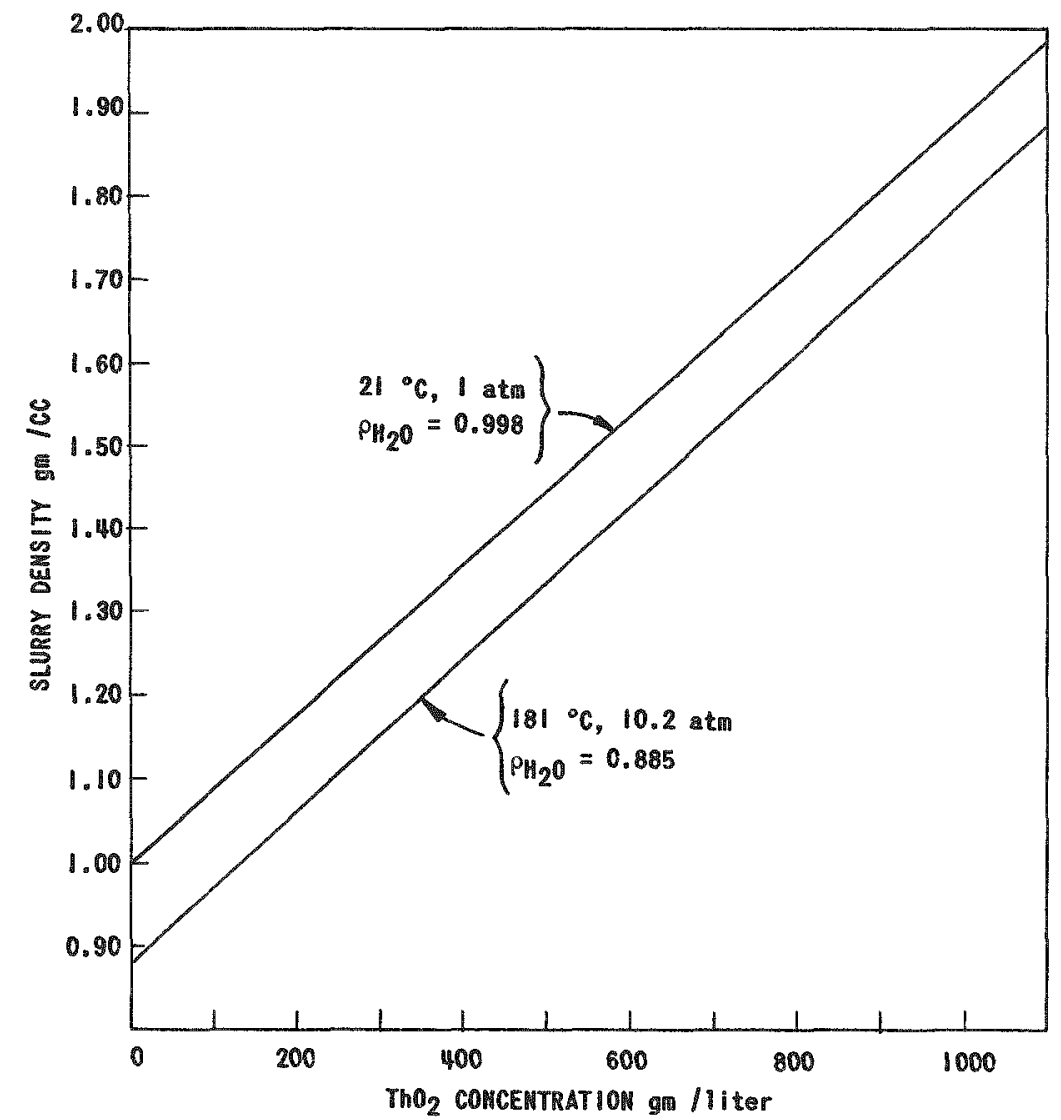

FIG. 35

SLURAY DENSITY VS. ThC 2 CONCENTRATION

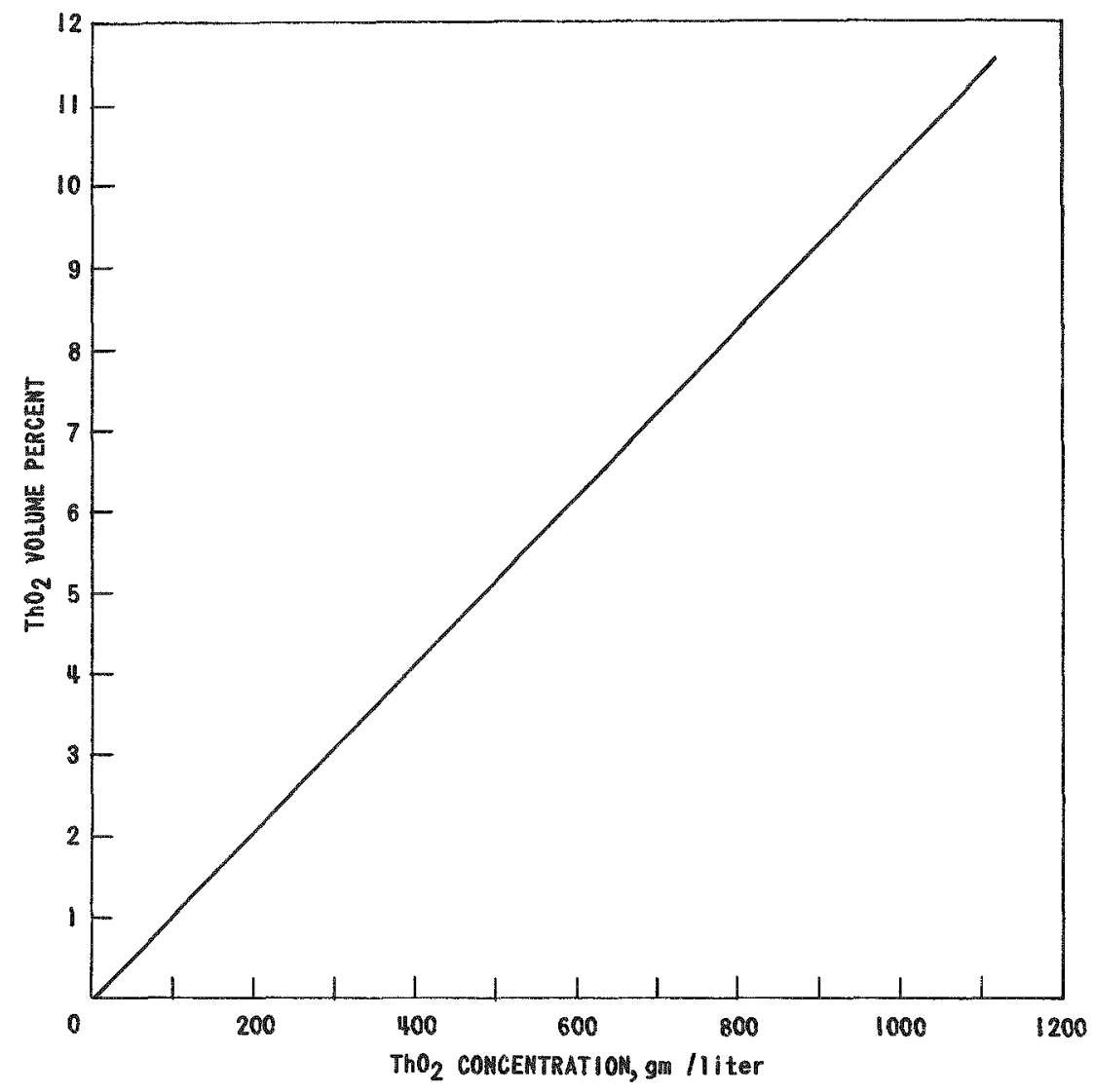

FIG. 36

$\mathrm{ThO}_{2}$ VOLUME PERCENT VS. CONCENTRATION 


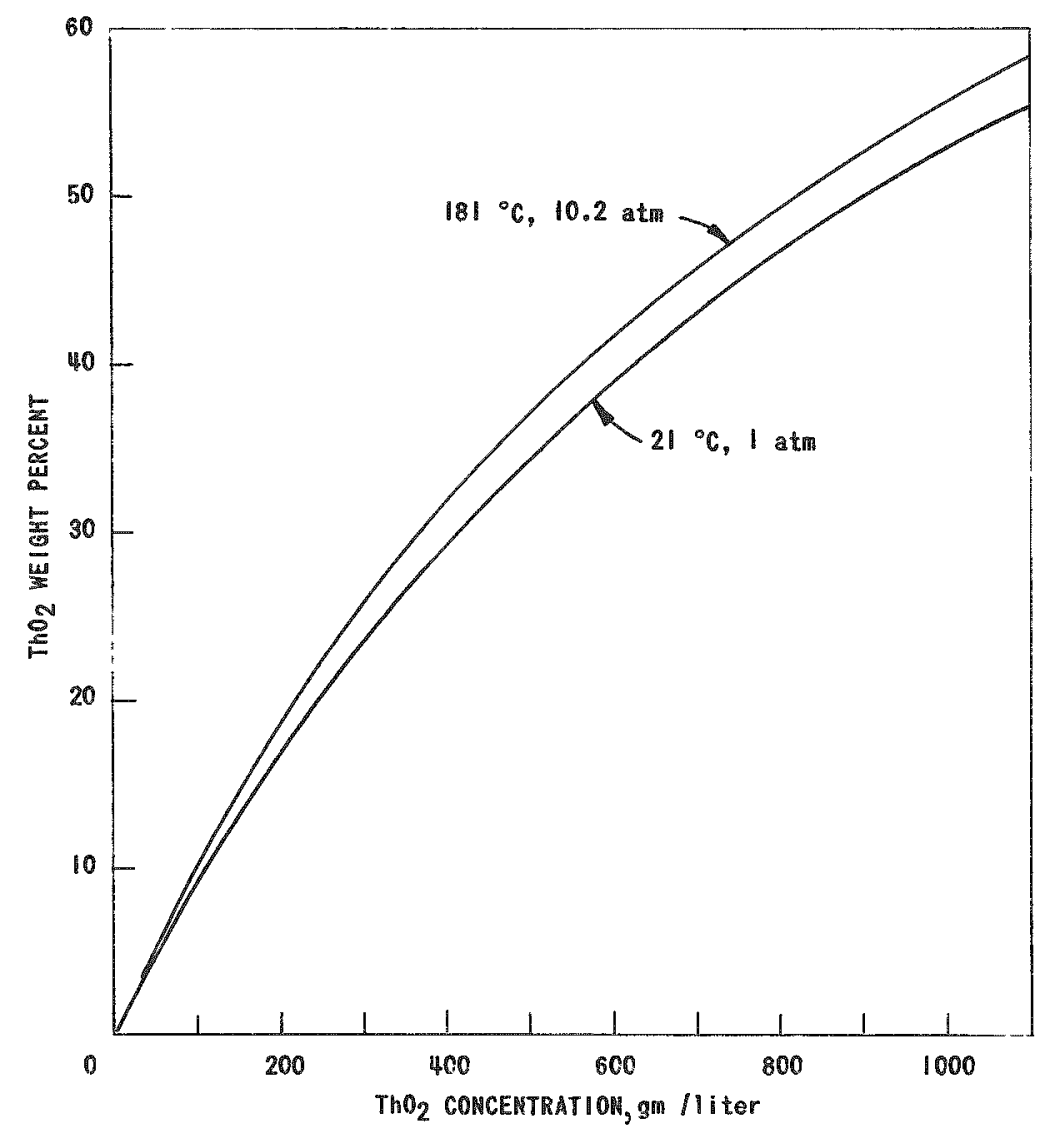

FIG. 37

$T_{2} \mathrm{O}_{2}$ MEIGHT PERCENT VS. CONCENTRATION

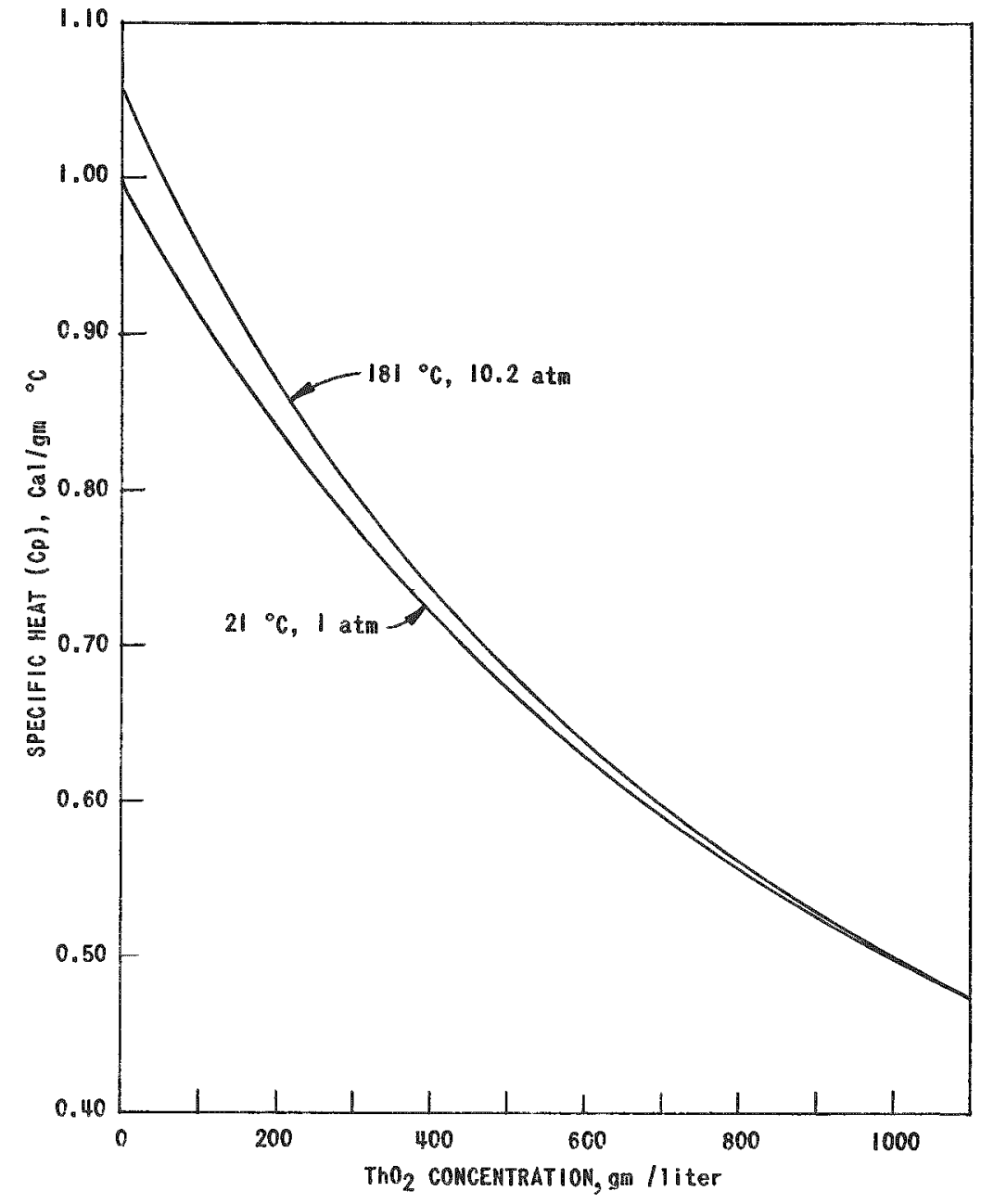

FIG. 38

SPECIFIC HEAT VS. CONCENTRATION 